\title{
The evaluation of HIV and AIDS interventions in secondary school in South Afrika: recommendations for systematic programme development
}

Citation for published version (APA):

James, S. (2006). The evaluation of HIV and AIDS interventions in secondary school in South Afrika: recommendations for systematic programme development. [Doctoral Thesis, Maastricht University]. Universiteit Maastricht. https://doi.org/10.26481/dis.20060317sj

Document status and date:

Published: 01/01/2006

DOI:

10.26481/dis.20060317sj

Document Version:

Publisher's PDF, also known as Version of record

Please check the document version of this publication:

- A submitted manuscript is the version of the article upon submission and before peer-review. There can be important differences between the submitted version and the official published version of record.

People interested in the research are advised to contact the author for the final version of the publication, or visit the DOI to the publisher's website.

- The final author version and the galley proof are versions of the publication after peer review.

- The final published version features the final layout of the paper including the volume, issue and page numbers.

Link to publication

\footnotetext{
General rights rights.

- You may freely distribute the URL identifying the publication in the public portal. please follow below link for the End User Agreement:

www.umlib.nl/taverne-license

Take down policy

If you believe that this document breaches copyright please contact us at:

repository@maastrichtuniversity.nl

providing details and we will investigate your claim.
}

Copyright and moral rights for the publications made accessible in the public portal are retained by the authors and/or other copyright owners and it is a condition of accessing publications that users recognise and abide by the legal requirements associated with these

- Users may download and print one copy of any publication from the public portal for the purpose of private study or research.

- You may not further distribute the material or use it for any profit-making activity or commercial gain

If the publication is distributed under the terms of Article $25 \mathrm{fa}$ of the Dutch Copyright Act, indicated by the "Taverne" license above, 


\section{The Evaluation of HIV and AIDS Interventions in}

Secondary Schools in South Africa: recommendations for systematic programme development

Shamagonam James 
$2008+2$

$-8304$ 


\title{
The Evaluation of HIV and AIDS Interventions in Secondary Schools in South Africa: recommendations for systematic programme development
}

\section{DISSERTATION}

\author{
to obtain the degree of Doctor at \\ the Maastricht University, \\ on the authority of the Rector Magnificus. \\ Prof. Dr. G. P. M. F. Mols \\ in accordance with the decision of the Board of Deans. \\ to be defended in public \\ on Friday March 17.2006 at 12.00 hours
}

by 


\section{Supervisor(s):}

Prof. dr. H. W. van den Borne

Prot dr. S. P. Reddy (MRC, South Africa)

\section{Co-supervisor:}

Dr R. A. C. Ruiter

\section{Assessment Committee:}

Prof dr. G. J. Kok (Chairman)

Prof dr. A. D. MBewu (MRC, South Africa)

Prof. dr. M. F. Ramashala (MRC, South Africa)

Dr. H. P. Schaalma

Prof dr. N. K. de Vries

Cover graphic: Muhdni Grimwood

From design to print-ready: Muhdni Grimwood

ISBN $1-920015-30-2$

The studies presented in this thesis were conducted at and funded by the National Health Promotion Research and Development Group, Medical Research Council, South Africa, WC-NACOSA and the Horizons Project which is funded by the U.S.Agency for International Development, under the terms of HRN-A-97-00012-00. 


\section{Acknowledgements}

A special thank you to all the people who so kindly and patiently worked with and supported me through the entire time of this process and in whatever way was necessary.

Thank you to Professor Bart van den Borne, Professor Priscilla Reddy and Dr Rob Ruiter, for your guidance, teaching, availability and support throughout the project and for the reviewing of the numerous drafts of this manuscript. Thank you to all the co-authors for your support and timely responses and to Mieke van den Borne-Hoeks for the Dutch translation of the summary.

To the Department of Education, principals, educators, parents and learners of the schools included in the study, thank you for working so co-operatively with us. To Eshania Thumbadoo and Khanyesile Zondi thank you for your excellent assistance in managing and collecting the data.

To my family, Sherwin, Kiran and Nikhil thank you for your unfailing support, love and care during this process.

Shegs James 
$\therefore \quad-\quad 3$

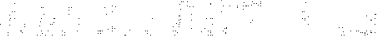

$\therefore \quad \therefore \quad \therefore \quad \therefore \quad:$

$\therefore \quad$ a

$\therefore \quad \therefore \quad-\quad \therefore$ 


\section{Contents}

Chapter 1 page 9

Introduction

Chapter 2

Young people, HIV/AIDS/STIs and sexuality in South Africa:

the gap between awareness and behaviour

Chapter 3 page 37

Alcohol and substance use as moderators of sexual behaviour amongst secondary school students in KwaZuluNatal, South Africa: A view to comprehensive programme development

Chapter 4 page 51

The effects of a systematically developed photo-novella on knowledge, attitudes, communication and behavioural intentions with respect to sexually transmitted infections among secondary school learners in South Africa

Chapter 5

The Impact of a HIV and AIDS Lifeskills Programme on Secondary School Students in KwaZulu-Natal, South Africa

Chapter 6 page 87

The South African HIV/AIDS risk reduction programme for secondary school learners: Refocusing the effort

Chapter 7 page 115

General discussion and conclusion

Surmmary page 133

Samenvatting page 137

Curriculum Vitae 
Chapter 1

Introduction 


\section{Introduction}

HIV and AIDS is a serious health problem for the Southern African region with South Africa being most affected (UNAIDS, 2004). A recent national household survey reported a HIV prevalence rate of $15.6 \%$ amongst the adult population. In absolute numbers, the age group between 15 to 24 years is most affected with a HIV prevalence rate of $9.3 \%$. There was a marked difference in the rate by gender for this age group, with more women (12\%) than men being affected (6\%) (Mandela Foundation/HSRC, 2002).

The 1st Youth Risk Behaviour Survey (YRBS) carried out in schools in South Africa in 2002 amongst grade 8 - 11 learners reported on eight risk related behaviours affecting school-going youth of which sexual behaviour was one. Nationally $41 \%$ of learners reported ever having had sex and of those reporting ever having had sex $29 \%$ reported always having used a condom during sex and $14 \%$ reported initiating sex below the age of fourteen (Reddy, Panday, Swart, Jinabhai, Amosun, James et al., 2003).

KwaZulu-Natal (KZN) has $20.7 \%$ of the population of South Africa, with $35.5 \%$ being under 15 years old. It has the highest school-going population of the nine provinces (Bot, Dove, \& Wilson, 2000). For KZN the reported figures for ever having had sex, always using a condom during sex and for initiating sex below fourteen years old were $37 \%, 15 \%$ and $16 \%$ respectively (Reddy et al., 2003). The majority of the learners (73\%) in the KZN YRBS-study were between 14 and 18 years with an average age of 15.93 years.

HIV/AIDS has a huge impact on the quality of personal life and on society in general in South Africa. The prevention of further spread of the epidemic in young people that start having sex is of utmost importance. Sexuality education programmes have been implemented but have not been experimentally tested. The main objective of this series of studies is to generate empirical data on the effectiveness of implemented school-based interventions and, additionally, to inform the systematic development of future sexual health programmes for young people. Before introducing the studies reported on in chapter 2 to 6 , a brief overview of adolescent sexuality education programmes in South Africa and the lessons learned from previous studies into the effectiveness of schoolbased health programmes in sub-Saharan Africa is provided as well as a short description of the South African Lifeskills HIV/AIDS programme. 


\section{Adolescent Sexuality Education in South Africa}

The consequences of early sexual activity like teenage pregnancy and sexually transmitted infections have always been a concern for the South African Departments of Health and Education. There have been attempts to address the situation by including sexuality education in the school curriculum. Little is known about the development of these interventions but some documentation on the process issues provides an overview of sexuality education in South Africa.

The introduction of sexuality programmes known as "family life education" began long before the reorganisation of government from apartheid to democracy in 1994. During apartheid, the five different education departments representing the racially segregated system under which education was being delivered implemented the "family life education" programme. Due to the discrepancy in service delivery as a result of discrepant resource allocation amongst the departments, the programme varied in quality, structure and delivery. A review of school-based education programmes in KwaZulu-Natal (KZN) carried out prior to 1994 , showed that the attempt to introduce school sexuality programmes during that time had failed due to (Varga \& Shongwe, 1999):

- division and unequal resource allocation between education departments;

- lack of systems-level support for school-based sexuality education;

- inadequate preparation and training of teachers;

- lack of community and systems-level resources for education aftermath;

- reliance on NGOs and other external agencies; and

- lack of programmatic evaluation.

A few years before and after 1994, a considerable move to effecting changes in the education structure was undertaken. There was a call to devise strategies to provide equal education for all South Africans. The emphasis of learning was to shift from being a "memorization of facts and evaluation through examination performance" to "learning in a broad sense of accruing knowledge and experience, and evaluation through students" achievement of specified levels of functioning or outcomes". This emphasis is captured in the concept "Curriculum 2005": Lifelong Learning for the 21st Century (Department of Education, 1997). "Curriculum 2005 " is a curriculum framework devised by the National Department of Education to re-orientate the school curriculum by 2005 to reflect "a prosperous, truly united, democratic and internationally competitive country with literate, creative and critical citizens". To achieve this forward thinking approach the curriculum now has eight learning areas targeting various aspects of education like the development of new knowledge, skills and technologies. Through this it aims to develop learners into 
individuals that will take responsibility for personal performance, set and achieve high standards and work co-operatively. Life orientation is one of the eight learning areas and it is the designated learning area within which issues related to sexuality and sexual health is taught (Department of Education, 1997; Department of Education, 2005a).

The enrolment of learners in schools continues to rise as a result of the introduction of free education following the 1994 elections. Schools therefore continue to provide the opportunity for primary prevention of HIV infection among large numbers of potentially vulnerable young people. $K Z \mathrm{~N}$ has about 1697714 primary and 940302 secondary school learners (Department of Education, 2005b).

\section{The South African Lifeskills HIV/AIDS Programme}

The South African Lifeskills HIV/AIDS programme was initiated in 1997 to address the increasing prevalence of HIV amongst young people. The National Department of Education in collaboration with the Department of Health launched a programme to train two teachers from every secondary school in the country about HIV and AIDS. The programme was implemented differently in each of the nine provinces in terms of who did the training, what was done, and the extent to which the programme was implemented at school level. Harrison, Smit, and Meyer (2000) highlight, in their review of sexuality education, some of the draw backs in the implementation of the Lifeskills HIV/AIDS Programme. Time and space constraints within the teaching curriculum and insufficient support regarding teacher implementation were highlighted as important correlates of implementation failure. They also highlighted the need for rigorous evaluation of the programme.

Evaluation of the programme in KZN showed that the process was slowed at the beginning by the delay in funds from the National Department of Health (Markham, 1998). The crisis in education at the time, for example the redeployment of teachers which was undertaken to redress the inequities in the liducation system in terms of the teacher/learner ratios gave rise to a lot of uncertainty and disruption within the school system. Of the 1002 teachers who were trained, some had left the formal education setting and due to ineffective follow-up and monitoring it was unclear as to how many of the trained teachers were still within the education system. This resulted in the programme not being implemented as set out in the business plan (Markham, 1998). A national assessment of the implementation of the programme (carried out by November 1999) by Khulisa Management Services (2000) showed that KZN had an implementation rate of $13 \%$ which was the lowest of all the provinces. This was thought to be due to a general lack of training of the teachers among KZN schools. 
As the impact of the HIV/AIDS epidemic was becoming more visible and in the absence of a medical cure, steps to have an effective sexuality programme in place had become a matter of urgency. By December 1999 the South African government intensified its' response and this was reflected in the development of an integrated plan for children infected and affected by HIV/AIDS (Department of Health, 2000). The plan outlines six components to be carried out in an integrated manner by three National Departments, i.e., the Departments of Health, Education and Social Development. The introduction of a life skills programme focusing on HIV and AIDS in schools was listed as the core component earmarked to receive the bulk of the funding in the initial years. The three departments were called upon to work in strong co-operation, co-ordination and in the sharing of resources especially on a community level (Department of Health, 2000).

This call was supported by the Department of Education as it was in line with the National Education Act, 1996 (No. 27 of 1996). The act stipulates that school governing bodies, acting within its functions under the South African schools act, 1996, shall give operational. effect to the national policy by developing and adopting an HIV and AIDS implementation plan that would reflect the needs, ethos and values of a specific school or institution and its community (Government Gazette, August 1999). The Department of Education further showed its commitment by developing and distributing the "Tirasano/ Working Together" document that provides guidelines for educators on HIV and AIDS (Department of Education, 2000a).

The KZN Department of Education in its second attempt at the teacher training, reworked its Business Plan of January 2000 to June 2000 to include the three Departments (Health, Education and Social Welfare), re-training of the existing trainers with regard to incorporating the Lifeskills HIV/AIDS programme into the Life Orientation Learning area, and targeting the teacher training to reach all schools by the end of three years (Department of Education, 2000b). At a provincial level the training programme was carried out by the Department of Education to train staff to function as co-ordinators of the Lifeskills HIV/AIDS programme in their districts. At a district level consultants from private consortiums were hired to train the teachers. To my knowledge no formal evaluation of the implementation was carried out in KZN at the time except for the impact evaluation reported on in Chapter 5 of this dissertation. James and colleagues (under review) present a rigorous evaluation of the way teachers implemented the programme as it was undertaken in two districts of the Pietermaritzburg region of $K \mathrm{ZN}$.

Two recent studies, one of national scope and one in $K Z N$, also evalluated the Lifeskills HIV/AIDS Programme carried out in schools. At the national level, 
Visser, Schoeman, and Perold (2004) from their process evaluation confirmed that the life skills programme is subjected to the organisational problems of schools such as lack of resources, lack of support from principals and other teachers and conflicting goals in the educational system. From their outcome evaluation they report a gain in knowledge and protective behaviour of learners but were unable to attribute this to the programme due to poor study design. Magnani, Maclntyre, Karim, Brown, and Hutchinson (2005) carried out a panel study in KwaZulu-Natal that aimed to assess the impact of exposure to life skills education on youth. They reported a substantial expansion of life skills education amongst Indian and African subgroups and concluded that schoolbased life skills education can help youth to acquire knowledge about HIV and AIDS, develop skills to reduce the risk of HIV transmission as well as change certain selected behaviours such as condom use.

The designs of both of these studies related to the persuasive effects of the programme at the student level cannot be described as rigorous. Both lacked a comparison condition, were vague about the intervention and the extent of its implementation as well as possibly included participants that did not receive the intervention at all. It is in this respect that the call for rigorous scientific evaluation of interventions continues and chapter 5 in this dissertation presents a randomised controlled trial of the effectiveness of the KwaZulu-Natal Department of Educations" Lifeskills HIV/AIDS Programme, which was based on the national programme, at the student level.

\section{Evaluation of sexuality education programmes in sub-Saharan Africa}

A review of literature on school-based interventions addressing sexual behaviour carried out in sub-Saharan Africa (SSA) shows a paucity in the systematic development, implementation and evaluations of such interventions (Gallant \& Maticka-Tyndale, 2004; Kaaya, Flisher, Mbwambo, Schaalma, Aaro, \& Klepp, 2002a; Kaaya, Mukoma, Flisher, Klepp, 2002b).

Kaaya et al., (2002a) reported a lack of comprehensive reviews documenting the current state of knowledge about the extent and nature of adolescent sexual behaviour in SSA. In their review of 47 studies carried out during 1987 and 1999 only 6 were interventions amongst school-based adolescents of which two were evaluations of interventions. They found that for both genders the age of sexual debut to be young, a large proportion of the sexually active adolescents reported unprotected sex and more than one lifetime partner. They recommend that each country should conduct its own analysis of behavioural risk factors to inform the development of prevention programmes.

In a later review capturing studies between 1990 and 2000 an increasing trend in the numbers of evaluated HIV and AIDS school-based interventions 
were reported (Kaaya et al., 2002b). This is encouraging and the review of these studies which were mainly outcome evaluations highlighted the need to incorporate other evaluations such as process evaluations. Process evaluations detail what was actually carried out and may help to interpret programme effects. The studies reviewed were analysed in terms of the type of evaluation carried out which were either process or effect evaluations. The three studies that carried out a process evaluation emphasized the importance of involving programme recipients (e.g., teachers) in the planning and implementation of the intervention. The effect studies were reviewed in terms of several factors like knowledge and attitudes, personal risk assessment, self-efficacy, communication on HIV/AIDS and risk and protective sexual behaviours. In summary, some of the findings cautions programme implementers to be more specific about what is being measured. For example, an increase in communication may not necessarily be positive if it is a response to conflicting conversations with parents. Studies need to describe the content of the communication. The minimal programme effects on actual or intended behaviours were reported as disappointing and possibly due to the limited duration of programmes. Activities demanding more interaction and preparation to address behavioural skills may have been compromised. It was noted that less demanding activities were more successful.

Gallant and Maticka-Tyndale (2004) reviewed the evaluations of 11 schoolbased interventions that aimed to reduce HIV transmission in youth in SSA from 1994 to 2002. They concluded that school-based HIV and AIDS interventions targeting youth may be successful in changing knowledge and attitudes and under certain conditions behaviour for example with younger primary school youth or youth that were virgins at the start of the programme. They identified a range of challenges facing the SSA region that needs to be heeded to improve intervention development, implementation and evaluation. Some of these challenges included designing programmes that take the context of the different SSA settings into account for example the reluctance to discuss condoms by teachers and the communities.

A review of behaviour change interventions carried out in South Africa by Harrison and colleagues (2000) reflects that South Africans, in general, have been exposed to a gamut of interventions. These interventions at first served to raise awareness about HIV and AIDS through mass media such as television programmes, radio and youth magazines like Laduma, a systematically developed photo-novella (see Chapter 4). Another example is the Department of Health's "Beyond Awareness" programme which focussed, as one of its objectives, on providing knowledge about HIV and AIDS and specific risks which precede behaviour change. Despite widespread awareness campaigns the 
findings of several studies reported discrepancies between the levels of knowledge and awareness and reported sexual behaviour of young people (James, Reddy, Taylor, \& Jinabhai, 2004; Harvey, Stuart, \& Swan, 2000; Kuhn, Steinberg, \& Matthews, 1994). A review of studies reporting sexual behaviour of adolescents by Hartell (2005) confirms that a substantial number of adolescents engage in early unprotected sex and have low levels of knowledge about protective sexual behaviour. Harrison et al., (2000) in the light of successful studies carried out in developed countries calls for an expanded approach to intervention development which includes interventions that develop skills in negotiation and decision-making especially for girls. Eaton, Flisher, and Aaro (2003), in their review of papers from 1990 to 2000, present a comprehensive account of the factors that perpetuate unsafe sexual behaviour amongst South African youth. These factors are broadly discussed in three categories i.e the personal (e.g., knowledge and beliefs), the proximal (e.g., interpersonal factors like negotiating condom use) and the distal contexts (e.g., culture). Beginning to understand sexual behaviour as a function of these various contexts may create the opportunity to unravel the complexity associated with sexual risk behaviour and may lend itself to addressing the issues which fall outside the realm of traditional behaviour change theories.

The increase in the number of studies reviewed in the latter 1990s is encouraging. The findings of the reviews highlight some critical gaps in intervention development, implementation and evaluation. In order to maximise the opportunity to influence the sexual behaviour of large numbers of young people rigorous development and implementation of programmes is critical. This thesis serves to answer a part of the preceding statement by reporting the evaluation of the implementation of the South African Lifeskills HIV/AIDS programme that was carried out in KwaZulu-Natal in 2001. It further aims to use this insight to propose a refocus of the Lifeskills HIV/AIDS programme as well as provides an overall picture of the target population through two descriptive and one evaluation studies. 


\section{Overview of Thesis}

The thesis is presented in three parts. Part 1 details the responses of learners captured during two cross-sectional studies. Part 2 outlines the two types of interventions that were evaluated, a one off reading of a print media intervention and an intensive teacher-driven Lifeskills HIV/AIDS Programme. Part 3 describes an analysis of three evaluations of the Lifeskills HIV/AIDS Programme with recommendations to improve the effort.

The studies reported on in parts $\mathbb{1}$ and 2 were carried out in late 1999 to 2001 at a time when the urgency for preventive HIV and AIDS education was most felt and time for the development of interventions was scarce. This resulted in the development of interventions that lacked an explicit theoretical base, systematic planning, implementation or evaluation. This thesis addressed part of this need by evaluating the given interventions, which were already in place and in use, in a scientifically rigorous manner and draws on the results to improve the development of the Lifeskills HIV/AIDS Programme in particular.

\section{Part l: Cross-sectional Studies}

Chapters 2 and 3 of this thesis reports on two cross-sectional studies that provide information about secondary school learners in terms of their knowledge about HIV/AIDS/STIs, attitudes to condom use, bellefs about condom use and reported sexual behaviour as well as the association of drug and alcohol use with sexual behaviour at a specific point in time.

The study reported on in chapter 2 intended to highlight the gap between knowledge and reported behaviour and the need to reorient sexuality education to that which includes the elements critical for behavioural change such as addressing gender discrepancies and promoting skills for communication through planned intervention programmes, a call that remains applicable currently due to a lack of systematically developed interventions (James, Reddy, Ruiter, Taylor, Jinabhai, Van Empelen et al., 2005). The study was carried out at a time when HIV and AIDS education in South Africa was based largely on information dissemination and creating awareness about the infection. The findings of relatively high levels of knowledge and reported unsafe behaviours in South Africa need to be interpreted in the context of the on-going exposure to sexuality education from a range of sources including the media and school education.

Chapter 3 reports on a sub-set of data from a study in which data were collected on a cluster of behaviours including sexual behaviour, alcohol and substance use. The data were collected country wide for the first Youth Risk Behaviour Survey 2002 (Reddy et al., 2003), at a time when life skills education at schools was being reoriented to include health issues and addressing risk behaviours. This chapter 
highlights the notion of clustering of behaviours, a concept that needs to inform HIV and AIDS intervention development taking into account the determinants of behaviour in general and sexual behaviour in particular.

\section{Part 2: Intervention Studies}

Chapters 4 and 5 evaluate more specifically the responses of students following exposure to two interventions in randomised controlled trials. In chapter 4 the intervention is a systematically developed photo-novella called Laduma, a print media intervention that was developed by an external team of professionals. Laduma presents the reader with factual information about sexually transmitted infections in a realistic way that aimed to increase knowledge and reduce misperceptions, engender a positive attitude towards safe sexual practices, enhance self-efficacy and the adoption of skills such as talking about sexually transmitted infections and prevention with partners, negotiate safer sexual practices and decision-making about seeking help.

As Laduma was developed to address a critical health issue whille taking into account additional issues related to print media development, like presentation of correct information in an appealing manner using photographs and characters that the target audience could identify with, it warranted evaluation to assess its impact on specific variables and to assess its value as an educational print medium. The study was carried out amongst 19 randomly selected schools in the Pietermaritzburg region of KwaZulu-Natal (KZN) amongst Grade 11 learners. In terms of the study design the students from randomly allocated schools were exposed to a single reading of Laduma and requested to complete surveys at baseline (T1), post reading three weeks later (T2) and follow-up six weeks later (T3) to determine the effect of the photo-novella on their knowledge, attitudes to condom use and to people with sexually transmitted infections (STIs including HIV/AIDS) as well as their intention to practice safer sex. These results were compared to a random selection of control schools.

In chapter 5 the evaluation of the KwaZulu-Natal Department of Educations' Lifeskills Programme focusing on HIV and AIDS is reported on. This was an enhanced teacher-driven curriculum that was implemented amongst grade 9 learners during two school terms. The programme addressed a range of topics starting with the facts about HIV and AIDS concerning the modes of transmission, the immune system, the progression of HIV to AIDS, and how to keep the body safe and healthy thus avoiding HIV infection as well as substance abuse and rape and abuse. This was followed by a component that addressed relevant determinants of lifeskills related to the prevention of HIV and AIDS. The focus was especially on knowledge about HIV and AIDS, attitude to condom use and people living with AIDS, gender norms and perceptions about sexual behaviour (e.g., I must have sex to keep my boyfriend or girlfriend). The 
content; which was guided by prescribed manuals, was taught through a combination of methodologies, didactic and interactive teaching, group work, and role-play. Teachers were trained to implement the curriculum and were requested to complete post-implementation surveys to assess the extent of the implementation in the different schools. The unique factor to this programme was that meetings were held to motivate and inform the school management committees, traditional healers and leaders and parents about the proposed curriculum and to gain their support. The study was carried out at 22 randomly selected schools in two districts in the Pietermaritzburg region of $\mathrm{KZN}$. The learners from both the intervention and control schools were assessed at baseline (T1), immediately after the implementation 6 months later (T2) and followed-up after a period of four months (T3).

Although aspects of theories were implicit in the content taught it was clear that the programme was not consciously developed taking behaviour change theories into account. Despite not being systematically developed the fact that the programme was a national programme and a roll out plan was in place for training of teachers and for implementation it was imperative that the programme be rigorously evaluated. Under the pressure to address the burgeoning HIV/AIDS issue amongst young people the need to provide some education was understandable. Not evaluating the current programme could result in a missed opportunity to improve on future programmes. Therefore the evaluation reported on in chapter 5 of this dissertation sought to address the gap regarding the paucity of soundly evaluated HIV and AIDS education programmes.

\section{Part 3: Refocusing the Lifeskills HIV/AIDS Programme}

The results of the above chapters provided the impetus for Chapter 6 in this thesis. Drawing on the studies reported on in this thesis and previous research done, a comprehensive assessment of the risk factors associated with sexual risk behaviour was made. An analysis of three evaluation studies about the Lifeskills HIV/AIDS Programme resulted in the development of a logic model that outlines the programme input and outputs and the extent of the implementation of the various areas of the teacher driven programme. The areas most lacking were identified as those related to implementation on the part of the teachers and principals. To address this and achieve the aims of HIV risk reduction amongst this target group, a set of implementation matrices related to teacher training and principal support was drawn up using Intervention Mapping as a tool to guide the development (Bartholomew, Parcel, Kok, \& Gottlieb, 2001; 2006). This is intended as a framework which can be explored with teachers and principals to inform the development of more contextualised matrices that allow for fuller implementation. 
Chapter 7 provides a general discussion of each of the chapters and provides an interpretation of the results by way of recommendations to inform the refocusing of future school-based HIV/AIDS life skills intervention efforts. It concludes with a discussion of the limitations of the studies in this thesis. 


\section{References}

Bartholomew, K. Parcel, G. Kok, G., \& Gottlieb, N. (2001). Interwention mopping designing theory-and evidence-based health promotion programs. Mountain View, CA: Mayfield.

Bartholomew, L. K. Parcel, G. S., Kok, G., \& Gottlieb, N. (In Press, 2006). Plorning Heolth Promoton Progroms: An Intervention Mapping Approach (2nd ed.). Jossey-Bass San Francisco.

Bot M. Dove. S. \& Wilson. D. (2000). The Education Foundation Adas of South Africa An Education Foundation Publication.

Department of Education, South Africa. (1997). Curriculum 2005, Lfelong leorning for the 21 st century. Absolutely Media Marketing.

Department of Education. (2000a). The HIVIAIS Emergency Guidelines for Educotors. Department of Education.

Department of Education and Culture, KwaZulu-Natal. 2000b). Integrated Plan For Children Affected And Infected With HIV and AlDS. Business Plan For Lifeskills \& HIW and AUDS Educotion: Secondory Schoois Phose 1 April 2000 - March 2001.

Department of Education. (2005a). Curriculum 2005 A User's Guide, [Online] Available: http://wmw.polityorg;za/htm//govdocs/misc.curr2005.htmllrebookmark=1, accessed 20 th December 2005 .

Department of Education, South Africa. (2005b). Educotion Statistics in South Africo at o Glance in 2003. Department of Education.

Department of Health. (2000). Droft Notionol Integrated Plon for Children Infected and Affected by HWADDS. Department of Heath.

Eaton, L., Flisher, A. J. \& Aaro, L. E. (2003). Unsafe sexual behawiour in South African adolescents. Sociol Science \& Medicine $56,149-165$.

Gallant, M., \& Maticka-Tyndale, E. (2004). School-based HW prevention programmes for African youth. Sacial Science \& Medicine, 58, |337-|35|

Government Gazette, August 1999. Notional Education Policy Act, 1996 (NO. 27 of 1996).

Harrison, A. Smit, J. A. \& Myer, L. (2000). Prevention of HIVIAIDS in South Africa: a review of behaviour change interventions, evidence and options for the future. South Africon foumal of Science, 96, 285-290.

Hartell, C. G. (2005). HIV/AIDS in South Africa: a review of sexud behoviour among adolescents. Available [Online]: http:/wmw.findarticles.com/p/articles/mi_m2248/is_.157_40/ai_n 13774352/print, accessed 14 December 2005.

Harvey, B., Stuartt, J. \& Swan, T. (2000). Evaluation of a drama-in-education programme to increase AlDS awareness in South African high schools: a randomized community intervention trial . Int I STD AIDS, $F e b_{1} / 1(2), 105-11$.

James, S., Reddy S.P. Taylor, M., \& linabhai, C. C. (2004). Young people, HIVIAIDS/SI" Is and sexuality in South Africa: the gap between awareness and behaviour. Acto Paediatr, 93, 264-269.

James, S., Reddy, S. P. Ruiter R. A. C., Taylor, M. Jinabhai, C. C. Van Empelen, P. \& Van den Borne, B. (2005). The effects of a systematically developed photo-novella on knowledge, attitudes, communication and behavioural intentions with respect to sexually transmitted infections among secondary school leamers in South Africa. Heolth Promotion Internotionol, 20(2).

Kaaya, S. F. Flisher, A. J. Mbwambo. J. K. Schaalma. H. Aano, L. E., \& Klepp, K. 1. (2002a). A review of studies of sexual behaviour of school students in Sub-Saharan Africa. Scond / Public heolth, 30, 148 160.

Kaaya S. F. Mukoma W. Flisher, A. J. \& Klepp, K. 1. (2002b). School-based Sexual Health interventions in Sub-Saharan Africa: A Review. Social Dynomics, 28(1), 64-88.

Khulisa Management Services. (2000). Assessment of the Implementotion of Life Skills HIVWADS Programme in Secondary Schools. Report.

Kuhn, L, Steinberg, M. \& Mathews, C. (1994). Participation of the school community in AlDS education: an evaluation of a high school programme in South Africa. Aids Core, $6(2), 161-171$.

Mandela Foundation/HSRC. (2002). South Africon Notional HN Prevalence, behovioural risks ond mass media: Household Survey 2002. Cape Town: Human Sciences. Research Council Publishers.

Magnani, R. Macintyre, K., Karim, A. M. Brown, L, \& Hutchinson, P. (2005). The impact of life skills education on adolescent sexual risk behaviours in KwaZ ullu Natal, South Africa fournol of Adolescent Heolth, 36 , 289-304. 
N. Kambaran, N. S, Omardien R. G, \& Van den Bome. H.W. (2003). Umthenthe Uhiabo UsomiloSouth African Youth Risk Behoyour Survey 2002. Cape Town: South African Medical Research Cou Varga, C. \& Shongwe, B. (1999). School Bosed Reproductive Heolth Educotion. Durban: Health Syst Trust.

Visser M. . Schoeman, I. B. \& Perold. 1. 1. (2004). Evaluation of HVIADS Prevention in South Af Schools journal of Health Psychology, $9(2), 263-280$.

UNADS (2004). ADS Epidemic Updote, 2004. [Online] http//wmwunaidsorg/wad2004/ 
Young people, HIV/AIDS/STIs and sexuality in South Africa: the gap beween awareness and behaviour

Published as S james, SP Reddy M Toylor and CC linabial. Young people, LIVAIDSISTIS and sexualiny in South Africas the gap beeween awareness and behaviour. Acta Paedatr 93: 264 269. 2004 


\section{Abstract}

Aim: To determine the baseline data of secondary school students in the Midlands district of KwaZulu-Natal, South Africa. The data provide details of students' knowledge about sexually transmitted infections (STIs) including HIV and AIDS, spread, prevention, how they can protect themselves from contracting an STI, their general awareness and sources of information, their perceptions of their vulnerability and their sexual practices.

Methods: A cross-sectional study was carried out among 1113 grade 11 students in 19 randomly allocated secondary schools. Data were collected through structured questionnaires and analysed using the SPSS software package

Results: The results confirm that knowledge levels were high for causes and spread of STIs and the participants were well informed about issues relating to protection against STIs and seeking treatment. However, there was significant deviation in reported behaviours.

Conclusion: This discrepancy between awareness and behaviour calls for a reorientation of sexuality education to include those elements critical for behavioural change, such as addressing gender discrepancies and promoting skills for communication through planned intervention programmes. 


\section{Introduction}

Sexually transmitted infections (STIs) pose a serious public health problem for South Africa with about 11 million episodes being treated annually (1). In the past decade there has been an increase in the consequences of unsafe sexual behaviour (2). In South Africa the National HIV sero-prevalence study focusing on women attending antenatal clinics at public health facilities indicated a prevalence rate of $22.4 \%$ (3). The age group most affected was women in their twenties; HIV prevalence in the 20 to $24-y$ age group was $25.6 \%$ and $26.4 \%$ in the 25 to $29-y$ age group. HIV prevalence rate for women under $20-y$ of age was $16.5 \%(3)$.

KwaZulu-Natal, the third smallest province, has $20.7 \%$ of the population of South Africa, $35.5 \%$ being $15-y$ of age (4). The school-going population, that is young people between 7 and 18-y, make up $27 \%$ of the national population with 2342760 attending schools in KwaZulu-Natal. This figure is the highest of all the provinces.

It is during these formative years that patterns of behaviour are developed that either protect or place young people at risk later in adult life (5). Developing protective sexual behaviour is dependent on the development, implementation and adoption of effective primary prevention programmes that address the behaviours that curb the increase of STIs including HIV and AIDS. To date, several prevention programmes concerning safer sexual behaviour in South Africa have been implemented but their level of success is uncertain, as they have not been effectively evaluated. Examples of such programmes fall broadly into the category of information, education and communication and include Soul City (television programme), Laduma (youth magazine) and the Department of Health"s Beyond Awareness campaign, which promotes condom use, dialogue about the disease and sponsorship of HIV-and AIDS-related activities (6). In light of the multiple sources of information available to young people, the aim of this study was to assess students' knowledge and general awareness and sources of information about HIV and AIDS, their perceptions of their personal risk for STIs, their beliefs and attitudes to condom use and sexual behaviour as well as their reported sexual behaviour. This study further seeks to evaluate those factors that could contribute to the development of a comprehensive STI/HIV/AIDS prevention programme that includes a planned and systematic approach to the task.

\section{Methodology}

This cross-sectional descriptive study was carried out among grade 11 students in the Midlands district of the province of KwaZulu-Natal $(K Z N)$, South Africa. 
The Midlands is a district in one of the eight regions of KZN. It has both rural and urban dwellers and a largely Zulu-speaking population. According to Bot et al. (4), most children, both boys and girls, in South Africa attend school. However, before 1996 when compulsory education was introduced for children under 16-y of age (7), children started school at varying ages depending on their social circumstances. Furthermore, those children whose education had been disrupted because of the effect of the political climate at the time were allowed to go back to school. Hence the small percentages of older people in schools. For the purposes of analysis, students over 22-y of age were excluded from this study, resulting in a sample size of 1113 students out of the original 1168.

There are 27 secondary schools in this district with a total of 24276 students. Initially, 20 schools were randomly allocated to participate in the study; however, 4 schools refused because of having to write year-end examinations. These schools were replaced by a random selection of 4 schools from the 7 schools that were originally left out but only 3 schools accepted, resulting in a total of 19 schools in the final sample. The schools comprised a mixture of rural and urban students. Two classes were randomly selected from all the grade 11 classes at the sampled schools. All the students from those two classes were included in the study.

The schools had adequate infrastructures in terms of buildings, classrooms and ablution facilities, but there was a scarcity of recreational facilities at the schools and the surrounding areas. Since 1994 the South African government has been making an effort to integrate schools in terms of "race", as well as to redress inequities owing to historical lack of resources among certain schools.

The study instrument was a questionnaire with categories yielding information about the demographic profile of the subjects, their knowledge, beliefs, attitudes and practices with regard to sexually transmitted infections including HIV and AIDS. The questionnaire was pre-tested among a group of students who were similar to the study sample, to ensure construct and face validity. The questions were closed ended with "yes", "no" and "unsure" responses. Six open-ended questions were used to enable students to freely express their views. The questionnaires were completed individually by the students and were supervised by a fieldworker and researcher, during a normal class lesson. The survey was conducted in English, the language used for instruction at schools. Grade 11 students were selected as they had already had four years of high school education in English and this ensured an adequate level of readability and understanding of the questionnaire. Students were given as much time as they needed to complete the questionnaire to allow for individual abilities. Time taken to complete the questionnaire varied between 30 and 50 min. To respect anonymity, students were requested not to write 
their names on the questionnaires. They were only identifiable by numbers for the purposes of gathering data. Written consent was obtained from the parents and the Department of Education. The students were also given the opportunity to decide whether they were comfortable with participating in the study. There were no refusals from the parents and only one learner refused to participate. The Faculty of Medicine, Nelson R. Mandela Medical School, granted approval of the ethics for the study.

\section{Results}

\section{Demographic profile}

Zulu was the home language of the majority of the students and $26 \%$ indicated that English was their home language. However, it must be noted that English was the medium of instruction at the schools.

Table 1: Socio-demographic variables of secondary school learners

\begin{tabular}{|c|c|c|c|c|}
\hline Variables & Missing & Male & Female & Total: \\
\hline Age $(y)$ & & & & \\
\hline $15-21$ & $1(0.1 \%)$ & $524(47.1 \%)$ & $588(52.8 \%)$ & $1113(100 \%)$ \\
\hline \multicolumn{5}{|l|}{ Language } \\
\hline English & & $164(14.9 \%)$ & $123(11.2 \%)$ & $287(26.1 \%)$ \\
\hline Zulu & & $345(31.4 \%)$ & $461(42.0 \%)$ & $806(73.4 \%)$ \\
\hline Other & & $3(0.3 \%)$ & $2(0.2 \%)$ & $5(0.5 \%)$ \\
\hline Missing & $15(1.3 \%)$ & & & $15(1.3 \%)$ \\
\hline
\end{tabular}

$n=1113$

"Variable totals only reported"

Students' risk of contracting sexually transmitted infections

In response to a question about perception of STIS, both males and females reported that STIs were a serious health problem (92\%). More than half of the respondents (of both sexes) feared that they were at risk of contracting an STI $(53 \%)$. This response decreased (for both males and females) when considering their risk over the next two years (17\%). Significantly more males than females reported knowing a friend with an STI $(p<0.05)$ and more students reported knowing a friend that had an STI as opposed to themselves (17.8\% vs $10 \%)$. 


\section{General awareness and sources of information}

Of the respondents, $80 \%$ had heard people talking about STIs, $64 \%$ reported they knew what a STI was and 55\% were able to name an STI. AIDS/HIV was listed by half of the respondents and about 34\% listed iDrop (colloquial word for an ST1). The remainder gave details of other individual conditions such as gonorrhoea, warts or a combination of conditions, for example AIDS or iDrop with thrush or herpes.

As depicted in Table 2, the most common reported source of information for both malle and female students was the media including newspapers, magazines and television. Friends and clinics play an important role as sources of information to males and females, respectively. Family was reported as the least accessed source of information.

\section{Table 2: Sources of Information}

\begin{tabular}{llll}
\hline Meard about STis from: & Male & Female & \\
Media & & & \\
Mriends & $83.2 \%$ & $85.0 \%$ & 0.089 \\
Clinic & $71.4 \%$ & $64.2 \%$ & $\mathbf{0 . 0 3 4}$ \\
Teachers & $51.8 \%$ & $67.2 \%$ & $\mathbf{0 . 0 0 0}$ \\
Family & $47.9 \%$ & $50.7 \%$ & 0.485 \\
& $32.5 \%$ & $33.1 \%$ & 0.331
\end{tabular}

Significant difference between gender in boldface.

Table 3 reflects a set of issues that young people generally discuss with significant people in their lives, for example parents, friends and partners. The Table further reflects the gender differences in each category as there was a difference with regard to what males and females communicated about; for example, significantly more males talked about condom use compared with females and significantly more females talked about HIV and AIDS compared with males.

The results indicated that both males and females communicate mainly with friends about sensitive issues. 
Table 3: Communication with parents, friends and partner

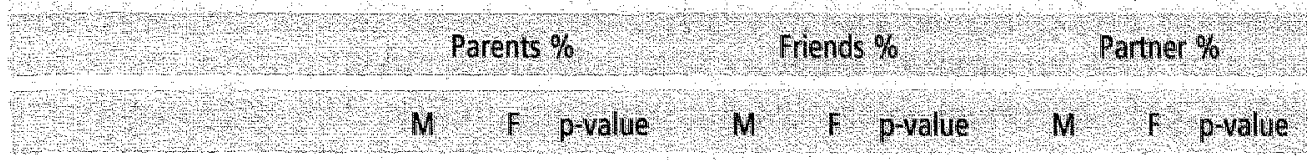

Communication about:

\begin{tabular}{|c|c|c|c|c|c|c|c|c|c|}
\hline HIV/AIDS & 46.6 & 52.2 & 0.04 & 73.0 & 78.1 & 0.03 & 58.6 & 62.1 & 0.13 \\
\hline Condom Use & 41.8 & 35.9 & 0.11 & 83.1 & 75.0 & 0.00 & 68.1 & 62.8 & 0.04 \\
\hline $\begin{array}{l}\text { Sexually transmitted } \\
\text { infections }\end{array}$ & 33.8 & 34.9 & 0.76 & 629 & 60.0 & 0.61 & 48.8 & 51.0 & 0.11 \\
\hline $\begin{array}{l}\text { Whether to have } \\
\text { intercourse }\end{array}$ & 33.9 & 26.0 & 0.02 & 82.5 & 63.2 & 0.00 & 69.9 & 50.4 & 0.00 \\
\hline $\begin{array}{l}\text { Whether or not to } \\
\text { have intercourse }\end{array}$ & $=$ & - & & 49.1 & 71.0 & 0.00 & 40.1 & 60.3 & 0.00 \\
\hline
\end{tabular}

$n=1113$

Significant difference between gender in boldface.

\section{Knowledge}

Table 4 reflects only those results that indicate a high level of knowledge relating to the causes, spread, treatment and how one would protect oneself against STIs.

Results on the spread of STII indicated that $79.4 \%$ of respondents answered 3-5 questions correctly.

An average of $78 \%$ of students were in agreement about the questions relating to the sexual causes of STIs, that is unprotected sex and having many sexual partners. Significantly more males than female respondents believe that girls are the cause of STIs $(p<0.05)$.

Students' knowledge about the use of a condom to protect themselves against STIs is favourably reflected by the $86.4 \%$ response rate. However, the results on protection reveal that only $43.9 \%$ of students answered 3-6 questions correctly. This is lower than the results for knowledge about causes and spread of STIs but compares favourably with the results concerning treatment, for which $47.8 \%$ of students answered 3-6 questions correctly (Table 4).

The response to an open-ended question on protection indicated that at least $87 \%$ of respondents were able to suggest an appropriate way to protect themselves against STIs. 
This included the use of condoms, delaying sex and a combination of using condoms and being fatthful to their partner. However, in an open-ended question that personalized whether a participant would know if he or she had an STI, only $26 \%$ were able to list the symptoms of STIs, $41 \%$ were unsure and $32 \%$ would consult a doctor so that an examination or blood tests could be done. It must noted that $27 \%$ of the sample omitted to respond to this question.

Table 4: Learners' knowledge about the cause, spread, treatment of, and protection from STIs

\begin{tabular}{|c|c|c|c|}
\hline \multicolumn{4}{|l|}{$\begin{array}{l}\text { Sexually transmitted } \\
\text { infections caused by: }\end{array}$} \\
\hline Condoms & 24.2 & 62.8 & 13.0 \\
\hline Uniprotected sex & 76.2 & 15.9 & 8.0 \\
\hline Having many sexual partners & 80.2 & 12.8 & 7.0 \\
\hline
\end{tabular}

Sexually transmitted infections are spread by:

Unprotected sex

A person protects oneself from contracting an STI by:

Having one faithful partner

Using a condom

86.4

If you were on treatment, would you:

Stop the treatment when you felt better

Share treatment with a friend,

Have sex without a condom

78.5

If you had an STI, would you go for treatment:

As soon as you have symptoms

No symptoms, but partner is infected 


\section{Attitude to condom use}

Attitude to condom use was assessed by the responses to eight questions. Table 5 reflects the gender differences for each of the response categories.

Despite the fact that significantly more males believe that condoms take the fun out of sex, significantly more males also bellieve that condoms are not embarrassing to use and do not harm the body; $68.5 \%$ of both males and females responded favourably to four and more of the statements; $82.7 \%$ of males and $51.2 \%$ of females reported that they knew how to use condom.

\section{Table 5: Learners" attitude to condom use}

\begin{tabular}{|c|c|c|c|c|c|c|}
\hline \multirow[b]{2}{*}{ Statement } & \multicolumn{2}{|c|}{ W/n agreement } & \multicolumn{2}{|c|}{ \% Not in agreemen } & \multicolumn{2}{|c|}{ \% Unsure } \\
\hline & $\mathrm{M}$ & $F$ & $M$ & F & $M$ & $F$ \\
\hline $\begin{array}{l}\text { Condoms take the fun out } \\
\text { of sex }\end{array}$ & 30.0 & $17.8^{*}$ & 40.4 & 39.2 & 29.6 & 43.0 \\
\hline $\begin{array}{l}\text { Condoms are embarrassing } \\
\text { to use }\end{array}$ & 16.7 & 13.2 & 61.4 & $54.4^{*}$ & 21.9 & 32.4 \\
\hline Condoms can harm your body & 7.0 & 11.0 & 69.8 & $52.9 *$ & $23.3^{*}$ & 36.2 \\
\hline $\begin{array}{l}\text { Condoms are important to use } \\
\text { every time you have sex }\end{array}$ & 82.0 & 88.1 & 10.7 & $4.6^{*}$ & 7.2 & 7.2 \\
\hline $\begin{array}{l}\text { Using a condom shows partner } \\
\text { that you do not trust him/her }\end{array}$ & 28.4 & 23.9 & 58.1 & 57.6 & 13.5 & 18.5 \\
\hline $\begin{array}{l}\text { Condoms work well to prevent } \\
\text { sexually transmitted infections }\end{array}$ & 77.2 & 73.3 & 6.5 & 6.9 & 16.3 & 19.8 \\
\hline Condoms also prevent pregnancy & 86.8 & 83.2 & 5.3 & 6.2 & 7.9 & 10.7 \\
\hline $\begin{array}{l}\text { Using a condom shows that you } \\
\text { care about your and your partner's } \\
\text { health }\end{array}$ & 90.6 & 88.4 & 3.9 & 3.3 & 5.5 & 8.4 \\
\hline
\end{tabular}

$n=1113$

Favourable or correct response in boldface $p<0.05$

\section{Sexual behaviour:}

Beliefs about sexual behaviour. A question about the right age to start having sex indicated that $47.8 \%$ of the students were in agreement with the age category, 15-19-y old. Significantly more males than females indicated a positive response towards this age range. 


\section{Sexual Practice}

Of the sample, $42.6 \%$ answered positively about having been sexually active in the past six months. There was a significant difference in this response between males and females $-52.9 \%$ males compared with $33.2 \%$ females $(p<0.05)$. Of those reporting positively to having had sex in the past six months (males and females), $81.5 \%$ were between 15 and $19-y$ of age.

\section{Condom use}

Of those reporting having been sexually active in the past six months, $33.3 \%$ reported not having used a condom at all, Of those students who reported using a condom, $41.8 \%$ indicated using a condom every time and $42.6 \%$ sometimes. Of those that used a condom, significantly more males $(73.7 \%)$ than females $(56.7 \%)$ reported that it was their idea to use a condom $(p<0.05)$. For $73.5 \%$ of subjects, the clinic was the main source for condom acquisition. Of the males who did not use condoms, $49.3 \%$ reported that it was due to personal preference. However, only $18.2 \%$ of females reported that their partners refused to use condoms. Of the students that reported being sexually active in the six months before the survey, 85\% were in agreement with the statement that it is important to use condoms every time. However, for these same students the response to a question on actual condom use was that $46.2 \%$ reported using a condom every time.

\section{Discussion}

The study examined the determinants of sexual behaviour (knowledge, attitudes and communication) in the context of the adolescents' exposure to information from the media, family, friends, clinics and teachers. These information sources have been successful in raising knowledge and awareness, as is evidenced by the high levels of knowledge on causes and transmission of sexually transmitted infections and the acceptance of condoms as a means of protection against sexually transmitted infections as has also been shown in other countries (8-11). The studies cited here were evaluations of school-based programmes that all showed a difference in knowledge and/or positive attitudes to condom use and people with AIDS. This confirms that almost all interventions will have some effect, especially on knowledge and attitudes. The effects of behavioural change are not readily reported and perhaps are the result of more intensive programmes, which have a clear focus on at least one behavioural change as an outcome (12).

There was a dearth of literature on the evaluation of interventions and the effect of general media strategies such as pamphlets, television and newspapers. However, media strategies have been widely used and proven to be important in creating awareness, which was confirmed by the response of $80 \%$ of the 
students who reported hearing about sexually transmitted infections. The discrepancy between unprotected sexual behaviour and improved knowledge and acceptance of condoms as well as the fact that only just over half of the students were able to name a sexually transmitted infection beckons the need for a more expansive approach to sex education $(6,8,13)$. A broader approach to sex education moves beyond dissemination of information but rather seeks to address the critical factors that impact on the factual knowledge and decision-making processes of young people.

Further assessment of the findings showed that young people have an unrealistic perception of the risk of their contracting sexually transmitted infections and an optimistically biased assessment of their comparative risk of being affected by sexually transmitted infections. They rated themselves to be less infected by such infections than their peers, a perception that is fundamental to understanding precautionary behaviour (14). Weinstein (15) also reported that preventive health behaviour results from a perception of personal risk. Although this study did not test for the association between personal risk and condom use, the individual results about personal risk and condom use in this study would appear to emphasize the need to include those strategies in interventions that are likely to influence students" perceptions of personal risk. However, in a review by Millstein and Halpen-Felsher (16) it is pointed out that adolescents do not see themselves as invulnerable and that approaches to intervention development need to include belliefs about the value attached to potential outcomes, expectations about social norms, and perceived benefits. Furthermore, Reinecke et al. (17), caution that sexual behaviour, in particular, is not under volitional control but requires the cooperation of others and propose that, in developing interventions, other theories that include skills and self-efficacy need to be applied as well.

In this study both males and females rely heavily on friends to communicate on issues concerning STIs/HIV/ AIDS and significantly more females reported talking to their partners about either having or not having sex. This highlights the need for planned programmes and the media to provide for the circulation of updated, accurate, personalized and relevant information that is accessible to young people (16). Furthermore, sex education needs to reflect the problem of STIs in a way that personalizes the issue as opposed to being a series of medical facts. It also needs to address the skills young people need to have in order for them to be able to communicate their concerns; for example the question that arises and that has not been investigated in this study is whether they feel confident about dealing with the reaction of their partners or about making their own position heard.

This study revealed that, despite the positive aspect of wide acceptance and 
the favourable attitude towards condom use, actual use and confidence about how to use a condom was low among both male and female students. The study also reflected that substantial numbers of students were unsure about the effects of condom use; for example condoms take the fun out of sex, condoms can harm the body and condoms are embarrassing to use. This is a reflection that current strategies about condom education are not reaching large numbers of students to impact positively on their attitudes about the benefits of condom use. As consistent condom use remains a crucial strategy in STI prevention, there is an urgent need for educational material to move beyond slogans or statements and to harness the already positive attitudes expressed, as well as to demonstrate the correct technique in using condoms to dispel unrealistic beliefs about it. This can be achieved by providing accurate and frank information about how condoms work and how they are used (18), thereby providing adolescents with the skills they need. Moreover, the gap between the discrepancies in male and female participants' attitudes, communication and knowledge regarding condom use needs to be bridged (19). A study conducted by Hocking et al. (20) confirmed that effective communication on sexual issues results in a greater likelihood that condoms will be used.

This study also highlighted that culturally sensitive programmes could contribute to overcoming barriers to effective education, such as the belief held by significantly more males than females that STIs are caused by females. This recommendation is supported by a study carried out by Reddy et al. (21) amongst a high-risk group of STI clinic attendees, and cautions that intervention development needs to take place within the context of the target group.

\section{Conclusion}

The results of this study emphasize the need to reorientate education to include the social, interpersonal and theoretical aspects associated with difficult behavioural choices and behavioural change. This focus will reflect an wnderstanding of the factors that contribute to behavioural choices made by young people, as well as an educational content that addresses the diverse needs of a wide age group and differences in culture, making the intervention context specific. Such education can be made effective through the provision of planned, monitored and evaluated educational expetiences (22), grounded in a sound understanding of behaviour related to gender discrepancies, communication and the development of skills pertinent to the group the interverition is intended for. 


\section{References}

1. Department of Health. HIVIAIDS \& STD Strategic Plan for South Africa 2000 2005; 2000

2. UNAIDS Report on the global HIN/AIDS epidemici June 2000

3. Department of Health. National HN Sero-prevalence survey of women attending public antenatal clinics in South Africa 1999;2000

4. The education foundation atlas of South Africa. Prepared by Bot M, Dove S, Wilson D. An Education Foundation Publication 2000

5. Wren PA, Janz NK, Carowano K, Zimmerman MA, Washienko KM. Preverting the spread of ADS in youth: principles of practice from I diverse projects. A Adolesc Health 1997; $21: 309-17$

6. Harrison A, Smit JA, Myer L. Prevention of HIV/AIDS in South Africa a review of behaviour change interventions, evidence and options for the future. SAfr I Soi 2000:96

7. Govemment gazette. National Education Policy Act, 1996 (No. 27 of 1996) August 1999

8. Svenson LW. Carmel $S$, Vamhagen CK. A review of the knowledge, attitudes and behaviours of university students concerning HVIAIDS. Health Promotion lint 1997; 12:61-8

9. Merson $M H$, Dayton JM, OReily $K$ Effectiveness of HIV prevention interventions in deweloping countries. AIDS 2000; 14 Suppl 2: $\$ 68-\$ 84$

10. Klepp K, Ndekj SS, Seha. AM, Hannan P: Lyimo BA, Msuya MH, et al. Aids education for primary school children in Tanzania: an evaluation study. AIDS 1994: 8:1157-62

11. Kuhn L. Steinberg M. Mathews C. Participation of the school community in ADS education: an evaluation of a high school programme in South Arrica. Aids Care 1994;6:000 0

12. Kirby D. No easy answers. Washington, DC.The National Campaign to Prevent Teen Pregnancy 1997

13. Salt $H$, Boyle M. Ives J. HM prevention: curnent health promoting behaviour models for understanding psycho-social determinants of condom use. AIDS Care 1997;2:000-00

14. Snyder LB. Rouse RA. The media can have more than an impersonal impact: the case of AlDS risk perceptions and behavior. Heath Comm 1995; 7; 125-45

15. Weinstein ND. Why it won't happen to me: perceptions of risk factors and susceptibility. Health Psychol 1984; 3: 431-57

16. Millstein S, Halpen-Felsher BL. Perceptions of risk and vulnerability ] Adolesc Health 2002:315: 10-27

17. Reinecke J, Schmidt P. Ajzen I. Application of the theory of planned behaviour to adolescents' condom use: a panell study. I Appl Soc Psychol 1996;26: 749-72

18. DiClemente RJ. Psychosocial determinants of condom use among adolescents. In: DiClemente R., editor. Adolescents and AlDS: a generation in jeopardy. Beverley Hills, CA: Sage 1992: 35-41

19. Redidy P. Meyer-Weitz A, Van den Bome B, Kok G. Determinants of condom-use behaviour among STI cinic attenders in South Arrica, Int STI AIDS 2000; 11:52:1-30

20. Hocking J $\mathbb{E}_{\text {n }}$ Turk $D$, Ellinger A The effects of partner insistence of condom usage on perceptions of the partner, the relationship, and the experience. I Adolescence 1999; 22: 355-67

21. Reddy $\mathrm{P}$, Meyer-Weitz A, Van den Borne B. Kok G. STI-related knowledge, beliefs and attitudes of Xhosa-speaking patients attending STl primary health-care clinics in South Africa. Int I STI AIDS 1999: 10: $392-400$

22. Kok $G$. Health education theories and research. For AlDS prevention. Hygie 1992; $10: 32-9$ 
Alcohol and substance use as moderators of sexual behaviour amongst secondary school students in KwaZulu Natal, South Africa: A view to comprehensive programme development 


\section{Abstract}

Purpose: To examine the association of alcohol and substance use on sexual behaviour amongst students in KwaZulu-Natal, South Africa.

Methods: A sub-set of a cross-sectional national study, the first Youth Risk Behaviour Survey, was used. The sample comprised of $46 \%$ male and $54 \%$ female students from grades 8-11. Data was collected on a cluster of risk behaviours. For the purpose of this paper data on reported alcohol use, substance use and sexual behaviour was analysed. Frequency and chi-square analyses were done to describe these behaviours and logistic regression analysis was used to determine the associations between selected predictor variables and two dependent variables: sexual behaviour and condom use.

Results: Significantly more male students than female students reported ever having had sex and using alcohol or drugs in their lifetime, initiating sex at a younger age and having had multiple partners. Students who drank alcohol and used drugs were much more likely to be sexually active (63\%), compared to those who only used alcohol (43\%) or only used drugs ( $47 \%$ ) or did not use alcohol or drugs (27\%). More students that drank alcohol and more students that received HIV and AIDS lessons used condoms when having sex.

Conclusion: Some students are sexually active at an early age and most experience unprotected sex. Steps to strengthen the HIV and AIDS education need to be taken. Such education needs to take the determinants of sexual activity into account that is age, gender, alcohol use, drug use and HIV and AIDS education in schools. 


\section{Introduction}

Several programmes have targeted behaviours related to adolescent health in South Africa. The behaviours most widely addressed were related to substance and alcohol use as well as unprotected sex. Initially these behaviours were viewed as individual behaviours resulting in specific outcomes, for example unprotected sex (non-use of condoms or contraceptives) was wiewed as contributing to the high rates of unplanned teenage pregnancies. However, in the light of the prevalence of a range of health related problems experienced by young people in South Africa [1], it has become crucial to delineate the factors associated with these behaviours and their association with each other, if any.

Several studies have shown that being under the influence of alcohol or drugs during sexual activity is associated with risky sexual behaviour [2-4]. The association of alcohol and drug use with sexual behaviour is explained through the disinhibition theory and pharmacological disinhibition effects of psychoactive substances which are theorised to be related to risky sexual behaviour $[2,3,5]$. It is theorised that alcohol clouds the judgement and releases behaviours that are normally suppressed [5,6]. In addition, clouding of judgement and logic may result in the loosening of inhibitions and a change in the nature of sexual behaviour resulting in people engaging in more risky sexual behaviours [2].

In addition to the psychobiological explanation, the interrelatedness of risky sexual behaviour, alcohol and drug use has also been explained in terms of clustering of risk behaviours and have led investigators to note that behaviours serve a common goal $[6,7]$. More generally, risk behaviours are explained as serving a developmental function for adolescents and are further mediated by other factors such as personality characteristics for example sensation seeking $[8,5]$. The complexity of the interrelatedness of these behaviours requires further investigation, however, for now an understanding of the interrelatedness of the behaviours should caution one to the potential ineffectiveness of addressing these behaviours independently of each other. In order to facilitate programme development that addresses these behaviours comprehensively, the present paper aims to report on the prevalence of alcohol, substance use and sexual behaviour practices as well as the association of these behaviours with each other, within the category of secondary'school students in KwaZulu-Natal (KZN), South Africa. In a National study carried out in South Africa recently, of the students that reported being sexually active, $13.8 \%$ reported having used drugs or alcohol the last time they had sex. For KwaZuluNatal this figure was $15.2 \%$ making it amongst the highest of the Provinces [1].

It is envisaged that the results reported will influence the development of intervention programmes that are coherent and comprehensive and that 
address all the relevant behaviours that underpin unsafe sexual behaviours. Such programmes may address the skills involved in protecting young people across the behaviours as opposed to the individual behaviours as well as include sections that pertain to the specific behaviours [9].

\section{Methods}

\section{Participants}

In 2002 the first Youth Risk Behaviour Survey (YRBS) was conducted in South Africa [1]. This was a cross-sectional national study that aimed to provide national. and provincial representative data on the prevalence of a cluster of behaviours that place secondary school students at risk. This cluster of risk behaviours included intentional and unintentional injuries, substance abuse tobacco, alcohol and other drugs, sexual behaviour, nutrition and dietary behaviours, physical activity and hygiene-related behaviours. For the purpose of this paper, a subset of the data collected for the first YRBS was used and reported on. This sub-set comprised of data from KwaZulu-Natal, one of the nine provinces in South Africa with the largest school-going population.

The sampling strategy consisted of a stratified, two stage cluster design to ensure the collection of provincially representative data from a population artanged into school and class-level clusters. At the first stage of sampling, schools were selected with a probability proportional to school student enrolment size in Grades 8 to 11 . At the second stage of sampling classes within each school were selected systematically with equal probability sampling (with a random start). All students in the classes were eligible to participate. A school and student participation rate of $80 \%$ was expected, based on experience of a similar national school-based survey [10].

The study sample $(n=1200)$ was comprised of Grades $8,9,10$ and 11 students from 20 randomly selected schools. Grade 12 students were excluded from the study due to time constraints related to their final year examinations. The sample comprised of $46 \%$ male and $54 \%$ female students. The majority were Zulu first language speakers $(89.5 \%)$. The mean age of the students was 15.93 years $(S D=2.72)$.

The data were collected using a self-administered questionnaire designed to obtain prevalence data from young people on a range of behaviours that affect their health profile. While the questionnaire draws on the experience of the Youth Risk Behaviour Surveillance System of the USA Centre for Disease Control 2001 [11], it was extensively revised and adapted to meet the needs within the South African context. The questionnaire was developed in English and pre-tested for face and construct validity. A first language Zulu speaking student translated the questionnaire into Zulu and another back-translated it in 
preparation for the pilot after which the final adjustments were made. The questionnaires were administered in Zulu and English depending on the students' preference.

Active informed consent to conduct the study was obtained from the National Department of Education, school principals, and parents. In addition, assent was also obtained from students on the day of the study. The students were informed about the purpose of the study, the steps taken to maintain their confidentiality and anonymity and then invited to participate. Their acceptance was indicated by signing an assent form. Students were requested not to write their names on the answer sheet to ensure their anonymity. To increase the confidentiality of the students fieldworkers conducted the survey and the teachers were requested to leave the classroom during data collection. Further, students were requested not to communicate with each other or to look at the answer sheet of their peers during the completion of the survey.

\section{Measures}

For the purpose of this paper data on demographic variables, substance use and sexual behaviour were analysed.

\section{Demographic Variables}

Students were asked single questions to illicit their age, grade and race group.

\section{Sexual behaviour}

Several closed ended questions were asked to determine the students life time sexual behaviour lever had sex (yes/no), age of initiation (never had sex; 11 years old or younger; 12 or 13 years old; 14 or 15 years old; 16 years old; 17 years old or older)], number of sexual partners (never had sex; 1 person; 2 people; 3 or more people) and condom use (never had sex; we never; rarely; sometimes; most of the time, always used a condom) as well as their current sexual behaviour [number of partners in the last three months (never had sex; had sex but not in the last three months; 1 person; 2 people; 3 or more people)] and their use of alcohol or drugs when they last had sex (never had sex; yes; no; I do not remember).

A single question was asked about whether students had been taught about HIV infection and/or AIDS in class (yes/no).

Due to discrepancies in some responses the final sexual behaviour variable was constructed by computing a variable that reflected all those students who responded to the questions related to sexual behaviour. They were categorised as being sexually active (1) if they responded positively to having had 1 or more partmers during their lifetime or in the past three months, or had sex but not in the past three months, or responded to one of the questions ranging from had 
never used a condom while having sexual intercourse to always used a condom. Those who responded never having had sex for each of these questions were categorised as not sexually active ( 0 ).

The condom use variable was dichotomised into students that reported never i rarely, sometimes or most of the time using condoms as non users of condoms (0), as they all were exposed to an element of risk and those that always reported using condoms as users of condoms (1).

\section{Alcohol use}

Students were asked about their life time use of alcohol [drink per days (never 0 days); rarely ( 1 or 2 day); sometimes ( 3 to 9 days); often (10 to 19 days); very often ( 20 or more days); where a drink referred to a glass of wine, a beer or 'tot" of brandy] as well as the age at which they had their first drink (never had a drink; only had a few sips; 8 years old or younger; 9 to 10 years old; 11 to 12 years old; 13 to 14 years old; 15 to 17 years old; 18 years old or older).

Their current use of alcohol was assessed by asking the number of days they had at least one drink in the past month ( 30 days) [never ( 0 days); rarely ( 1 to 5 days); sometimes ( 6 to 9 days), often (10 to 19 days; very often (20 to 30 days)]. The responses for current use were recoded into (0) for non alcohol users as indicated by never used alcohol or rarely and into (1) for alcohol users as in those that reported using alcohol sometimes, often and very often. The variable for alcohol use in the past month was transformed logarithmically, to meet the assumptions of the analysis.

\section{Drug use}

Life time dagga (marijuana) use indicated by the number of times used [never (0 times); rarely (10r 2 times); sometimes ( 3 to 9 times); often (10 to 19 times); very often (20 or more times)] and age of initiation was asked (never tried dagga; 8 years old or younger; 9 or 10 years old; 13 or 14 years old; 15 or 16 years old; 17 years old or older) as well as current dagga use that is the number of days dagga was used in the past month [never ( 0 days); rarely ( 1 to 5 days); sometimes ( 6 to 9 days), often (10 to 19 days); very often (20 to 30 ) days] .

Single questions on life time use of other drugs were asked. These included sniffed glue [(breathed contents of aerosol cans, inhaled paint thinners, petrol or benzene), mandrax, cocaine, heroin, illegal injected drugs and other illegal drugs (speed, LSD, magic mushrooms)]. There response options were [never (0 times); rarely ( 1 or 2 times); sometimes ( 3 to 9 times); often (10 to 19 times); very often ( 20 or more times) and (I don't know this drug for sniffed glue; mandrax; cocaine; heroin; and illegal drugs)].

A computed variable for life time drug use was constructed that included lifetime use of dagga, sniffed glue, mandrax, cocaine, heroin, injected illegal drugs and other illegal drugs (such as LSD and speed) (Cronbach's alpha 0.76). 
This scale was transformed (inverse) to better meet the assumption of the analysis regarding normal distribution.

\section{Data analysis}

Data were analysed using SPSS version 12 . Frequency and chi-square analyses were done to describe sexual behaviour, alcohol use and drug use among male and female students in our sample. Logistic regression was done to determine the associations of selected predictor variables (alcohol use, drug use, and interaction of alcohol and drug use) with two dependent variables: sexual behaviour (had sex and did not have sex) and condom use (never used a condom or always used a condom when having had sex). Co-variables in these analyses were age, gender and whether or not the student had had AIDSeducation. The analysis regarding sexual behaviour was based on all KZN students in the study $(\mathrm{N}=1200)$. A test for the full model with all predictors against a constant-only model was satisfactorily reliable for sexual behaviour, $\chi^{2}$ $(6, \mathrm{~N}=1200)=138.52, p<0.01$. The analysis regarding condom use only included those students that reported being sexually active, 411 students were included in this analysis. A test for the full model with all predictors against a constant-only model was satisfactorily reliable for condom use, $\chi^{2}(6, N=411)$ $=15.45, \mathrm{p}=0.02$. 


\section{Results}

\section{Sexual Behaviour and lessons about HIV/AIDS}

In terms of sexual behaviour significantly more male students $(50,4 \%)$ compared to females $(30,6 \%)$ reported ever having had sex in their lifetime, $\chi^{2}$ $(1,1132)=46.034, p<0.001$. Overall $39.6 \%$ of the students responded positively to having ever had sex and of these sexually active students $14.7 \%$ had reported always having used a condom. Of those students who ever had sex, more male as compared to female students initiated sex at age 15 years or younger, $\chi^{2}(5,406)=40.229, p<0.001$, and had had two or more sexual partners in their lifetime, $\chi^{2}(3,399)=62.000, p<0.001$ ) (Table 1). Significantly more male students who ever had sex also reported having more sexual partners in the past 3 months, $\chi^{2}(4,404)=41.602, p<0.001$, as well as having drunk alcohol or used drugs before having sex the last time, $\chi^{2}(3,407)=8.529, p<$ 0.05 . With respect to being taught about HIV and AIDS in the classroom, $72.5 \%$ of the students responded positively to having had such lessons.

Table 1: Self-reported sexual behaviour by gender amongst the sexually active secondary school learners in KwaZulu-Natal

Variable (r)

Age of initiation $<15$ years old

Number of sexual partners in Hifetime (2 or more)

Number of sexual partners in the past 3 months (2 or more)

Alcohol or drug use at last sex

Always used a condom
Male (\%)

$\mathrm{n}=260$

59.4

65.7

36.3

14.2

14.5
Female $(\%)$

$n=161$

$38.2 * * *$

30.7

$10.3 * *$

$8.7^{*}$

15.0

$* 0<0.001 ; p<0.05$ 


\section{Alcohol use}

Almost $20 \%$ of students reported having drunk at least one drink of alcohol in their life ranging from sometimes ( 3 to 9 days) to very often ( 20 or more days) while $80 \%$ reported rarely ( 1 or 2 days) to never having drunk alcohol. For those students who had drunk alcohol, $10.5 \%$ reported having had their first drink at 12 years or younger, $19.3 \%$ between the ages of 13 and 17 years, and $3.1 \%$ at 18 years or older. For current use of alcohol (had alcohol in the past 30 days), $74.3 \%$ of the students reported never having drunk alcohol and $25.7 \%$ reported drinking either rarely ( 1 to 5 days) to very often ( 20 to 30 days).

Significantly more male than female students reported having drunk alcohol sometimes, often or very often in the past 30 days, $\chi^{2}(4,1143)=44.026, p<001$. Also significantly more male than female students reported initiating drinking at age 15 years and older, $\left.\chi^{2}(7,1172)=34.208, p<001\right)$.

\section{Drug use}

Life time use of dagga was reported by $12,7 \%$ of the students with $10 \%$ reporting having used it rarely ( 1 or 2 times) or sometimes ( 3 to 9 times). For the students who did use dagga at sometime in their life, $4.5 \%$ were between the ages of 8 and 12 years old, $5.8 \%$ between 13 and 16 years old and $1.8 \%$ were 17 years and older when they first tried dagga. Current use of dagga ranged from $6 \%$ reporting rarely using it to $3.7 \%$ reporting sometimes to very often.

Other drugs like sniffed glue, mandrax, cocaine, heroin, injected drugs and illegal drugs (LSD, Speed) were not used by $85.2 \%$ of the students with the remainder having used them rarely to very often.

Significantly more male than female students reported using dagga rarely, sometimes, often or very often in their life and the past 30 days, $\chi^{2}(4,1151)=$ $57.896, p<0.001$ and $\chi^{2}(4,1170)=38.959, p<0.001$ respectively. Within all the categories for age of initiation of dagga significantly more male than female students, $\chi^{2},(6,1179)=55.546, p<001$, reported first use.

\section{Predictors of sexual behaviour}

\section{Sexual behaviour}

Apart from the relation with gender, ever having had sex was positively related to age, $\mathrm{t}(1153)=6.781, p<0.001$, and higher school grade, $\mathrm{t}(1153)=7.757$, $p<0.001$. A direct logistic regression was performed on sexual behaviour that is had sex, did not have sex and five predictors which included drug use, alcohol use, age, gender and having had HIV and AIDS education in class as well as an alcohol / drug interaction. According to the Wald criterion there was a main effect of drug use, Wald $(1,1.200)=23.41, p<0.001$, age, Wald $(1,1200)=31.20$, $p<0.001$, and an interaction effect of alcohol by drug use, Wald $(1,1200)=3.97$, $p=0.05$. Also, gender was found to be a significant predictor, Wald $(1,1200)=$ 
$22.70, p<0.001$, of sexual activity. As expected, older students were more sexually active and more male students than female students were sexually active. However, in particular those students who had drunk alcohol and also used drugs were much more likely to be sexually active $(63 \%)$ compared to those students who only used alcohol (43\%) or only used drugs (47\%) or did not use alcohol or drugs (27\%).

\section{Condom use}

Use of condoms among students who were sexually active was positively associated with alcohol and having received HIV and AIDS lessons in class. To correct for other variables in the model, for the students who were sexually active, a direct logistic regression analysis was performed on condom use as the dependent variable and five predictors which included having had HIV and AIDS education in class, age, gender, life time drug use and current alcohol use and an alcohol / drug interaction. According to the Wald criterion having drunk alcohol in the past month, Wald $(1,411)=5.72, \mathrm{p}=0.02$, significantly predicted condom use. Contrary to expectation, more students who reported drinking alcohol in the past month reported using condoms when they have sex compared to students who did not drink alcohol. Also, more students who had lessons on HIV and AIDS in class reported using condoms when having sex, Wald $(1,411)=3.95, \mathrm{p}=0.05$.

\section{Discussion}

In this study slightly more than a third of the grade 8 to 11 students reported ever having had sex. The results also showed a clear gender difference with more males reporting initiating sex at a younger age, having more multiple partners in their lifetime and currently as well as having drunk alcohol or used drugs when they last had sex. Of the students who reported being sexually active, only a small minority of them reported using a condom when they last had sex.

At least 1 in 10 students have had their first drink of alcohol at 12 years or younger and 1 in 4 reported, either rarely ( $1-5$ days) to very often ( $20-30$ days), having drunk alcohol in the past 30 days. For those students who reported having tried dagga at some time in their life $4.5 \%$ were below the age of 12 and current use (sometimes to very often in the past 30 days) was reported by $3.7 \%$. At least $15 \%$ of students had used other drugs like sniffed glue, mandrax, cocaine, heroin, injected drugs and illegal drugs (LSD, Speed) in their lifetime.

For the variables investigated in this study, except for always using a condom, the results showed no significant difference from the national prevalence rates reported in the 1st Youth Risk Behaviour Survey of 2002 [1]. 
The reported consistent condom use for $\mathrm{KZN}(14.7 \%)$ was significantly lower then the average National prevalence ( $28.8 \%)$.

Sexual activity was associated with age, gender as well as with drug use in combination with alcohol use. If the students were older, male and used drugs either alone or in particular together with alcohol, they were more likely to report being sexually active.

Condom use was associated with having had HIV and AIDS lessons at school and with current alcohol use. Those students that reported having had at least one drink sometimes, often or very often in the past month as well as those that received HIV and AIDS education at school, were more likely to have used a condom when having sex.

As was expected being older and male was a strong predictor of sexual activity. The finding that sexual activity is associated with students who reported using either drugs or drugs and alcohol, is supported by the idea of the clustering of behaviours in that adolescents engaging in one risk behaviour are more likely to engage in other risk behaviours. Clearly the association of alcohol or drugs with sexual behaviour differs and this study does not lend itself to offering an explanation for this, except to confirm that there are possibly other factors like personality traits, a difference in pharmacological interactions as well as a paucity of information about alcohol or drug use in relation to sexual activity $[4-6,12]$.

The positive association between alcohol use and condom use during sex may at first be a surprising finding considering the explanation offered by the plarmacological disinhibition theory. However, in this study we know that more male students engaged in alcohol use than female students. If we surmise that alcohol as well as condoms is more available in urban areas than rural areas then an association between these two behaviours is more likely to be found in a random sample of urban than rural students. Also, the disinhibition theory would predict that after having had alcohol, students might be more comfortable with talking about condom use with a partner, possibly leading to more condom use. Supporting these notions is the positive association between HIV and AIDS lessons with condom use where it would be expected that, due to discrepancies and redress issues, more formal lessons are delivered in urban areas than rural areas. Such lessons may advocate the use of condoms to sexually active students. However, it is crucial that such findings are strengthened by studies that are able to explain the relationship of alcohol and condom use better by considering amongst others the methodological concerns for example measurement issues related to bias of self-report, social desirability and memory [4] and personality characteristics of the participants [5].

In light of the current HIV and AIDS prevalence in KZN and the early onset 
of sexual activity of some of the students and the low level of condom use, steps need to be taken to delay the onset of sexual activity as well as to increase the consistent use of condoms when having sex. To achieve this, a thorough understanding of the factors that are associated with or determine sexual activity and condom use is needed. Some of these factors, as identified in this study, are age, gender, alcohol use, drug use, and HIV and AIDS education in schools.

In summary, these findings depict a situation in which some students are sexually active, at an early age, most of them have unprotected sex and for a percentage of them there is an association with substance use. As KZN has the highest number of students in school in the country and more than two thirds reported having received HIV and AIDS lessons, strengthening the HIV and AIDS education would appear to be what is required to curb the spread of HIV. Developing an expanded approach to the current HIV and AIDS education is what seems to be needed [13-15] and this includes developing a general programme that addresses all the skills required to protect oneself from all risk behaviours including a programme with skills that are specifically related to the relevant behaviours.

Such programmes need to be developed taking into account the possible social and gender related issues as well as association of substance use with sexual behaviour and condom use that have been found to underpin sexual behavioural practices in this study. Furthermore, the access of condoms for sexually active students is an issue that seems to need special attention. In particular in rural areas condoms are often not easy for students to obtain. This issue of accessibility and availability of condoms needs to be studied and tested if education about condom use is to prove effective. 


\section{References}

1. Reddy P. Panday S, Swart D et al. Umthente Uhlaba Usamila - The I" South Afroch Notiond Youth Risk Behoviour Survey 2002. Cape Town: South African Medical Research Cound; 2003

2. Jemmott JB, Jemmott LS.Alcohol and Drug Use During Sexual Activity Predicting the HIM-Risk-Related Behaviors of Inner-City Black Male Adolescents. Journol of Adolescent Reseorch 1993: Wol. $8 \mathrm{No}$ 1:41.7

3. Santelli $J S$, Robin L, Brener ND, et al.Timing of alcohol and other Drug Use And Sexual Risk Behaviors Among Unmarried Adolescents and Young Adults. Fomily Panning Perspectives 2001; Vol 33, No. 5: 20005

4. Leigh BC, Stall R. Substance Use and Risky Sexual Behavior for Exposure to HIV: Issues in Methodology, interpretation, and Prevention. Americon Psyohologist 1993; Wol 48 No.10:1035-45

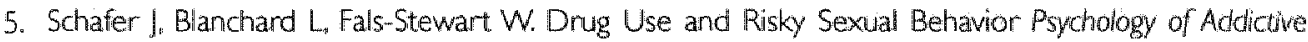
Behoviors 1994; Vol. 8. No. 1:3 7

6. Ford K, Norris AE. Alcohol Use, Penceptions of the Effects of Alcohol Usen and Condom Use in Urban Minority Youth. Journal of Acquired Immune Deficiency Syndromes ond Humon Retrovirology 1999, 17 : $269-74$

7. Paavola M, Vartiainen E, Haukkala A. Smoking, Alcohol Use, and Physical Activity; A I3-Year Longitudinal Study Ranging from Adolescence into Adulthood. Journol of Adolescent Heolth 2004; 35: 238-4.4

8. Champion HLO, Foley KL, DuRant RH, et al. Adolescent Sexual Victimization, Use of Alcohol and Other Substances, and Other Health Risk Behaviors. Journol of Adolescent Health 2004:35: 221-238

9. Coates T], Szekeres G. A Plan for the Next Generation of HIV Prevention Research: Seven Key Pollcy Investigative Challenges. Americon Psychologist 2004: 11:747.57

10. Swart D, Reddy P. Pitt B. Panday S. The prevolence and determinants of tobocco-use among Grode B-10 students in South Africa. The Global Youth Tobacco School-Bosed Survey. Cape Town: South African Medical Research Councill 1999

II. Centre for Disease Control and Prevention - Morbidity and Mortality Weekly Report. Youth Risk Behavior Surveillonce-United States. 2001; 51: SS - 4

12. Kingree 1 B, Braithwaite R, Woodring T. Unprotected Sex as a Function of Alcohol and Marijuara Use Among Adolescent Detainees. Joum of of Adolescent Health 2000; 27: 179-85

13. Svenson LW, Carmel S, Vamhagen CK. A review of the knowledge, attitudes and behaviours of university students concerning HIV/AIDS. Mealth Promotion Internotional 1997; Vol 12, No 1:61-8

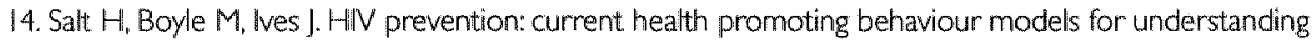
psycho-social determinants of condom use. AIDS Core 1990; Vol. 2, No.1:69-75

15. Harrison A. The social dynamics of adolescent risk for HIV: using research findlings to design a schoolbased intervention. Agendo 2002; 53: 43-52 


\section{Chapter 4}

The effects of a systematically developed photo-novella on knowledge, attitudes, communication and behavioural intentions with respect to sexually transmitted infections among secondary school leamers in South Africa

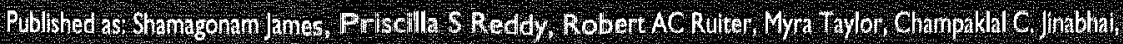
Pepin Van Empelen and Bar Van den Borne (2005) The elects of a systematically daveloped photo-novella on knowledge, atududes, conmunication and behaveural intentions with respect to sexually transminted infectons among secondary school learners in South Arrica. Healeh Promotion lntematienal, Vol, $20 \mathrm{No} 2$. 


\section{Summary}

A pre-post test follow-up design was used to test the effects of a systematically developed photo-novella (Laduma) on knowledge, attitudes, communication and behavioural intentions with respect to sexually transmitted infections, after a single reading by 1168 secondary school learners in South Africa. The reading resulted in an increase in knowledge on the spread of sexually transmitted infections (STIs), change in attitude to condom use and towards people with STIs and/or HIV/AIDS, as well as increased intention to practice safe sex. Laduma did not influence communication about sexually transmitted infections and reported sexual behavior and condom use. While print media proved to be an effective strategy to reach large numbers of youth and prepare them for adequate preventive behaviours, the study also identified the need to combine print media with other planned theory-based interventions that build confidence and skills to initiate the preventive behavior. 


\section{Introduction}

Sexually transmitted infections pose a serious public health problem for South Africa with about 11 million episodes being treated annually (Department of Health, South Africa, 2000). The emergence of HIV/AIDS has called for a reassessment of sexually transmitted infections as a co-factor in the transmission of HIV (Colvin, 2000). Since sexually transmitted infections play a role in the transmission of HIV and HIV alters the pattern of sexually transmitted infections (UNAIDS, 2000), their concurrent existence renders an infected individual more infective to their sexual partners (Colvin, 2000). Sexually transmitted infections and HIV share not just a biological link but a behavioural link as well; both infections are mainly transmitted through unprotected sexual activity (UNAIDS, 2000). This combined behavioural and biological link requires an integrated approach to its management with the emphasis on its prevention as well as treatment. The prevention of sexually transmitted infections requires interventions that increase knowledge and awareness, cultivate attitudes and social norms that are conducive to healthy and preventive behaviours and increases the intentions to practice such behaviours.

This study tested the hypotheses that a single reading of a print media intervention called Laduma, by secondary school learners, will lead to a change in their knowledge and behaviour regarding sexually transmitted infections and safe sex. It specifically tested for an increase in knowledge about sexually transmitted infections, more positive attitudes towards safe sexual behaviour (abstinence and use of condoms), more communication about safe sexual behaviour with partners, parents and peers, and increased intentions to safe sexual behaviours.

\section{Print Media in the context of Health Promotion}

Print media may be used to deliver health messages that aim to influence and reduce behaviours that place people at risk for disability and disease. Print media development that takes into account the characteristics and factors that lead to a problem and that is developed in conjunction with relevant stakeholders, including the target group, have been found to be more effective (Roter et al., 1981). This is because the emphasis is no longer sollely on. knowledge acquisition but on experiential education that is learner directed. This participatory approach to media development is grounded in theories of health promotion and social learning (Kok et al., 1996). These theories have reoriented health education from being a passive process of information dissemination to one that is more action based. A participatory approach to media development also ensures inculcation of health promoting beliefs and 
cultural norms that are relevant to the target group. Research into cognitive psychology shows that motivation to learn increases when educational content relates to personal beliefs and experience, for example, through open-ended stories, socio-dramas or pictures depicting typical health-related situations.

\section{Methods}

\section{Participants and setting}

The study was carried out among secondary school learners in the Midlands district of the province of KwaZulu-Natal (KZN) with over 2.7 million learners. The Midlands district is one of the eight regions of $K Z N$. It has both rural and urban dwellers and a largely zulu speaking population.

There are twenty-seven secondary schools in the Midlands district. Initially twenty schools were randomly selected to participate. Four of the schools refused due to time constraints (year end examinations). A further four were randomly selected from the remaining seven schools. Three accepted, resulting in a total of nineteen schools in the final sample. The schools were equally distributed in rural and urban areas. Two classes were randomly selected from all the grade 11 classes at each of the sampled schools. All the learners from those two classes were included in the study. This resulted in a sample size of 1168 learners at baseline. The language of instruction at all schools is English. Therefore, both the intervention (Laduma) and the questionnaires were conducted in English and grade 11 learners were selected as they have already had four years of secondary school education.

Written consent was obtained from parents and the Department of Education. The learners were invited to participate on a voluntary basis. There were no refusals from the parents and only one learner refused to participate. The Faculty of Medicine, Nelson R. Mandela Medical School, University of Natal granted ethical approval for the study.

\section{Study design}

The study design was an experimental design measuring a range of outcomes between control and intervention groups of learners over three time periodsbaseline (T1), post-test three weeks after the baseline (T2) and six weeks after the post-test (T3). The sample size was estimated from an expected change of $15 \%$ on critical outcomes, such as, changes in knowledge about sexually transmitted infections, attitude towards preventive behaviours, communication with significant others about sexually transmitted infections and prevention and intentions for safe sexual practices.

\section{Sampling, allocation and phases of study}

The schools were randomly allocated to control (did not read Laduma) and 
intervention (did read Laduma) groups. There were ten control and nine intervention schools (see Figure 1). All the learners from both the control and intervention schools were requested to respond to a baseline questionnaire, phase one (T1). The second phase took place three weeks later (T2). At this phase the control schools were given the same baseline questionnaire to answer again in the context of normal (not Aids-related) school lessons. The intervention schools were given Laduma to read; a break and then a questionnaire, which had baseline and Laduma-specific questions, to answer. Learners had to return Laduma and were only given a copy to keep on completion of the study. The reading of Laduma took about one hour. The third phase (T3) was carried out six weeks after T2. Learners from the control schools repeated the baseline questionnaire and learners from the intervention schools repeated their second questionnaire. At the end of the study learners from the control schools were also given a copy of Laduma so as not to disadvantage any participant. A limitation to the study was the high drop out rate of $38.2 \%$ at T3, which was attributed mainly to the impending school examinations.

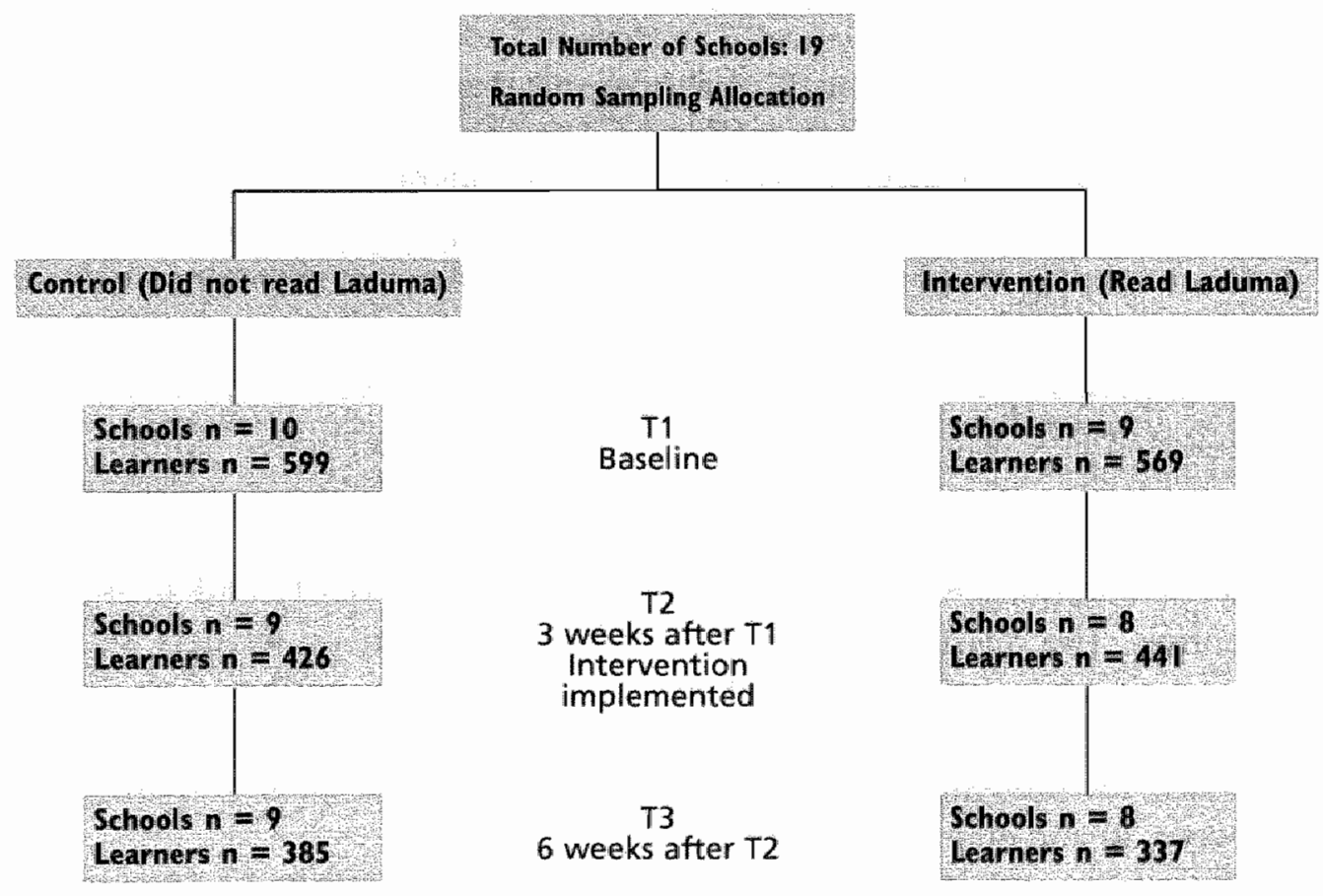

Figure 1: Flow diagram of sampling of schools 


\section{Intervention}

Laduma provides the reader with accurate factual information to increase their knowledge and reduce misperceptions about sexually transmitted infections, exposes them to real life situations, possible risks and solutions in a manner that they can identify with. It also aims to engender a positive attitude towards safe sexual practices and to enhance self-efficacy and adoption of skills, such as talking about sexually transmitted infections and prevention with partners, negotiating safer sexual practices and decision-making about seeking help. Factual information is provided about sexually transmitted infections, through appropriate responses by a clinic nurse and discussion amongst friends. Their responses are reinforced by a question and answer section at the back of the comic. The use of condoms as a means of protection against sexually transmitted infections is clearly demonstrated by a set of colour photographs, illustrating the correct way to use a condom. An intense discussion between the lead characters about their relationship, commitment to each other and the role of condoms as part of their sexual lives is well dramatized following an incident of unfaithfulness on the part of one of the partners. This discussion shows the need for skills that enable effective communication, decision-making and the ability to resist negative peer influences. The story in Laduma was generated through workshops with youth from Khayelitsha and Gugulethu in Cape Town and Kwamashu, Inanda and Thornwood in $\mathrm{KZN}$. It was expected to appeal to youth in terms of its approach to contemporary sexual practices, its portrayal of characters and the views depicted both for and against safer sexual practices. Laduma is one of few print media AIDS education interventions that was developed systematically in Africa and therefore warranted being evaluated.

\section{Study instrument and dependent measures}

A questionnaire was used to collect data and was pre-tested among sixty learners from a secondary school in the research area to ensure construct and face validity.

Most questions were closed ended with yes (1), no (-1) and unsure (0) responses. The questionnaire was individually filled in by learners and was supervised by a fieldworker and researcher during a normal class lesson. Learners were given as much time as they needed to complete the questionnaire to allow for Individual abilities. Time to complete the questionnaire varied between 30 and $50 \mathrm{~min}$.

Knowledge: Knowledge regarding the spread of sexually transmitted infections was measured by four items (Cronbach's Alpha $=0.60$ ) and knowledge about the causes of sexually transmitted infections by three items (Cronbach's Alpha $=0.53$ )

Attitudes: Learners' attitude to condom use was measured with seven items, 
which were com $\neg$ bined in a moderate reliable index (Cronbach's alpha $=0.57$ ). Attitude towards people (friends) infected with sexually transmitted infections or HIV/AIDS was measured through six items (Cronbach's alpha $=0.70$ ).

Communication about sexually transmitted infections: Three groups of five items each asked pupils whether they communicate about sexually transmitted infections and HIV/AIDS and about prevention with: their parents, friends and boy or girlfriend. Within these three groups, items were combined to create adequately reliable scales measuring communication with parents (Cronbach's alpha $=0.77$ ), communication with friends (Cronbach"s alpha $=0.65$ ) and communication with girlfriend/boyfriend (Cronbach's alpha $=0.68$ ).

Sexual behaviour. Sexual behaviour was measured through one item asking if one had sex during a specified period prior to the survey. Condom use was measured by asking those who had sex during the specified period if they used a condom every time they had sex, sometimes or not at all.

Intention to use condoms in the future. Intention to use condoms in the future was measured only at T3 through one self-report variable: what will your choice be for the next year? Answer alternatives were not to have sex, to have sex with a condom, to have sex without a condom.

\section{Data analysis}

As the data were organized at two levels (students within schools) and assignment of subjects to experimental and control group was done at school level, a linear mixed model data analysis procedure (SPSS 12.0) was applied with the interval level dependent variables (knowledge, attitudes, communication). To identify intervention effects at student level, predictors at student as well as school level were included in repeated measurement analyses. In the analyses different prediction models were fitted and choices were made for the best fitting models. For each of the analyses groups (experimental-control), gender and repeated measures (T1, T2, T3) were included as fixed factors and language as a covariate. Hierarchical logistic regression analysis was used in the case of dichotomous variables (having had sex, condom use and intention to use condoms). Possible interaction terms were included at the second step, and removed again from the model in case of non-significant contribution to the prediction of the dependent variable. 


\section{Results}

\section{Dropout and demographic profile}

Of the 1168 learners that filled in the questionnaire at $T 1,18.6 \%$ failed to fill in the questionnaires at both $\mathrm{T} 2$ and $\mathrm{T} 3$. No difference in drop out between intervention group and the control group was found.

The demographic profile of the learners is presented in Table 1. Tests of independence revealed that both the distribution of boys and girls and the distribution of first language (English versus Zulu) differed for the intervention and control group, $\chi^{2}(1, \mathrm{n}=1164)=8.30, \mathrm{p}<0.05$, and $\chi^{2}(1, \mathrm{n}=1152)=20.24, \mathrm{p}<$ 0.001 , respectively, and were therefore controlled for in testing the effects of the intervention.

Table 1: Socio-demographic profile of secondary school learners

\section{Variables}

Male

\section{Control Group}

Female

Total

Intervention Group

Male Female Total

Age (years)

$\begin{array}{lcccccc}15-18 & 199(33.2 \%) & 187(31.2 \%) & 386(64.4 \%) & 148(26.1 \%) & 233(40.9 \%) & 381(67.0 \%) \\ 19-21 & 92(15.4 \%) & 91(15.2 \%) & 183(30.6 \%) & 85(1.4 .9 \%) & 77(13.5 \%) & 162(28.5 \%) \\ >22 & 12(2.0 \%) & 15(2.5 \%) & 27(4.5 \%) & 6(1.1 \%) & 13(2.3 \%) & 19(3.3 \%) \\ \text { Unknown } & & & 3(0.5 \%) & & 7(1.2 \%) \\ \text { Total } & 303(50.6 \%) & 293(48.9 \%) & 599(100 \%) & 239(42.0 \%) & 323(56.8 \%) & 569(100 \%) \\ \text { Horne language } & & & & & & \\ \text { English } & 111(18.8 \%) & 69(11.5 \%) & 180(30.1 \%) & 53(9.3 \%) & 54(9.5 \%) & 107(18.8 \%) \\ \text { Zulu } & 186(3 \% 1 \%) & 222(37.1 \%) & 408(68.1 \%) & 184(32.3 \%) & 268(47.1 \%) & 452(79.4 \%) \\ \text { Other } & 2(0.2 \%) & & 2(0.2 \%) & 1(0.2 \%) & 2(0.4 \%) & 3(0.2 \%) \\ \text { Unknown } & & & 9(1.5 \%) & & 7(1.2 \%) \\ \text { Total } & 299(49.9 \%) & 291(48.6 \%) & 599(100 \%) & 238(41.8 \%) & 324(57.0 \%) & 569(100 \%)\end{array}$

$n=1168$ 


\section{Impact of Laduma on knowledge, attitude and communication}

In testing the impact of Laduma on knowledge, attitude and communication, the most parsimonious effect model for all these dependent variables included Gender, Group (control versus intervention) and Time (T1 versus T2 versus T3) as fixed factors, language (Zulu versus English) as a covariate, school (2nd level) as a random intercept, and 'Unstructured' as repeated covariance type. The mean scores within the control group and intervention group at the three measurements and the F-values for the fixed effects resulting from the linear mixed model analyses are presented in Table 2 . Difference between mean scores at $\mathrm{T} 1, \mathrm{~T} 2$ and $\mathrm{T} 3$ within both the control group and intervention group were tested by using pairwise comparisons within the linear mixed models analyses. These analyses were performed separately for males and females, in case of a three way interaction effect.

Knowledge about spread of sexually transmitted infections. A detailed analyses of the significant interaction effect in the linear mixed model analysis of Group and Time on knowledge about spread of sexually transmitted infections revealed that the knowledge levels of the intervention group and the control group did not differ at baseline. In accordance with our hypothesis, an effect of group was found both at T2 $(p<0.01)$ and at T3 $(p<0.001)$. At both T2 and T3, participants in the intervention group had more knowledge about the spread of sexually transmitted infections than participants in the control group (see Figure 2a). Analyses of the differences between mean scores within the intervention group showed that the knowledge about spread of sexually transmitted infections significantly increased at $\mathrm{T} 2$ as compared with $\mathrm{T} 1$ $(p<0.001)$, and was maintained at the same high level at T3 (T1 versus T3: $p<0.001)$. Within the control group the different measures were not significant $(\mathrm{p}>0.06)$.

Knowledge about causes of sexually transmitted infections. Only a significant effect of Time was found indicating that knowledge about the causes of sexually transmitted infections increased over time, but this could not be attributed to an effect from Laduma.

Attitude towards condom use. Analysing the interaction effect of Group and Time on attitude towards condom use (Table 2), we found no difference between the intervention and control group at baseline. An effect of Group was found in the predicted direction at both T2 $(p<0.001)$ and at T3 $(p<0.001)$. At both post-tests, participants in the intervention group had a more positive attitude towards condom use than participants in the control group (see Figure 2b). Analyses of the differences between mean scores within the intervention group showed that the positive attitude towards condom use significantly increased after reading Laduma (T2) compared with the baseline level 
$(p<0.001)$, and this was maintained at the same level at T3 (T1 versus T3: $p<0.001 ; \mathrm{T} 2$ versus T3: $\mathrm{p}=0.96$ ). Within the control group there was no significant difference between the three time measures $(p>0.30)$.

Attitude towards persons infected with sexually transmitted infections or HIV/AIDS. The significant three-way interaction effect of Gender, Group and Time revealed that the twoway interaction effect of Group and Time was significant among males $(p<0.05$ ) (see Figure $2 c$ ), but not among females. Analyses of the differences between mean scores among males within the intervention group showed that the attitude towards persons with a sexually transmitted infection or HIV/AIDS was more positive at T3 than at baseline $(p<0.05)$. The differences between the mean scores among males within the control group were not significant ( $p>0.10$ ).

(a)

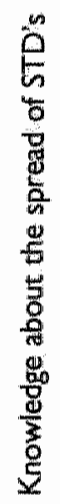

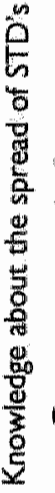

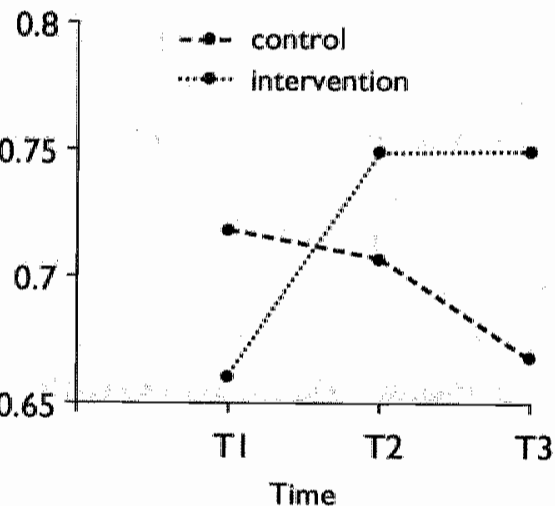

(b)

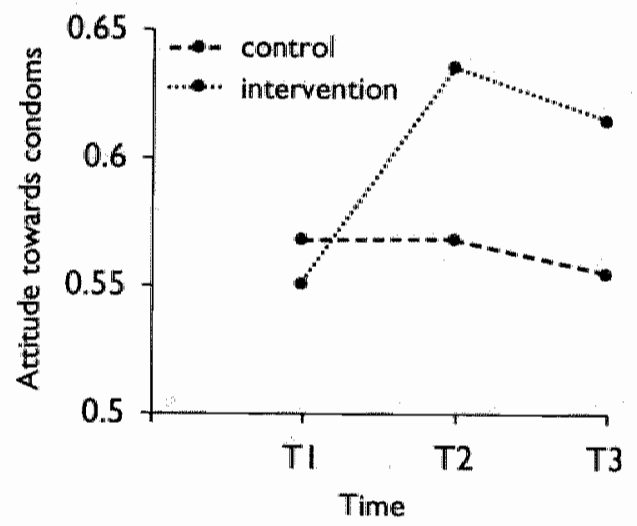

(c)

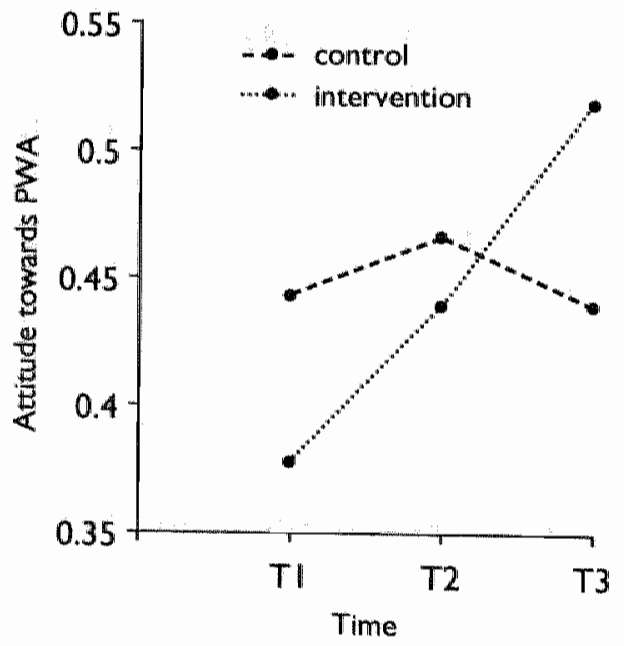

Figure 2: Effects of Group at $\mathrm{T} 1, \mathrm{~T} 2$ and $\mathrm{T} 3$ on (a) knowledge about spread ${ }_{i}$ (b) attitude towardls condom use and (c) male learners' attitude towards friends with HIV/AIDS 


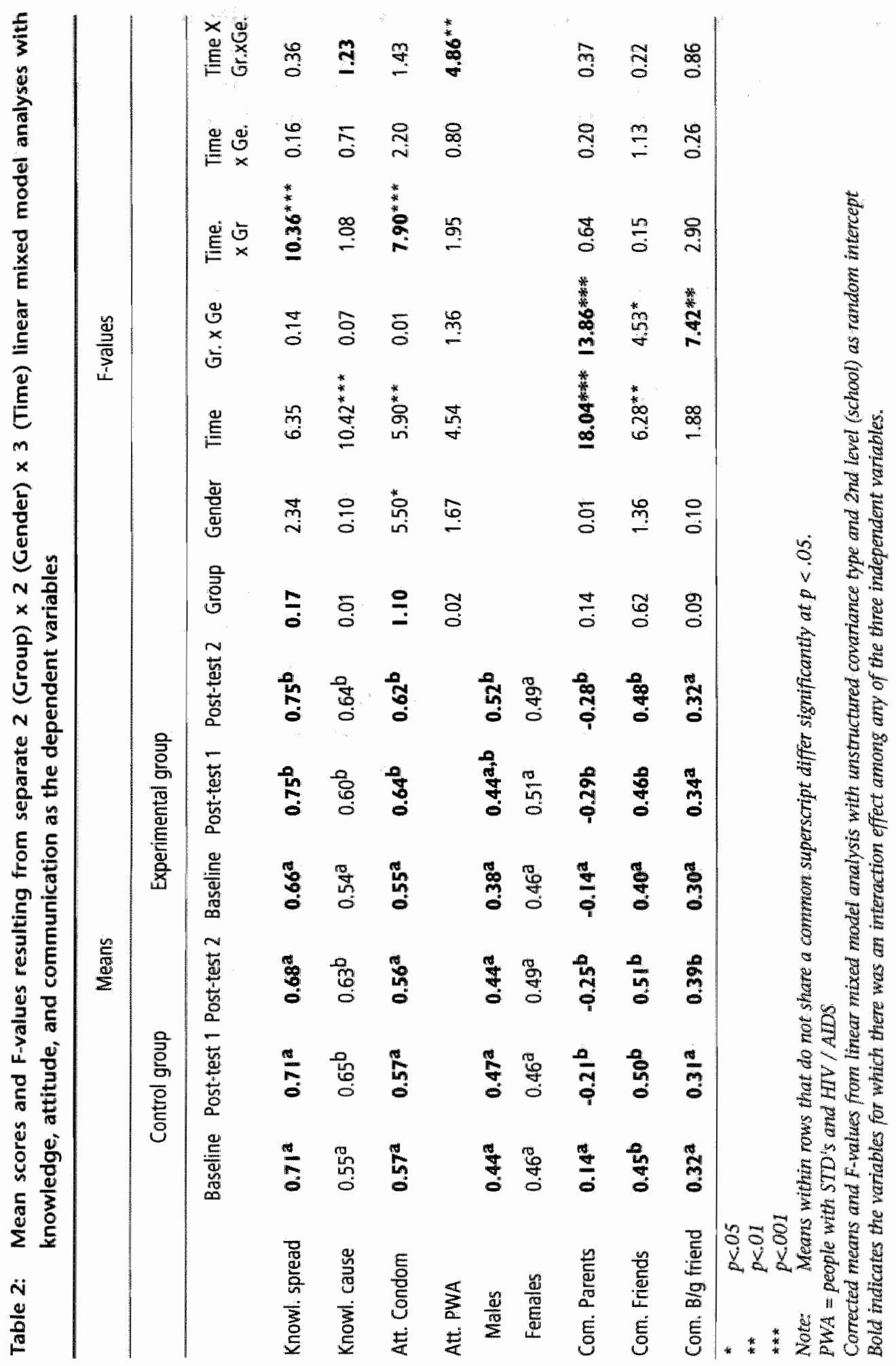




\section{Impact of Laduma on sexual behaviour, condom use and future intentions}

Sexual behaviour and condom use. Of all learners $(n=1168) 43.3 \%$ reported having had sex in the last six months before the study, with the percentage of male learners that was sexually active being higher $(53.6 \% ; n=281)$ than the percentage of female learners $(34.2 \% ; n=202), \chi^{2}(1, n=1115)=42.48, p<0.001$. A hilerarchical logistic regression analysis was performed with having or not having had sex in the six-week period between $T 2$ and $\mathrm{T} 3$ as the dependent variable. Covariates in the model at step 1 were 'having had sex in the last six months' before the intervention (past sexual behaviour), language, Gender and Group (intervention versus control); at step 2 the interaction of Gender and Group was added to the model. Sexual activity at the last measurement was strongly predicted by sexual activity in the six months prior to the study, Wald $(1)=82.33, p<0.001$, and to a lesser extent by Gender, Wald $(1)=20.72$, $p<0.001$, with the percentage of males being sexually active in the six weeks between $\mathrm{T} 2$ and $\mathrm{T} 3$ being higher $(42.5 \%)$ than the percentage of females (21.9\%). Language did not contribute to the prediction of sexual activity, Wald $(1)=2.57, \mathrm{p}=0.11$.

Of all learners who at baseline reported to have had sex in the six months preceding the study $(\mathrm{n}=484), 42.4 \%$ reported having used a condom every time they had sex. A hierarchical logistic regression analysis was performed with condom use at $\mathrm{T} 2$ as the dependent variable. Covariates at step 1 were condom use at baseline, language, Group and Gender. The interaction effect between Gender and Group was included at step 2. All learners that had sex in the period between six months before the study and six weeks after the intervention were included in this analysis. Consistent condom use at six weeks after the intervention was predicted by past condom use $(6$ months preceding the study), Wald $(1)=47.02, p<0.001$. All other covariates had no significant predictive value $(p>0.25)$

Of all learners who had sex during the six months before the study and did not consistently use condoms, $75.2 \%(\mathrm{n}=103)$ also did not consistently use condoms during the six-week period after the intervention. Of the learners who had sex six months prior to the study and reported using condoms consistently during that period, $71.6 \%(\mathrm{n}=73)$ also reported using condoms consistently in the six-week period after the intervention. The intervention (reading Laduma once) had thus no significant effect on consistent condom use six weeks later.

Intentions to use or not use condoms or to abstain. At T3 learners were asked for their intended choice with respect to preventive behaviour for the next year. Of all learners in the control group $(\mathrm{n}=346), 41.9 \%$ intended not to have sex, $52.3 \%$ intended to have sex with a condom and a small minority of $5.8 \%$ intended to have sex without a condom. For the learners in the intervention 
group $(n=292)$ these percentages were significantly different, $\chi^{2}(2, n=516)=$ $8.19, p<0.05$, with $28.1 \%$ intending not to have sex, $65.1 \%$ intending to have sex with a condom and $6.8 \%$ not intending to use a condom. More learners in the intervention group than in the control thus seem to intend to have sex with a condom.

A hierarchical logistic regression analysis was performed on all learners who intended to have safe sex with a condom $(n=371)$ or to abstain from sex for the next year $(n=227)$, with the intention to analyse which variables explained the kind of preventive behaviour of their choice (abstinence or condom use). Covariates at step 1 were language, Gender, Group and past sexual behaviour, at step 2 the interaction of Gender and Group was added to the model. The variables that significantly contributed to the prediction of the kind of safe sex choice were Gender, Wald $(1)=59.50, p<0.001$, Group, Wald $(1)=21.70$, $p<0.001$ and past sexulal behaviour, Wald $(1)=21.13, p<0.001$. Of the learners in the intervention group $69.9 \%$ intended to have sex with a condom as compared with $55.5 \%$ in the control group, while $30.9 \%$ intended to abstain from having sex as compared with $44.5 \%$ in the control group. Male learners reported a higher intention $(79.54 \%)$ to have sex with a condom than female learners (47.0\%). Just over half of the female learners $(53.0 \%)$ intended to abstain from sex in the next year against 20.5 of the male learners. Learners who had sex in the past had a much higher intention $(78.9 \%)$ to have sex with a condom for the next year than learners who did not have sex yet (52.3\%).

\section{Discussion}

This study reports a significant increase in knowledge about the spread of sexually transmitted infections in male and female learners after a single reading of a systematically developed educational photo-novella. In addition, reading Laduma contributed to a more positive attitude to condom use in male and female learners six weeks after the intervention. The study also showed that male learners reading Laduma reported a more positive attitude towards persons infected with a sexually transmitted infection or HIV/AIDS, lasting at least 6 weeks. These positive attitudes are important in influencing intentions to use condoms as well as in creating a social environment that is supportive of people living with HIV/AIDS, a condition perceived as threatening and stigmatizing.

Although in Laduma a lot of attention is paid to enhance an open discussion about sexually transmitted infections, the intervention had no significant effect on communication with boy-or girlfriends, with other friends or with parents about sexually transmitted infections and HIV/AIDS and about prevention of infection. No change was found on having sex and on condom use during the 
six weeks after the intervention. However, an effect was found on future intention to use condoms in the next year. Learners who read Laduma reported a higher intention to use condoms when having sex in the next year than learners in the control group. However, while Laduma was successful in influencing the learners' intentions to use condoms, it did not influence their current sexual practice and condom use behaviour.

Our findings confirm that awareness of the problem, positive attitudes towards the desired behaviour and a positive intention to perform the desired behaviour are prerequisites but not sufficient to realize actual behaviour change (Prewitt, 1989; Petosa and Wessinger, 1990).

To achieve the adoption of desired behaviours learners also need to have the confidence and skills to be able to execute the preventive behaviour. Consistent condom use, for example, is a complex behaviour requiring a series of actions. These actions include talking about sexually transmitted infections and HIV/AIDS with ones' partner, talking about and negotiating condom use, buying condoms or equesting it from clinic staff, putting on and removing the condom in a way to enhance enjoyment and minimize embarrassment. To increase self-confidence (self-efficacy) and self-regulatory skills to perform a specific preventive behaviour among specific social groups as school learners, strategies like enactive mastery learning, coping modelling, mastery modelling, instructive modelling and guided skill perfection may be more appropriate (Bandura, 1997). Recent reviews of the literature on the effectiveness of HIV/AIDS education programmes for school youth and adolescents in developing countries and in Southern Africa confirm that programmes, which showed success in terms of adoption of safer sexual behaviours frequently include a strong skills development component (Van Empelen et al., unpublished manuscript, 2001). Effective programmes also seem to have appropriately trained educators who have time available and the necessary skills to implement the programmes (Kirby, 1997).

Our data strongly confirm the need to develop programmes that teach selfregulatory skills. Any attempt to address the issue of sexually transmitted infections within school curricula requires further a sound understanding of human sexuality, gender issues and role definitions as it pertains to relationships and the specific context of the learner. In taking up the call to address the issue of sexually transmitted infections including HIV/AIDS through the formal school curricula, it is imperative that the needs of the individual learner are taken into account. This calls for tailored programmes that address the concerns of both sexually active and inactive learners. Selfregulatory skills development needs to target both groups and, for example, teach assertiveness related to abstinence (no I am not ready for sex) and 
condom use (no I will not have sex without a condom).

The evaluation of Laduma also suggests that planned sexual programmes that promote condom use do not necessarily lead to an increase in sexual activity. Interventions like Laduma ought to be made avallable to young people in order to help start out there lives based on informed decisions and to create an environment that is normative to healthy sexual practices.

\section{Acknowledgements}

This research was made possible by a research grant from NACOSA. The authors would like to thank Nilen Kambaran for his help in preparing the data set, and the Department of Education - KwaZulu-Natal for their approval to conduct the study. 
Baindura, A. (1997) Self-eficocy the Exercise of Control. Freeman, New York

Colvin M. (2000) Sexually transmitred infections in southem Africa: a public health crisis. 50 Joumol of Science, $96,335-342$.

Department of Health South Arnica (2000) HIVIAIDS \& STD Strategic Plan for South Africa 2 Kiby, D. (1997) No Easy Answers. The National Campaign to Prevert Teen Pregnancy Washir Kok, G. Schaalma, H. De Vres, H, Parcel, G. and Paulussen, T. (1996) Social psychology: education. In Stroebe, W. and Newstone, M. (eds), Europeon Review of Sociol Psychology. $V$ York, Vol 7, pp $241-282$

Petosa, R. \& Wessinger.J 1990. AIDS education needs of adolescents: A theory - based appr Education and Prevention, $2,126-136$

Prewitt VR. (1989) Health beliefs and AIDS educational materials. Family Community Health, Roter, DL, Rudd, RE, Frantz, S.C. and Comings, I.P. (1981) Community- produced materials education. Public Heolth Report, 2, $169-172$.

UNAIDS. (2000) Report on the global HINAIDS epidemic June 2000. joint United Nations $P$

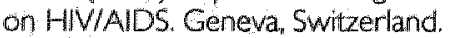

Van Empelen, P., Kok, G., Van Kesteren, N.M.C., Van den Bome, B., Bos, A.E.R., Dijker. A.J. et Unpublished manuscript. Effectiveness of psychological HIV prevention programmes: a revi 
The impact of a HIV and ADS Lifeskills Programme on Secondary School Students in KwaZtulu Natal. South Africa 


\section{Abstract}

A randomised controlled study evaluated the Department of Education's lifeskills programme focussing on HIV and AIDS prevention amongst grade 9 students in 22 schools in KwaZulu-Natal, South Africa. On average the programme was provided in 12 lessons. When controlling for baseline, at the immediate post-test and at the follow-up four months later, a significant increase in student knowledge about HIV/AIDS only was found in the intervention group as compared to the control group. No effects were found on safe sex practices (condom use, sexual intercourse) or on measures of psychosocial determinants of these practices (e.g., attitude, self-efficacy). A process evaluation among the teachers after the intervention resulted in schools being categorised into those that implemented the programme fully ( 7 schools) and those that implemented the programme partially ( 4 schools). In an exploratory analysis, these schools were compared to each other and to the eleven control schools. Students who received the full intervention were more positive in their perceptions about sexual behaviour, perceived social support (T3), reported less sex and more condom use (T2) than students in the partial and control groups. Maintenance of condom use was not established at T3. The rather limited effects on the psychosocial determinants and sustained condom use in this enhanced sexuality education programme calls for further analysis of the content and implementation strategies used in the classroom. 


\section{Introduction}

Over the years there have been several attempts to address sexuality education in South Africa. The objectives of such attempts have varied and ranged from reducing teenage pregnancy rates and its consequent effects, such as school drop out, financial, social, and emotional strain on young people and their famillies to increasing safer sex practices to protect against sexually transmitted infections including HIV and AIDS (Varga \& Shongwe, 1999). Despite these efforts the increase of sexually transmitted infections including HIV and AIDS and teenage pregnancy (South African Health Review; 2000) has resulted in a re-look into the development and implementation of lifeskills programmes designed to promote safe sexual behaviour amongst young people of school going age who are, or are near to becoming, sexually active.

The success of these earlier lifeskills programmes carried out in schools is unclear, as no studies thus far have been reported in the scientific literature that evaluate the success of these programmes in the South African context. In general, in this part of the world, programmes that aimed to increase knowledge about sexual health and HIV and AIDS and positive attitudes towards people with HIV and AIDS and safer sex practices namely condom use have not been systematically evaluated. Those programs that have been evaluated failed to meet most of the criteria to be defined as soundly designed evaluation studies (Oakley, Fullerton, \& Holland, 1995; Rossi, Freeman, \& Lipsey, 1999). Soundly designed studies are those that include core quality criteria such as using a control group, pre- and post intervention data and report on all targeted outcomes. This lack of high quality evaluation reduces the chances to learn from previous experiences and improve future interventions.

Numerous documents describe the seriousness of both HIV and AIDS in the Southern African region with particular emphasis on South Africa being most affected (UNAIDS 2000). For example, the national HIV sero-prevalence study done on women attending antenatal clinics at public health facilities showed a prevalence rate amongst pregnant women of $22.4 \%$ (Department of Health, 2000). The prevalence rate for all South Africans is estimated to be $12.5 \%$, which is one of the highest national prevalence rates in the world. The South African government therefore has committed itself to the development of several policies that seek to address the impact of the HIV and AlDS epidemic on society. The resulting National AIDS Plan provides guidance for impacting on several levels of the HIV and AIDS epidemic which includes primary prevention interventions such as school-based lifeskills programs, the promotion of early detection via voluntary testing and counselling, and at the patient care level various forms of individual and community based care.

In KwaZulu-Natal (KZN), the province with the highest number of school 
going children in South Africa of 2.7 millition, a lifeskills programme focussing on HIV and AIDS was developed by the Provincial Department of Education in consultation with other organisations working in the area of adolescent sexuality education. The Lifeskills and HIV / AIDS Education Programme (KZN, Department of Education, 2000) was designed to facilitate lessons with young people about their development in relation to themselves, their school, and their communities. The approximately 12 classroom lessons were about their physical development in particular and the implications of this on their health, and how to care for themselves, their emotions and their relationships towards their parents and peers of the opposite gender as well as lifeskills focusing on HIV and AIDS.

The present study aimed to evaluate in an experimental design whether students exposed to this intense teacher led programme would have more knowledge about HIV and AIDS and its prevention, report more safer sex practices and intentions to practice safer sex and express more positive attitudes towards conclom use and people living with AIDS than comparable students who were not taught the programme. Furthermore, we specifically examined the extent to which the programme was implemented at the intervention sites (schools). Although it is generally known that a full implementation of the developed and pre-tested programme is essential to ensure completion of the objectives that have been set (Rogers, 1995), time, financial, and capacity restraints often make it difficult to implement the full programme, leaving a partly implemented programme. We therefore administered postimplementation questionnaires amongst teachers that implemented the programme to measure the degree of programme implementation in the intervention schools.

\section{Method}

\section{Participants:}

The study was carried out among 1141 grade nine secondary school students in the Pietermaritzburg region of the province of KZN, South Africa. The two districts allocated to the study had both rural and urban dwellers and a largely Zulu speaking population. Written consent was obtained from parents and the Department of Education. The students were invited to participate on a voluntary basis. There were no refusals from the parents or students to participate. The Faculty of Medicine, Nelson R. Mandela Medical School, University of Natal Durban, granted ethical approval for the study.

\section{Design and Sampling:}

The study design was a pre-test multiple post-test experimental-control group design. Participants were randomly allocated to the intervention or control 
group based on school membership. There were an equal number of control and intervention schools in the study of 11 each. Two grade nine classes at each of the selected schools were randomly selected to participate in the study. All the students present on the day of the survey in those classes were included in the study. Measures were taken at three time periods through self-administered questionnaires. Students from both the control and intervention schools first responded to a baseline questionnaire (T1). In the six months thereafter students from the intervention group were exposed to the Lifeskills programme focussing on HIV and AIDS prevention. Students in the control group received odd lessons about aspects of HIV and AIDS education in a non-structured format and in some cases celebrated awareness days on the topic. After this six month period a post-test measure was taken (T2) followed by a follow-up measure four months later (T3). Figure 1 graphically illustrates the allocation of students to the intervention and control groups and the number of students present at the three times of measurement.

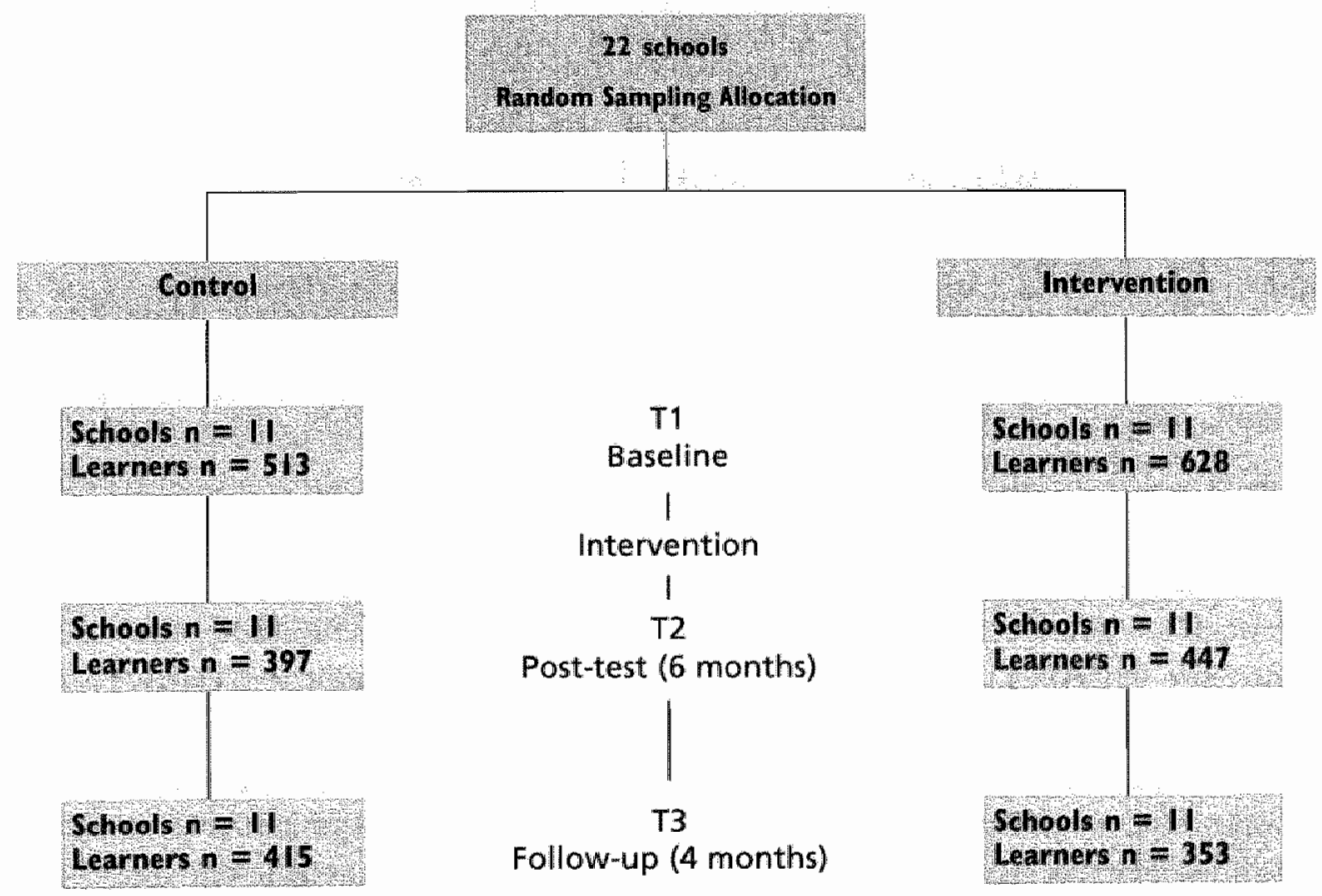

Figure 1: Learner Allocation and Drop Out 


\section{Lifeskills Intervention}

The Lifeskills Intervention was a 16-hour programme. It was intended to bi implemented in the life orientation lessons at least one lesson a week over twe school terms ( 20 weeks). The programme addressed a range of topics startin with facts about HIV and AIDS concerning the modes of transmission, thi immune system, the progression of HIV to AIDS, and how to keep the body safi and healthy thus avoiding HIV infection. This was followed by a componen that addressed the relevant lifeskills related to the prevention of HIV and AIDS The focus was especially on knowledge about HIV and AIDS, attitude to condom use and people living with AIDS, gender norms and perceptions abou sexual behaviour. The content which was guided by the prescribed manuals wa: taught through a combination of methodologies, didactic and interactivi teaching, group work, and role-play.

The programme further included a training programme for the teachers Teachers were selected by their respective schools to participate in a training course for five days. The training programme for teachers covered broad topic. related and implementation-related areas such as lifeskills in relation to HIV and AIDS prevention, care and support of people living with AIDS, and skills development related to teaching methods and facilitation, project management, monitoring, and evaluation of the programme. The training was carried out by consultants working in the area of facilitation related tc educational change and transformation in the Pietermaritzburg region of $K Z \mathrm{~N}$, which was the study site. At the end of the training, teachers were given a set of manuals covering the topics they were to facilitate in the implementation with the students.

Of the 11 control schools none of the teachers reported providing a structured programme to their students. They did, however, have odd lessons about aspects of HIV and AIDS education and in some cases celebrated awareness days on the topic.

\section{Study Instrument and Procedure}

A baseline semi-structured questionnaire was developed to collect data with respect to the demographic characteristics of the students and a range of outcome variables that were to be addressed by the programme (see measures). The questionnaire was based on an earlier study done amongst a group of adolescents and young adults in the Western Cape south Africa (Reddy, MeyerWeitz, Van den Borne \& Kok, 1999) as well as derived from general cognitive frameworks such as Ajzen's (1991) theory of planned behaviour and Bandura's (1986) social cognitive theory. The questionnaire was translated from English to Zulu and then back translated to English to ensure a similar understanding of the questions between the two language groups and pre-tested among 
secondary school studients in the research area to ensure construct and face validity. The questionnaire was redeveloped, tested and then finalized. Students could respond to the questionnaire in English or Zulu. The post-test questionnaire used at $\mathrm{T} 2$ for the control group was similar to the baseline questionnaire. The intervention group answered additional questions that were related to the liking, understanding, and usefulness of the Lifeskills Intervention programme (reported elsewhere, see Reddy, James, \& McCauley, $2003)^{3}$. The follow-up questionnaire at T3 was the same for both the intervention and control groups. Students filled in the questionnaires during school hours in the classroom supervised by researchers. Confidentiality was assured by explaining to students that only the researchers had access to their questionnaires, no names were attached to the questionnaires and that their responses would not be discussed with the school staff.

\section{Measures}

Demographic characteristics that were measured were students' age (recorded as is; recoded into $12-15=1 ; 16-18=2 ; 19-21=3$, unknown $=4$ ), gender (male =1; female $=2$ ), language $(1=$ English; $2=$ Afrikaans; $3=$ Zulu; $4=$ Other; $5=$ Xhosa) and religion ( $1=$ Christian; $2=$ Moslem; $3=$ Hindu; $4=$ Jewish; $5=$ Other; $6=$ Shemba; $7=$ Roma; Recoded Christian $=1 ;$ other $=2$ ). The outcome variables of interest were knowledge about HIV infection, attitudes to condom use and people living with HIV and AIDS, perceptions about sexual behaviour, communication about safer sex, perceived social support, confidence to assert oneself, and reported intended sexual behaviour. Each variable was measured by a set of items. Factor and reliability analyses were used to select relevant items and combine them into scales with moderate to high internal consistency.

Knowledge about HIV. Students were asked to respond to 18 statements related to the causes and spread of, and protection against HIV infection. Their responses were indicated by whether they thought the statement was true, false or 1 don't know, and recoded into $1=$ correct, $-1=$ incorrect, and $0=I$ don't know. At each of the three measures (T1, T2 and T3), the items were combined in moderately reliable indices of knowledge with possible scores ranging from -18 to +18 (Cronbach's alpha's $>.62$ ).

Attitude towards condom use. Attitude towards condom use was originally measured with twelve items ( $1=$ fully disagree, $5=$ fully agree $)$. In response to a two-factor solution suggested by factor analysis, two scales were created with moderate reliability. A first scale of six items reflected the perceived negative consequences of condom use by including the items: "Condoms are embarrassing to use", "Condoms can harm the body", "Using a condom shows that you do not trust your partner"; "Condoms take the fun out of sex"; "A woman loses a 
mans' respect if she asks him to use a condom"; and, "Girls who carry condoms are not respected" (Cronbach's alpha's $>.65$ ). A second scale of three items reflected the perceived positive consequences of using condoms by including three items: "Condoms work well to prevent the spread of HIV" "Condoms also prevent pregnancy"; "Condoms are important to use every time you have sex" (Cronbach's alpha's $>.61)$.

Attitudes towards people living with ADS. Nine items assessed the attitude of students towards people living with AIDS. Six of these items were combined at the three measurements into scales of adequate internal consistency that reflected the students' attitude about having close social contact with a person who is HIV positive or has AIDS (Cronbach's alpha's > .70): "A student with HIV should be allowed to attend school; "A teacher with HIV should be allowed to continue teaching at school"; I would mind being in the same classroom as a HIV positive learner" (recoded), "I would hug a friend with HIV and AIDS"; "I would care for a relative with HIV in our household"; and " $\mathrm{I}$ would buy food from an HIV positive shopkeeper" $(1=$ definitely not, $5=$ definitely yes $)$.

Perceived social support. Eight items were used to determine the students" perception of support that they received from significant people like family, filends, and school-teachers. Six of these items were combined into scales at the three time measures that measured perceived social support with adequate internal consistency (Cronbach's alpha's > .68): "Teachers at this school care about the student"; "There is a teacher that I can talk to if I have a problem"; "My mother cares about me a lot", "My father cares about me a lot"; "My family pays attention to me a lot"; "When I do well my family praises me" $(1=$ fully disagree, 5 = fully agree).

Confidence to assert oneself: Six statements were posed to students that probed their perception of their confidence to assert themselves in demanding sttuations by resisting pressure with regard to drinking alcohol, using drugs, refusing a partner sex, asking a partner to use a condom, using a condom correctly, and about knowing where to take an HIV test 1 = not at all confident, $5=$ very confident). These items were combined into scales with good internal consistency at the three measurements (Cronbach's alpha's $>.77$ ).

Percetion of sexual behaviour. Several statements about beliefs related to sexual behaviour were subjected to factor analysis. Six of these items were reflective of normative beliefs about sexual behaviour: "Men need to have more than one sexual partner, often at the same time"; "My friends encourage me to have sex"; "It is okay for a boyfriend to force his girlfriend to have sex"; "I must have sex to keep my boyfriend or girlfriend" "It is alright for a boy to demand sex from a girlfriend"; "It is alright for a girl to demand sex from a boyfriend" $(1=$ totally agree, $5=$ totally disagree). A scale of these items that were answered 
by both boys and girls had good internal consistency at the three time measurements (Cronbach's alpha's $>.72$ ).

Communication about HIV and AIDS and Safer Sex. Five statements related to the appropriateness of a male or female partner to bring up the subject of HIV and AIDS and safer sex were combined into a scale measuring communication about HIV and AIDS and Safer Sex with high internal consistency at the three measurements (Cronbach's alpha $>.83$ ). The items answered by both girls and boys were: "It is okay for a girl to bring up the subject of HIV and AIDS with her boyfriend"; "A boy should be able to ask whether his partner has other sexual partners"; "A girl should be able to ask whether her partners have other sexual partners"; "A boy should be able to talk to his partner about safe sex"; "A girl should be able to talk to her partner about safe sex" ( 1 = totally disagree, 5 = totally agree .

Reported sexual behaviour. . The participants were requested to report whether they were ever sexually active $(0=n o, 1=y e s)$, sexually active in the recall period (six months at $\mathrm{T} 1$ and $\mathrm{T} 2$, three months at T3), and whether they used a condom the last time they had $\operatorname{sex}(0=n o, 1=$ yes; only measured at $\mathrm{T} 2$ and T3).

Intention about sexual behaviour. Intended sexual behaviour was assessed at the three measures by asking participants their intention about using a condom when they next have sex $(0=$ no or unsure, $1=$ yes $)$ as well as their intention to use a condom for the next three months $(0=$ not to have sex or have sex without a condom, 1 = have sex with a condom).

Implementation of the programme. Information about the degree of programme implementation in the intervention schools was obtained from teachers through a questionnaire that they filled in at the end of the implementation period. Some of the questions the teachers were asked, were related to the number of lessons they taught (every week for many weeks, not every week but often, occasionally, I don't remember how often), the topics covered (yes / no / I don"t know was indicated as applicable for each of the 11 topics), the methodology used (formal lessons, group work, role play, peer discussions, other), and the materials they had used (indicated by ticking off: the manuals they used from the list given).

\section{Data analysis}

The data set was analysed using SPSS version 12.0. Respondents who were not present at both $\mathrm{T} 2$ and $\mathrm{T} 3(\mathrm{~N}=178)$ were excluded from the analyses, which left us with a total sample of $N=963$ for the analyses. Assessments of the influence of cluster sampling at school level illustrated that the intraclass correlation coefficient (ICC) for each of the dependent variables was high (ICC range: $.03-.12$ ), indicating that adjustment of the analyses for within- 
cluster correlation would better fit the observed data (Hannan \& Murray, 1996) Subsequent multilevel analyses used the LINEAR MIXED MODEL procedur within SPSS to test the effects of Intervention on the dependent variables fo the random influence of school membership. As the number and size of cluster were high ( 22 schools with on average 44 participants per cluster), this sam procedure also allowed us to interpret the significance of the effect $o$ Intervention on those dependent variables with a binary distribution.

The covariance structure for the random effect model was modelled after thi variance components structure, assuming constant variance and no correlatior between the within and between-group components. Visual inspection of thr data across time measurements and dependent variables indicated that separat analyses of the short-term and long-term effects was more appropriate thar repeated measures analyses of the effect of Intervention across T1, T2, and T3 For each analysis, the baseline measure of the respective dependent variable wa: included as covariate to control for pre-existing differences between the contro: group and intervention group. The Kenward-Rogers method was used for calculating the degrees of freedom.

After the tests for the programme effectiveness, exploratory analyses wert performed using linear fixed effect models to explore the possible effects of the substantial differences in incompleteness of programme implementation among the experimental schools for all outcome variables at interval level. Full implementation and partial implementation schools were compared againsi the control group, which was the same 11 schools, on the outcome variables at $\mathrm{T} 2$ and $\mathrm{T} 3$ respectively, in a one-factorial (Degree of Implementation: full vs. partial vs. control) fixed model design with the baseline measures as covariate. For the dichotomous variables logistic regression analyses were performed that used dummy coding to compare the full and partial implementation groups against the partial and control groups and the full and control groups respectively.

\section{Results}

\section{Dropout analysis}

At baseline 1141 students entered the study and answered the baseline questionnaire. At T2, directly after the intervention, 844 students returned to answer the second questionnaire (drop-out rate $=26 \%$ ). At T3, the four-month follow-up, 768 students answered the third questionnaire (drop-out rate compared to $\mathrm{T} 1=32.7 \%$ ). Statistical analyses were conducted to see whether students that dropped out of the study after baseline $(N=178)$ were different on the demographic and outcome variables at $\mathrm{T} 1$ from those that were present at either of the two or both post-intervention measures. On the demographic 
variables those who dropped out were older $(M=16.10 ; S D=1.60$ vs $. M=15.50$; $S D=1.60), F(1,1093)=32.81, p<.001$, and Zulu speaking $(95 \%$ vs. $86 \%)$, $\chi^{2}(1,1110)=20.53, p<.001$, than those who did not drop out. The drop-out rate was higher for the control group (31\%) than for the intervention group. Furthermore, the findings showed that the students who dropped out of the study had less knowledge about HIV and AIDS $(M=11.30 ; S D=4.16$ vs. $M=$ $11.93 ; S D=3.81), F(1,1139)=5.79, p<.05$, felt less social support from their environment $(M=4.00 ; S D=0.78$ vs. $M=4.13 ; S D=0.65), F(1,1133)=8.79$, $p<.01$ and more reported having had sex $(M=.29 ; S D=.45$ vs. $M=.20 ; S D=$. $40), F(1,996)=10.00, p<.001$, than those that remained in the programme. On the other outcome variables no differences were found between those that stayed in the study and those that dropped out $\left(p^{\prime} s>.11\right)$.

\section{Demographic Profile of Students}

The mean age of the students was 15.52 years with the youngest being 12 and the oldest 21 years. The majority of the students indicated Zulu as their first language $(84.5 \%)$. There was an allmost equal distribution of male $(48.5 \%)$ and female $(50.8 \%)$ students $(0.7 \%$ missing). The most commonly reported religion was Christianity (80.9\%). Table 1 shows the distribution of students across gender, age, religion and home language for the control and intervention conditions. Statistical comparisons between the intervention and control groups on the demographic variables by means of Chi-square analyses and independent samples t-test showed that the two groups did not differ on the distributions of age, gender, and language ( $p$ 's $>.70)$. Only for religion a difference was found with the percentage of Christians being higher in the experimental group $(55.3 \%)$ than in the control group $(44.7 \%), \chi^{2}(N=882,1)$ $=4.17, p<05$. Religion was not included as an additional predictor in the design due to the low count of non-Christians in certain schools. 


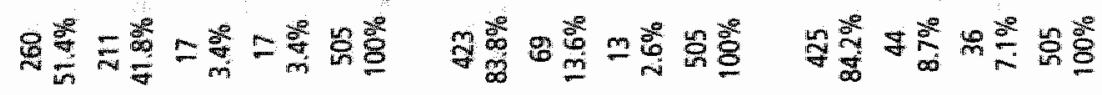

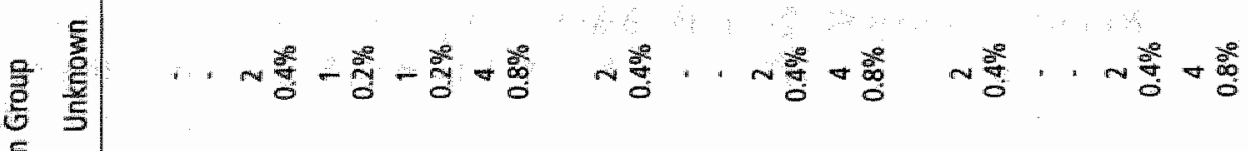

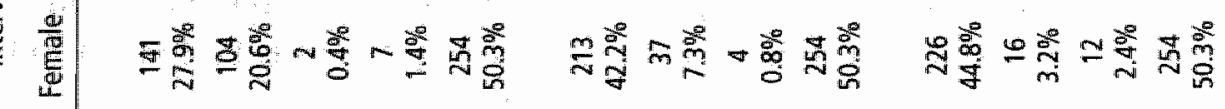

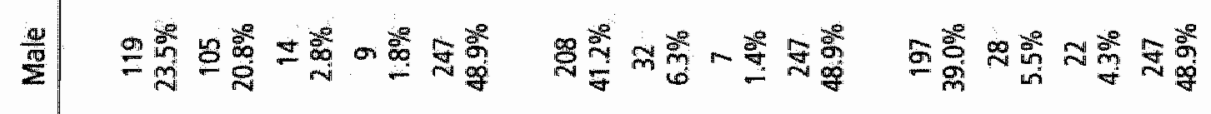

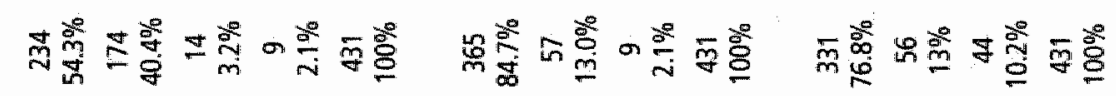

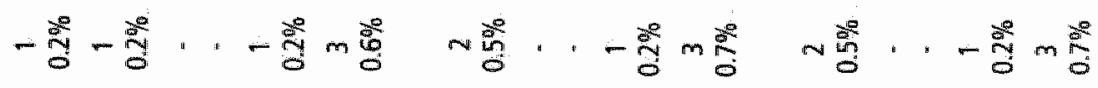

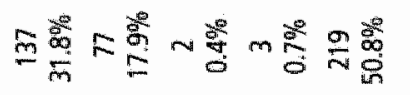

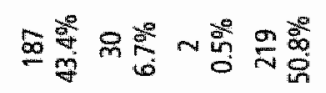

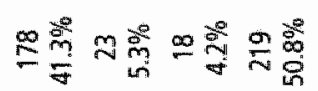

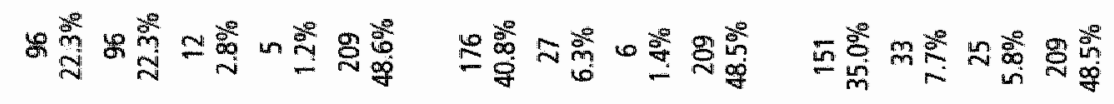

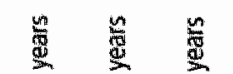

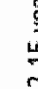

$\frac{1}{2}$

8 


\section{Short-term Effects of the Intervention}

Multilevel analyses revealed only a significant effect of Intervention on knowledge scores, $t(20.272)=2.39, p<.05$. At $\mathrm{T} 2$, students in the intervention group had on average higher knowledge scores $(M=13.43 ; S D=3.28)$ than students in the control group ( $M=12.45 ; S D=3.80$ ). On the dependent measures of attitude towards condom use, attitude towards PLWA, perceived social support, confidence to assert oneself, perception of sexual behaviour, communication about HIV, reported sexual behaviour, reported condom use, and future intentions no significant effects of Intervention were found $\left(\rho^{\prime} \mathrm{s}>.27\right)$.

\section{Long-term Effects of the Intervention}

The findings at T3 replicated those of T2. Again the effect of Intervention on knowledge about spread of HIV was significant, $t(17.802)=2.99, p<.001$, while no effects for Intervention were found on the other measures ( $p$ 's $>.10)$. At T3, the mean knowledge score was higher in the Intervention group $(M=13.70$; $S D=3.45)$ than in the control group $(M=12.73 ; S D=4.00)$.

\section{Degree of Implementation}

A closer look at the degree of implementation of the intervention at the experimental schools suggested that the lack of meaningful differences between the intervention and control group on the outcome variables partly might have been caused by differences in the extent to which intervention schools implemented the programme. Based on the answers from teachers at the end of the implementation period, we were able to distinguish between two categories of teachers, those that fully implemented the programme, that is every week for many weeks, and those that partially implemented the programme, that is every week for a few weeks or only occasionally. The schools that fully implemented the programme reported working on all 11 topics whilst the schools that partially implemented the programme omitted at least four topics. This resulted in seven schools with 320 students being categorised as the full implementation group and four schools with 185 students being categorised as the partial implementation group. The three groups were compared on the outcome variables by means of ANOVA's and logistic regression analyses. The latter analysis used dummy coding to compare the full and partial. implementation groups against the partial and control groups and the full and control groups respectively.

Short term effects. The exploratory analyses confirmed the main short term effect for knowledge, $F(2,824)=12.04, p<001$. Pairwise comparisons showed that students in the full implementation group $(M=13.64, S D=3.20)$ and the partial implementation group $(M=13.02, S D=3.41)$ acquired more knowledge 
than those in the control group $\left(M=12.43, S D=3.83 ; p^{\prime} s<.001\right)$, while the full implementation and partial implementation groups did not differ $(p=.64)$. In addition, a significant short term effect for perceptions of sexual behaviour was found, $F(2,812)=6.28, p<.01$. Pairwise comparisons showed that the full implementation group $(M=4.30, S D=0.63)$ had more positive perceptions of sexual behaviour than the partial implementation group $(M=4.09, S D=0.54)$ and the control group $(M=4.16, S D=0.70 ; \mathrm{p}$ 's $<.01)$, whereas the partial implementation and control groups did not differ significantly $(p=.64)$.

A logistic regression on reported sexual behaviour at $T 2$ with past sexual behaviour at $\mathrm{T} 1$ and the two dummy variables as predictors showed a significant effect of the variable comparing the full implementation group against the partial and control groups, indicating that students in the full implementation group reported less sexual activity in the previous six months $(B=-.53, S E=.24$, Wald $(1,657)=4.98, p<.05, \mathrm{OR}=.59)$. No effect was found comparing the partial implementation group against the full and control groups $(B=-.05, S E=.26$, Wald $(1,657)=0.03, \mathrm{p}=.86, O R=1.04)$. On reported condom use among those students that reported being sexually active in the six months preceding $T 2$, a significant effect of the variable comparing the full implementation group against the partial and control groups emerged, indicating that students in the full implementation group reported more condom use at last sex $(B=-.80, S E=.40$, Wald $(1,157)=4.16, p<.05, \mathrm{OR}=.45)$. No effect was found comparing the partial implementation group against the full implementation and control groups $(B=-.21, S E=.41$, Wald $(1,157)=0.27$, $\mathrm{p}=.60, \mathrm{OR}=.81$ ).

Long term effects. The long term effect for knowledge, $F(2,752)=8.26$, $p<001$, was practically the same as for the short term and showed that students in the full implementation group $(M=13.99, S D=3.09$; $)$ and the partial implementation group $(M=13.18, S D=3.98)$ acquired more knowledge than those in the control group $(M=12.71, S D=4.01$; $p$ 's $<.02)$, whereas the full implementation and partial implementation groups did not differ $(p=.39)$. A significant effect was again found for the perceptions of sexual behaviour, $F(2$, $744)=3.94, p<.05$, with only the full implementation group $(M=4.27, S D=$ 0.66) scoring more positive than the partial implementation group ( $M=4.08$, $S D=0.66, p<.01)$ and the control group $(M=4.20, S D=0.69, p<.05)$. The partial implementation and control groups did not differ $(p=.24)$. Also a significant long term effect for perceived social support was found, $F(2,748)=4.57, p<.01$. Pairwise comparisons showed that the full implementation group $(M=4.31, S D$ $=0.59$ ) experienced a higher level of social support than the partial implementation group $(M=4.12, S D=0.63, p<.01)$ and scored marginally different from the control group $(M=4.20, \mathrm{SD}=0.60, p=.07)$. The partial 
implementation group and the control group did not differ $(p=.11)$.

A logistic regression on reported sexual behaviour at T3 with past sexual behaviour at $\mathrm{T} 1$ and the two dummy variables as predictors showed a significant effect of the variable comparing the full implementation group against the partial and control groups, indicating that students in the full implementation group reported less sexual activity $(B=-.54, S E=.23$, Wald (1, $626)=5.53, p<.05, O R=.58)$. No effect was found comparing the partial implementation group against the full and control groups $(B=-.29, S E=.27$, Wald $(1,626)=1.13, \mathrm{p}=.29, \mathrm{OR}=.75)$. Among those students that reported being sexually active in the three months preceding $\mathrm{T} 3$, no significant effect of the variable comparing the full implementation group against the partial and control groups was found $(B=-.41, S E=.38$, Wald $(1,159)=1.15, \mathrm{p}=.28$, OR $=.66$ ). There was also no effect found comparing the partial implementation group against the full implementation and control groups $(B=-.13, S E=.42$, Wald $(1,159)=.09, p=.77$, OR $=.88)$.

\section{Discussion}

The findings of this study highlight some important aspects about the development and implementation of the KZN Department of Educations' lifeskills programme focusing on HIV and AIDS. The programme aimed to increase grade 9 student's knowledge and attitude with regard to HIV and AIDS and condom use and, on a more general level, student's confidence to assert themselves, feelings of social support from significant others and their beliefs regarding appropriate sexual behaviour, in order to practice safer sex.

The lack of significant results, except for knowledge, between the intervention and control groups, on the initial multi-level analysis prompted an analysis of the process evaluation carried out with teachers at the end of the implementation. This analysis showed that teachers implemented the programme to varying extents (full vs partial implementation) in the different schools in terms of time spent on the lessons, the number of lessons carried out and the content covered. In total teachers used a didactic style more and reported comfort with teaching more fact based rather than skill based topics. This will explain the higher impact on knowledge compared to the lack of impact on the psychosocial determinants or sexual behaviour.

However in analysing these almost naturally differentiated groups that were created a reasonably successful level of effect was found in that there was, in addition to an increase in knowledge levels of students about the spread and transmission of HIV and AIDS, an increase in perceptions of social support (T3), a reduction in negative perceptions about sexual behaviour, a decrease in reported sexual activity and an increase in condom use at T2. Importantly, 
however, except for knowledge, these programme effects were restricted to those students that received the full programme. For those schools that indicated implementing the programme partially, the students' responses on most variables were not significantly different from the responses of students in the controll schools.

The findings further showed that despite the positive effects of the fully implemented programme on relevant cognitive determinants of sexual behaviour, the full programme did not influence behaviour in terms of condom use in the long term indicating that condom-using behaviour requires more than just knowledge, positive attitudes and beliefs about its use. It requires skills that address the more proximal determinants of safe sexual behaviour, such as self-efficacy beliefs and skills related to actual condom use (Schaalma, Kok, \& Peters, 1993). Theses skills as well as those that enhance communication with ones" partner about safer sex, for example the confidence to communicate with a partner about accessing and using condoms correctly will be needed to enhance the content of a programme.

Further, skills development in students requires specific training on the part of the teacher. The teacher must acquire the ability, skills and confidence to move away from fact-based information-giving to methodologies that engage the students in discussion, role-play, and active student participation. Teachers need to have the appropriate materials at their disposal that provide for interactive teaching. Teacher-training programmes thus need to consider the differences of the individual teachers when enlisting them for training to carry out the programme as well as create the opportunity to address these differences.

The process evaluation of the varying duration and content covered by teachers may be reflective of the individual teachers' commitment to the programme and the motivation they had to implement the full programme. The outcomes that these teachers failed to impact on could possibly be attributed to the omission of the content in the curriculum and training.

The discrepancies in the findings maybe substantiated by the lack of systematic information that was available on the empirical and theoretical underpinnings upon which the KZN Department of Education lifeskills programme was based; a finding similar to reports of those educational programmes that were not grounded in a theoretical understanding of adolescent sexual behaviour and were not premised on empirical data that may explain adolescent risk taking or risk reducing sexual behaviour (Baldo et al, 1993; Reddy, Meyer-Weitz, Van den Borne, \& Kok, 1999). As a result the evaluation questionnaires used in the present study could not be fully adapted to the contents of the programme as the proximal objectives of the programme were not fully clear. 
Such a programme needs in its development to reflect the elements that have been found to be effective in similar sexuality education curricula. Some of these elements, from which the KZN Department of education lifeskills' programme (or similar programmes) may benefit, are that there be a clear focus on reducing one or more sexual behaviours that lead to unintended pregnancy or HIV and sexually transmitted infections, a sufficient length of time be allocated to complete scheduled activities adequately, the use of a variety of teaching methods designed to involve the participants and that promote internalization of the information, allows for the use of modelling techniques and practice of communication, negotiation, and refusal skills as well as the selection of teachers who believe in the programme and receive appropriate training and support from their school management committees to implement the programme (Kirby, 1997).

On a more general level, systematic attention needs to be given to the planning and implementation process of health education programmes as the quality of these processes determines the success of a health education programme (Kok, 1992), while programme evaluation is integral to determining their effectiveness (Kok, 1992; Mullen, Green, \& Persinger, 1985; Reddy, Kok, Van den Borne, \& Yach, 1995). With regard to systematic planning an example of how this process may start off is with, a thorough empirical and theoretical assessment of cognitive (i.e., beliefs), affective (i.e., feelings) and behavioural (i.e., risk behaviour) factors that influence the health problem.

The identified factors (i.e., determinants) are then translated into individual learning objectives (e.g., positive attitude towards condoms) and external change objectives (e.g., condom availability). These proximal programme objectives, in turn, mediate the effects of the intervention programme on the performance or behavioural goals that are set to reduce the health problem (e.g., condom use to prevent HIV infection). Ideally, this stage in intervention development needs significant input from behavioural scientists and health education professionals to ensure an appropriate selection of objectives, methods and strategies to reach these objectives (Bartholomew, Parcel, \& Kok, 1998; Bartholomew, Parcel, Kok, \& Gottlieb, 2001).

In South Africa presently, teachers are not only faced with the challenges of teaching about HIV and AIDS, but are in schools that are undergoing structural and curriculum reform as well. Therefore, education about lifeskills focusing on HIV and AIDS needs to address the broader issues of school reform such as the school culture, communication between and amongst stakeholders, teacher efficacy, and teacher behaviour (Norman, 2003). Further, alternate teaching techniques need to be included in teacher training programmes through namely presentations, demonstrations, modelling, and peer coaching (Fullan, 1982). 
The development of effective school based lifeskills programmes focussing on HIV and AIDS is a sound investment towards the sexual health of young people as it is well documented that schools provide a structured or established venue for such education as well as a captive audience as in recent years schools in South and Southern Africa have shown an increase in enrolment and an increase in the number of students moving onto secondary schools (Speizer, Magnani \& Colvin, 2003; Gallant \& Tyndale; 2003). With the opportunity to carry out sexuality education programmes aimed at prevention and behaviour change, the systematic planning, implementation, and evaluation of such programmes is much needed.

Footriote:

Between $77 \%$ ard $86 \%$ of students agreed that the programme was interesting, informative, educational, and useful. The students further indicated that they liked the course because it increased their knowledge about HIV and ADS and their skills to protect themselves against infection.

An! intention-to-treat analysis, in which for each wariable and each participant a missing value at $T 2$ was replaced by the score at baseline and a missing value at $T 3$ was replaced by the score at $T 2$, exactly replicated the pattern of findings of the effect analyses reported on in this paper.

\section{Acknowledgement} for Intemational Development, under the terms of HRN-A-00-97-00012-00. The opinions expressed herein are those of the authors and do not necessarily reflect the views of the U.S. Agency for intemational Development. 


\section{References}

Ajzen, 1. (1991). The theory of planned behaviour. Orgonizotionol Behowour and Human Decision Processes, $50.179-211$.

Baldo, M., Metcalfe, O, Barthes, A. M., Collins, J., Ricand, E., Marx, E, \& Schaalma, H. (1993), Developing and implementing curricula to address HW infection and other important health problems. Hygle, 12,25 . 26.

Bandura, A. (1986). Sociol foundotions of thought and action. A Social cognitive theory. Englewood, NJ.: Prentice Hall.

Bartholomew, L. K. Parcel, G. S., \& Kok, G. (1998). Intervention Mapping.A process for developing theoryand evidence-based health education programs. Health Educotion and Behoviour, 25, 545-563.

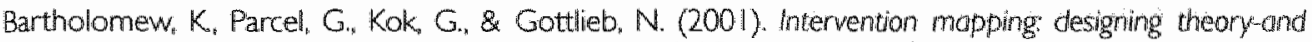
evidence-bosed heolth promotion progroms. Mountain View, CA: Mayfield.

Department of Education and Culture, KwaZulu-Natal, 2000). KwaZulu-Natal, Integroted Plon for Children Affected And infected With HN ond ADS. Business Plon For Lifeskills \&. HN and AIDS Educotion: Secondary Schools Phose I April 2000 - March 2001.

Department of Health, South Africa, (2000), Nationol HIV Sero-Prevalence Survey of Women Attending Public Antenotal Clinics in South Africa 1999. Directorate: Health Systems Research \&. Epidemiology

Fullan, MD. (1982). Taken from Norman, S. J. 2003. The Human Face of School Reform http://Mmwnationalforum.com/

Gallant, M. \& Maticka-Tyndale. E. (2003). School-based HW prevention programmes for African youth. Social Science \& Medicine. In Press.

Hannan P. Murray D. "Gauss or Bemoulli? A Monte Carlo comparison of the performance of the linear mixed model and the logistic mixed model analyses in simulated community trials with a dichotomous outcome variable at the individual level". Evaluotion Review, 1996;20:338-352.

Kirby, D. (1997). No Easy Answers: Research Findings on Programs to Reduce Teen Pregnancy, Washington, DC: The National Campaign to Prevent Teen Pregnancy, 28-30.

Kok, G. (1992). Health Education Theories and Reseanch for AlDS Prevention. Hygie 1992, 10,32 - 39.

Mullen, PD. Green, L.W. \& Persinger G. S. (1985). Clinical trials of patient education for chronic conditions: A comparative meta-analysis of intervention types. Preventive Medicine, 14,753-781.

Norman, 5.). (2003). The Humon Foce Of School Reform http:/ wmwnationalforum.com

Oakley, A, Fulherton, D., \& Holland, J. (1995). Behavioural interventions for HIV and AIDS prevention. ADS, 9.479-486.

Reddy, P. Kok, G., Van den Bome, B., \& Yach, D. (1995). Unravelling health promotion: in pursust of mone successful interventions. CHASA Journol of Comprehensive Heolth, $6,110-114$.

Reddy P. Meyer-Weitz A, Van den Bome B, Kok G. (1999). ST"L-related knowledge, beliefs and attitudes of Xhosa-speaking patients attending STI primary health-care clinics in South Africa. Int J STIADS. 10: 392 400.

Reddy, P. Meyer-Weitz, A van den Bome, B., \& Kok, G. (1999). Developing health education interventions targeted at STD clinic attenders. MRC Policy Brief No I, July.

Reddy. P. Jarnes, S., \& McCauley, A. 2003). Progromming for HW Prevention in South African Schools: A Report on Progrom Implementotion. Cape Town: Medicall Research Council.

Rogers, E. M. (1995). Diffusion of innovations. (4 ed). New York: The Free Press.

Rossi, PH., Freeman, H.E, \& Lipsey, M.W. (1999). Evoluotion A systemotic opprooch (6th edition). Thousand Oaks, CA: Sage publications.

Schaalma, H.P, Kok, G. \& Peters, 1. (1993). Detenminants of consistent condom use by adolescents: The impact of experience with sexual intercourse. Heolth Education Research, 8, 255-269.

South African Health Review 2000. Dickson-Tetteh, K \& Ladha, S. Youth Heodth. Chapter 20, 393-410. Health Systems Trust.

Speizer 15. Magnani R.. \& Colvin CE. (2003). The effectiveness of adolescent reproductive health interventions in deweloping countries: a review of the evidence, journat of Adolescent Heolth, $33(5)$ : $324-348$.

UNAIDS, 2000. Report on the glabol HW and ADS epidemic fune 2000. Geneva, Switzerland: joint United Nations Programme on HN and AIDS.

Varga, C. \& Shongwe, B. (1999). School Bosed Reproductive Heoulh Educotion. Durban: Health Systems trust. 
The South Arican HIV ADS risk reduction programme for secondary school leamers Refocusing the effort 


\section{Abstract}

In this paper we reviewed the evaluation reports of the existing South African life skills HIV/AIDS programme for secondary school learners, to present recommendations for improving the effort. Based on available research on HIV/AIDS risk behaviours of South African youth a risk model of sexual behaviour was developed. This model suggests that sexual risk behaviours are a complex probllem that needs to be contextualized by the proximal and distal influences on these behaviours. The results of three studies that evaluated the South African Lifeskills HIV/AIDS programme were reviewed. The main conclusion of these process and effect evaluations was that the programme covered some relevant areas that an effective programme should include, but that key-components relevant to behaviour change were not adequately implemented. The limited implementation effects of the prevention programme were mainly restricted to an increase in the learners' knowledge about HIV/AIDS and prevention and some, but weak, effects on learners' attitudes, self-efficacy for condom use and reported condom use behaviour. Based on the risk model, the evaluations of the programme and on theories of behaviour change a logic model of the life skills programme was developed using the Intervention Mapping framework. Recommendations for programme change focus on helping teachers" develop student lifeskills applied to HIV risk including the enhancement of administrative support to strengthen the environmental context (policy and teacher support) that will enable teachers to fully implement the modified programme. Suggestions for continued programme evaluation are made. 


\section{Introduction}

The incidence of HIV and AIDS (HIV/AIDS) is an unabated problem through sub-Saharan Africa (SSA) and South Africa in particular. In 2003 the Department of Health estimated that in South Africa 5.6 million people were HIV positive (Department of Health, 2004). These estimates were based on an extrapolation of the 2003 antenatal survey carried out amongst pregnant women attending antenatal clinics at the sentinel sites. In KwaZulu-Natal $(K Z N)$, a province in the north east of South Africa, the prevalence of HIV amongst pregnant women was the highest in the country at $37.5 \%$ (Department of Health, 2004). A national household study reported that the prevalence rates for adults (15-49 years) was $15.6 \%$ and that for youth (15-24 years) was $9.3 \%$ with a distinct difference between female youth (12\%) and male youth (6\%) (Mandela Foundation/ HSRC, 2002).

Several epidemiological studies confirm that youth have improved their understanding of HIV/AIDS as a result of widespread awareness campaigns. This is evidenced by high levels of knowledge about HIV/AIDS (over $80 \%$ correct responses) and the high percentages (76-86\%) who report knowing ways of protecting themselves from getting sexually transmitted infections including HIV (James, Reddy, Taylor, \& Jinabhai, 2004; Simbayi, Kalichman, Jooste, Cherry, Mfecane, \& Cain, 2005). However, despite awareness by youth of HIV/AIDS and ways to prevent transmission, there remain high rates of sexual risk behaviour.

The first national survey on youth risk behaviour, carried out in South Africa, amongst grades 8-11 youth in 2002 reported a national prevalence of $41.1 \%$ for students who reported ever having had sex ( $79 \%$ were $14-18$ years old), with significantly more male students (50.1\% [47.0 - 53.2]) than female students $(34.1 \%[31.1-37.1])$ reporting ever having had sex. Of those students (nationally) who reported being sexually active, 29\% reported consistent condom use $14 \%$ reported their age of initiation of sex as being less than fourteen with significantly more males $(25.4 \%[23.1-27.7])$ than females $(5.6 \%$ [4.6 - 6.6]) reporting this young age of initiation of sexual intercourse (Reddy, Panday, Swart, Jinabhai, Amosun, \& James et al., 2003).

The prevention of HIV infection through the adoption of safer sexual behaviours (abstinence or condom use) remains the key strategy to decreasing the prevalence of HIV/AIDS. One of the strategies of the Department of Education, in South African schools, was to address this issue by implementing an intensive teacher-led programme amongst secondary school students, the Lifeskills HIV/AIDS Prevention Programme (LHAP).

The purpose of this paper is to present recommendations for the refocusing of the national South African school-based efforts to reduce HIV risk behaviours among adolescents. The recommendations are based on a review of program 
evaluation reports of the LHAP (one of national scope and two from KZN) and literature on factors related to unsafe sexual behaviour as well as the Intervention Mapping framework (IM) (Bartholomew, Parcel, Kok, \& Gottlieb, 2001; 2006) a framework for systematic health promotion program planning and evaluation. $\mathbb{M}$ has been used to develop health promotion programs for asthma management (Bartholomew, Shegog, Parcel, Gold, Fernandez, Czyzewski et al, 2000), nutrition (Brug, Oenema, \& Ferreira, 2005) and HIV prevention (Tortolero, Markham, Parcel, Peters, Escobar-Chaves, \& Basen-Engquist et al., 2005) amongst others. Recommendations include intensifying the skills components of the curriculum, focusing more explicitly on the social environmental context, and enabling teachers to fully implement a modified program.

\section{Needs Assessment}

Whether developing a new program or modifying one that has been evaluated, the IM systematic health promotion planning process begins with a needs assessment to determine the nature of the health problem and previous attempts at solutions (Bartholomew et al., 2001; 2006; Tortolero et al., 2005) For the assessment of the problem of HIV risk taking among South African adolescents we have used the Precede model as an organizing framework (Green \& Kreuter, 2005).

\section{HIV/AIDS Risk Behaviour}

The priority population for our programme recommendations is secondary school students in South Africa. There are 4186882 million secondary school students in the country distributed among the nine provinces representing a wide range of ethnic groups. KZN, where two of the evaluation studies on the LHAP have taken place, has the largest school going population of any province with 960996 secondary school learners (Department of Education, 2005). "The majority of students in $\mathrm{KZN}$ are IsiZulu first language speakers and live in areas that are more rural in terms of access to infrastructure such as water, electricity, clinics and recreation.

Figure 1 is a modifted Precede risk model of the factors related to the practice of HIV sexual risk behaviours by South African adolescents (Green \& Kreuter, 2005). The middle column of the model depicts behaviours that place South African adolescents at particular risk. Several studies have been crucial in confirming the risk behaviours for contracting STIs such as HIV (Flisher, Roberts, \& Blignaut, 1992; Abdool Karim, Abdool Karim, Preston-Whyte, \& Sankar, 1992; Flisher, Reddy, Muller, \& Lombard, 2003; Reddy et al., 2003; Taylor, Dlamini, Kagoro Jinabhai, \& de Vries, 2003; Simbayi, Chauveau, \& Shisana, 2004; Pettifor, Rees, Kleinschmidt, Steffenson, MacPhail, Hlongwa-Madikizela et al, 
2005). These behaviours may broadly be categorised as the early initiation of sex, multiple sexual partners and unprotected sexual intercourse.

The findings from the YRBS for the province of $K Z N$ for ever having had sex, consistent condom use and initiation of sex below fourteen years old was $37 \%$, $15 \%$ and $16 \%$ respectively (Reddy et al., 2003). In a study by James et al., (2004) amongst grade 11 students in $\mathrm{KZN}, 42.6 \%$ reported being sexually active in the recalled period of six months. Of this group, $33.3 \%$ reported not having used a condom at all, and of those reporting having used a condom $42.6 \%$ reported using a condom sometimes and $41.8 \%$ reported using a condom every time. A review by Eaton, Flisher, and Aaro (2003) reported a large variation in reported number of partners amongst adolescents. While $60 \%$ of university students reported no or one partner in the last year prior to the review, the majority of school-going learners reported one or two partners in their lifetime and a persistent minority reported more than four partners per year. This is a cause for concern when one considers the recent findings of a community-based study that shows that participants reporting more than one lifetime partner were almost twice as likely to be HIV infected than participants reporting one lifetime partner (Pettifor, Kleinschmidt, Levin, Rees, MacPhail, Madikezela-Hlongwa et al., 2005).

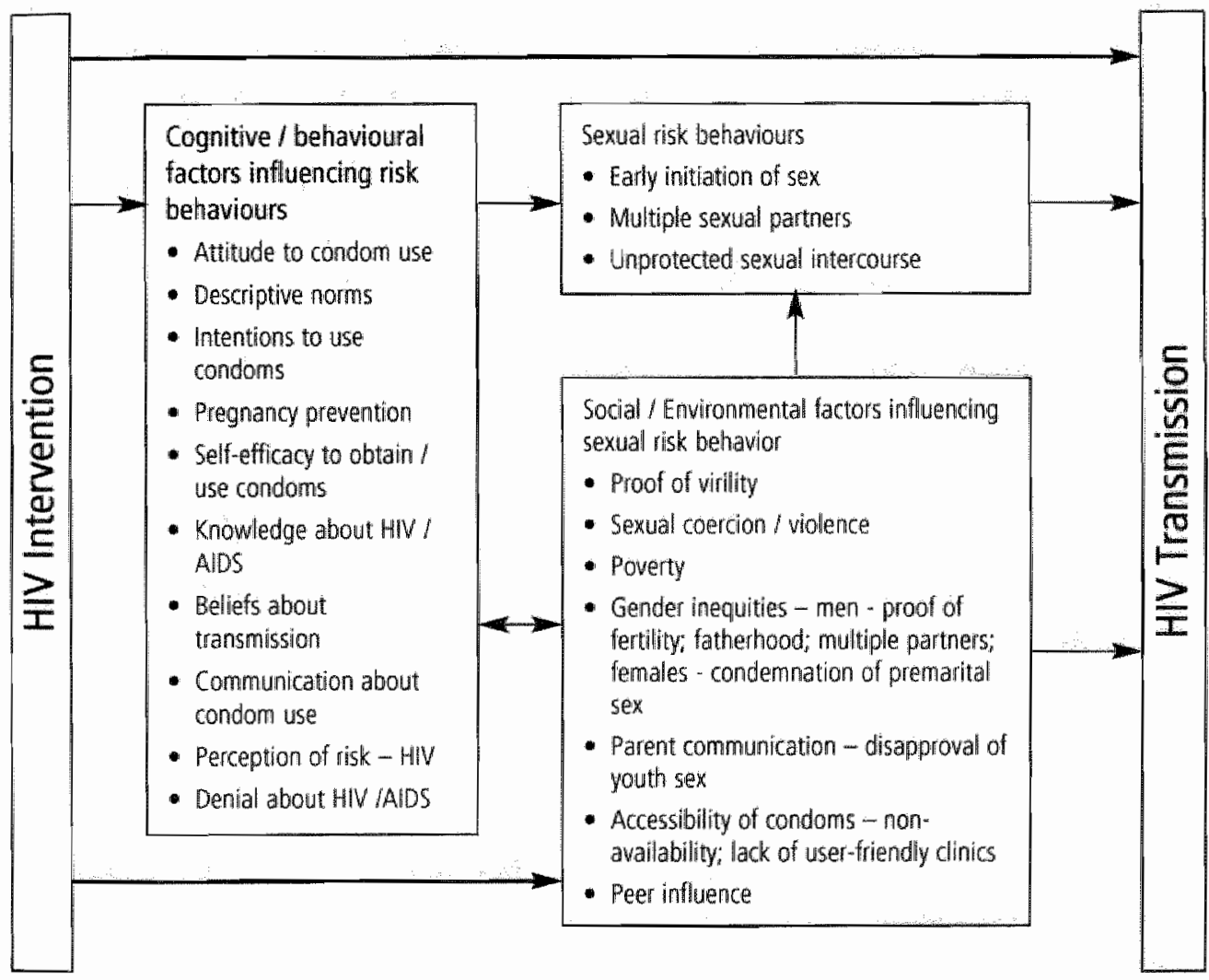

Figure 1: Modified Precede Risk Model 


\section{Factors Related to Risk}

In addition to providing a picture of the magnitude of risk, the prevalence information leads to the question of "why?". Why do adolescents in South Africa engage in unsafe sex? The challenge in the development of HIV/AIDS interventions lies in creating strategies that address the factors related to or determinants of these behaviours. Moving to the bottom of the model, the social environmental (more distal) factors that may be influencing adolescent behaviour are addressed, and the column on the far left depicts the cognitive/behavioural (more proximaly determinants. The Precede-type logic model of the probllem presents a simplified albeit very useful version of the problem causation and outcomes for the purpose of thinking about program planning and adaptation.

Effectively addressing youth sexual risk behaviours requires a sound understanding of the factors that may influence the behaviours. However, trying to answer this question requires the consideration of a fairly broad range of both qualitative and quantitative evidence as the model is meant to suggest leverage for intervention not a conclusive picture of the problem. Our requirement for a proposed determinant is that it is based on empirical evidence from more than one source or on the strong relation of a theoretical construct to an empirical finding (for example, because self-efficacy was a measured variable, we added skills since they are theoretically strongly related).

We first added theoretical determinants of condom use based on two metaanalyses of international studies of psychosocial correlates for heterosexual male condom use (Sheeran, Abraham, \& Orbell, 1999; Albarracin, Johnson, Fishbein, \& Muellerleile, 2001). These studies suggest that five cognitive variables have consistent medium to large correlations with condom use. Sheeran and colleagues (1999) describe the variables attitudes toward condoms, descriptive norms, intentions to use condoms and pregnancy prevention motivation. A fifth cognition, perceived behavioural control over the behaviour (including self-efficacy) was suggested by Albarracin and colleagues (2001)

We then searched for empirical studies of determinants of HIV risk behaviour in South African youth. The left column in the model includes knowledge, a factor that remains somewhat problematic. Simbayi et al., (2005) reported some important remaining deficits in HIV/AIDS related knowledge amongst a group of youth from a formal and the surrounding informal settlements who (one in three) believed that washing one's genitals after sex reduces the risks for HIV infection and that AIDS is caused by spiritual forces (39\%).

Communication with ones partner was found to be related to condom use (Reddy, Meyer-Weitz, van den Borne, \& Kok, 2000); unfortunately Varga (1997) has suggested that young people may hold a strong belief that HIV/AIDS are prohibited topics of conversation with partners and describes a social norm of 
avoidance of direct conversation about sexual behaviour. Reddy and colleagues (2000) also found attitudes towards condom use and general self-efficacy in condom use to be associated with the different stages of change related to condom using behaviour amongst a group of young people attending STI clinics. The study by Meyer-Weitz and colleagues (1999) showed that male participants with the most negative attitude to condoms were more likely to engage in highrisk sexual behaviour compared to the participants with moderate, positive and very positive attitudes (Meyer-Weitz, Reddy, Weilts, Van den Borne, Kok, \& Pietersen, 1999). Having used condoms in the past was also found to be a significant predictor of consistent condom use indicating that ones positive experience and self-efficacy play a part in determining continued use of condoms (James, Reddy, Ruiter, Taylor, Jinabhai, Van Empelen, \& Van den Borne, 2005).

The relative importance of risk perception and the factors that may influence risk perception is a complicated issue. Macintyre and colleagues (2004) in their study amongst adolescents and young people in $\mathrm{KZN}$ found that $20 \%$ of the sample was highly vulnerable because they did not consider themselves to be at risk despite being in the high risk category and having reported risky sexual behaviour (Macintyre, Rutenberg, Brown, \& Karim, 2004). The main reason for not believing that they were at risk was that they saw themselves as being abstinent $(17 \%)$, only having had one partner $(26 \%)$, or always having used a condom (30\%). This was inconsistent with their reported behaviours. MacPhail and Campbell (2001) also report low levels of perception of personal risk despite high levels of infection. It appeared that the young men (70\%) were unable to assess whether they were personally vulnerable or not, indicating an inability to make the connection between their behaviour and the HIV risk messages. The feeling of personal vulnerability appeared to be strongly related to whether one knew someone with AIDS as this influenced whether they belleved the disease existed or not. Reporting knowing someone with AIDS appears to have changed over time. In Varga (1997) young men expressed disbelief about the existence of AIDS due to not having seen a person with the sickness (AIDS) or perceiving the AIDS situation to be a political plot "from the old government or overseas", while in MacPhail and Campbell (2001) AIDS is acknowledged and having seen someone with the disease has been reported.

Some qualitative research in the area of adolescent sexuality provides rich data and insight into the social environmental part of the model. Such literature plays a crucial rolle in deterring one from perpetuating the ideology that adolescents are a homogenous group. In fact adolescent behaviour and experiences are reflective of a range of issues like their cultural background, gender, sexuality and socio-economic status (Rivers \& Aggleton, 2005). This literature is growing, and sheds light on the both the complexity and the power 
of the normative environment in which adolescents have to negotiate their way to safer sex. In a study by Varga (1997), the meaning of sex differed for men and women with the consummation of a sexual relation adding to the status and competence of men as well as legitimising the "love" relationship. Women were in a more compliant role in which refusal meant possible physical coercion or abandonment. MacPhail and Campbell (2001) highlighted the economic implications of abandonment or lack of a male partner for young women in poor and developing areas. Poverty entraps women in situations where they are dependent on the financial favours and material goods of men (Pettifor, Measham, Rees, \& Padian, 2004; Campbeli, Foulis, Maimane, \& Sibiya, 2005).

The issue of condom use is embedded for many South African young people in a web of norms that differ for men and women and lead to unsafe sex. For men norms are based on the value of fertility, fatherhood and multiple partners whereas for women premarital sex is condemned leading to fear of judgement and rejection for carrying condoms or asking for their use. In general, youth sexuality and sexual behaviour carry intense social disapproval (Varga, 1997; MacPhail \& Campbell, 2001). A mans' sexual status is defined by the number of partners he has and his ability to "legitimise" the relationship in a short time. Disapproval of youth sex by parents leads to youth not using condorns as opposed to not having sex. They risk having sex while their parents are out, as most stay with their parents, so condoms are either not available and sexual intercourse takes place in a hurry. Use of condoms for girls in particular is further hindered by the difficulty of accessing condoms (negative attitude of clinic staff) as well carrying condoms (fear of being labelled promiscuous). Peer influence appears to play a part in adolescent sexuality (more so for boys than girls) in that it makes it difficult for them to practice safer sex. Boys who choose to use condoms or abstain risk being jeered at and belittled by their friends.

\section{Summary}

The needs assessment suggests the importance of an ecologic approach to planning solutions for the problem of adolescent HIV/AIDS risk in South Africa (Visser, Schoeman, \& Perold, 2004; MacPhail \& Campbell, 2001; Campbell et al., 2005). The problems of risk are embedded in a complex web of both proximal and distal factors including social and cultural forces of poverty, gender inequities, the meaning of sex and fertility, and individual beliefs towards personal risk and condom use (Eaton, Flisher, \& Aaro, 2003; Varga, 1997; Jewkes, Levin, \& Penn-Kekana, 2003). Careful planning will be required to build a program that begins to address adolescent risk behaviour within this web and that provides a context for, as MacPhail and Campbell (2001, p. 1614) state, "renegotiation of dominant high-risk behavioural norms by young people". 


\section{The Lifeskills HIV/AIDS programme - Did it work?}

The next step of applying IM to adapting or refocusing an evaluated program is to describe the program itself. IM suggests the importance of understanding what the original program was attempting to achieve in terms of long range objectives, intermediate behavioural and cognitive outcomes, and implementation of theoretical methods and practical strategies. The analysis should also include a description of program resources or inputs and the elements that were meant to ensure full implementation with appropriate fidelity to programme design (Tortolero et al., 2005; Bartholomew et al., 2006). The description of the LHAP presented here is based on three evaluation studies (James, Reddy, Ruiter, \& Van den Borne, in review; Visser et al., 2004; Magnani, MacIntyre, Karim, Brown, \& Hutchinson, 2005)

\section{Description of the Program}

The LHAP intervention is a 16- hour curriculum that was designed to enable the following 11 learner objectives: (1) demonstrate a clear and accurate understanding of sex, sexuality, gender, and STIs; (2) identify ways in which HIV/STIs can and cannot be transmitted; (3) identify and evaluate the effectiveness of HIV/STI prevention methods; (4) identify, access and mobilize sources of assistance within a community; (5) critically evaluate reasons for delaying sexual intercourse or practicing abstinence; (6) respond assertively to pressures for sexual intercourse and unprotected sex; (7) critically evaluate reasons and methods for having protected sex if sexually active; (8) accept, cope and live positively with the knowledge of being HIV positive; (9) show compassion and solidarity towards persons with HIV/AIDS and those affected; (10) be able to provide basic care for persons living with HIV/AIDS in the family and community; and (11) understand and cope with the grieving process (Magnani et al., 2005). The lessons were to be taught at least one lesson a week over two schools terms. The content covered a range of topics that included facts about HIV and AIDS and the use of life skills focusing on HIV risks, for example assertiveness and decision-making to guide behavioural cholces. These sessions were intended to be implemented in classrooms by teachers using didactic and interactive teaching group work and role-play methods.

Safer sex behaviour is built on the foundation of generic social skills including decision-making, communication and negotiation (Kirby, 2002). The aim of the LHAP was to bridge the gap between the high levels of awareness reported by adolescents and their unsafe sexual practices. Schools were already committed to reform and were implementing the "Curriculum 2005" syllabus, based on outcomes based education with a designated learning area for decision making, critical and creative thinking, effective communication, development 
of healthy relationships, and a positive self-concept. These were seen as broad themes within which core skills (empathy, self-awareness, problem-solving, coping with stress and emotions, and interpersonal relationships) are developed and presented in a culturally serisitive manner (Department of Education, 1997).

The life orientation learning area became home to the LHAP because it was already focused on (1) addressing the developmental (physical, emotional and cognitive) stages that young people pass through and the skills they need to transit to adulthood, (2) providing participatory and interactive academic methods; and (3) using culturally relevant and gender-sensitive learning activities within a safe and open environment. A school-based HIV/AIDS programme could then focus on translation of lifeskills to the HIV/AIDS prevention arena.

The program was implemented through a national series of ten-day teacher trainings. Eight hundred and forty master trainers in provinces and districts trained 13,609 locally implementing teachers who were intended to implement three potentially intensive domains of program activity: (1) adapt the program for their schools based on local needs and community values; (2) teach the 11 learner objectives; and (3) act as change agents to principals, other teachers and parents to firmly integrate the Lifeskills curriculum into the school's instructional program (Visser et al., 2004).

\section{Program Evaluation Findings}

James and colleagues (under review) evaluated program outcomes and process in KZN amongst 22 schools with two classrooms in each school in which were nested 1141 grade 9 students with a mean age of 15.6 years. The schools were randomised into treatment (those implementing the program) and control (those not implementing the program). Outcomes measured by a self-report questionnaire were the following: knowledge about HIV, attitudes towards condom use (percelved positive and negative consequences); attitudes toward people living with AIDS, percelved social support, confidence to assert oneself, perception of sexual behaviour, communication about HIV and AIDS and safer sex, reported sexual behaviour and intended condom use behaviour.

Measures were taken at baseline, six months after baseline immediately following the implementation, and four months after the completion of the programme. The results of the multi-level analysis carried out on the intervention and control groups showed that except for knowledge there were no significant differences between pre- and post-intervention scores.

The process evaluation of teacher implementation of the program asked on a questionnaire what teachers recalled teaching, how often they taught the lessons and the methodology that was used. The researchers also observed the 4.5 day teacher training for the teachers from the 11 intervention schools. Teachers 
indicated mostly didactic teaching methods and little that might be construed as skill development. Schools did not implement the program uniformly or with fidelity to a program design intended to build skills. Schools could be differentiated by frequency of lessons, topics covered and methods used. Dose of implementation was indicated by number of topics (learner objectives) taught. Seven schools were designated as fully implementing the programme because they reported working on all 11 leamer objectives whilst 4 schools partially implemented the programme (taught 7 or fewer learner objectives). The teachers taught the sections of the curriculum that covered information about HV and AIDS and less about the life skills components of the course and caring for people living with HIV and AIDS. All schools used formal lessons, group work or a combination of both as a mean of delivery (Redidy, James, \& McCauley, 2003).

Further analysis carried out on the differentiated study groups, which are full implementation, partial implementation and control groups, showed that under conditions of full implementation, the program was associated with increases in knowledge about HIV, more positive perceptions of sexual behaviour, a decrease in reported sexual activity in the preceding six months and an increase in condom use at last sex in the short term, that is immediately after the intervention was implemented. In the longer term, that is four months after the intervention was implemented learners were able to maintain the significant effects found on the variables immediately after the intervention was implemented as well as experience a higher level of perceived social support (James et al., under review).

Visser and colleagues (2004) evaluated the Lifeskills program for both process and outcomes using a systems approach to understand what inhlbited the implementation and effectiveness of the intervention. The intervention was evaluated in two educational districts involving 24 schools. The outcome evaluation used a pre- and post- intervention questionnaire to assess the following variables: (1) knowledge about HIV/AIDS; (2) knowledge about protective behaviour; (3) attitude about HIV/AIDS; (4) attitude about condom use; (5) reported high risk behaviour (sexual experience, multiple partners, and not using condoms); (6) feelings of personal control; and (7) psychological wellbeing. Learners from one class of 35-40 learners in each grade in each school responded to the questionnaire $(873$ learners at pre-test and 794 learners at post-test for 667 matched pairs).

The process evaluation used interviews and focus groups with various school personnel a month after the training to ascertain how teachers implemented the program in the schools including the impact of the teacher training on capability to present the program. During the second year of the implementation, trained teachers and principals of five schools were interviewed about the program implementation. Focus group discussions were conducted 
with groups of learners and with all teachers in the five evaluation schools.

In the quantitative study, Visser and colleagues (2004) found postintervention period changes only in knowledge about HIV/AIDS, protective behaviour and attitude toward HIV/AIDS. No other variables changed in a positive direction and reported sexual behaviour was slightly more risky after the intervention. The process evaluation led to insight into the barriers teachers faced in implementing the program. The teachers needed; but did not always receive, time on the schedule for teaching the program and support from the principal. There did not seem to be enough personnel trained to implement the program; teachers did not see HIV/AIDS prevention as part of their roles; and teachers experienced a lack of support from the principals and other [untrained] staff members. Further teachers lacked the facilitative relationships with learners that might have been needed to effectively teach the program. HIV/AIDS was not seen as a priority in the school system compared to improving low academic standards and the improvement of examination result. Finally, overall school realignment further stretched teacher attention and focused resources away from non-examinable subjects.

In another evaluation study of the Lifeskills program in KZN Magnani and colleagues (2005) found slightly more hopefull results in a program evaluation. These researchers assumed that the Lifeskills program had been implemented to some extent in all secondary schools in KZN by 2001. They used the variability in program scope across schools in the province and measured impact by the magnitude of the dose response relationships between measures of exposure to the education and outcomes of interest. Exposure to the program was measured by number of topic areas taught as in the evaluation by James and colleagues (under review). The outcomes of interest were the following: (1) sexual debut; (2) secondary abstinence; (3) number of sexual partners in the month before the survey; (4) condom use at first sex; (5) consistent condom use; and (6) condom use at last sex. This study found modest changes in knowledge of HIV/AIDS transmission, STIs, and contraception as well as self-efficacy for condom use. Results included increases for program-exposed youth in condom use during first sex, consistent condom use, and condom use during last sex (Magnani et al., 2005).

Working from the curriculum materials and the evaluation reports (James et al., under review; Visser et al., 2004; Magnani et al., 2005) we have developed a logic model of the intended inputs, outputs, potential determinants of behaviour or mediating variables, and outcomes of the program. This model (Figure 2) enabled us to map both process and outcome evaluation findings onto the effects that seem to have been intended program effects.

Beginning on the left side of the model, we have listed the components that contributed to the design and implementation of the Programme. Moving to 


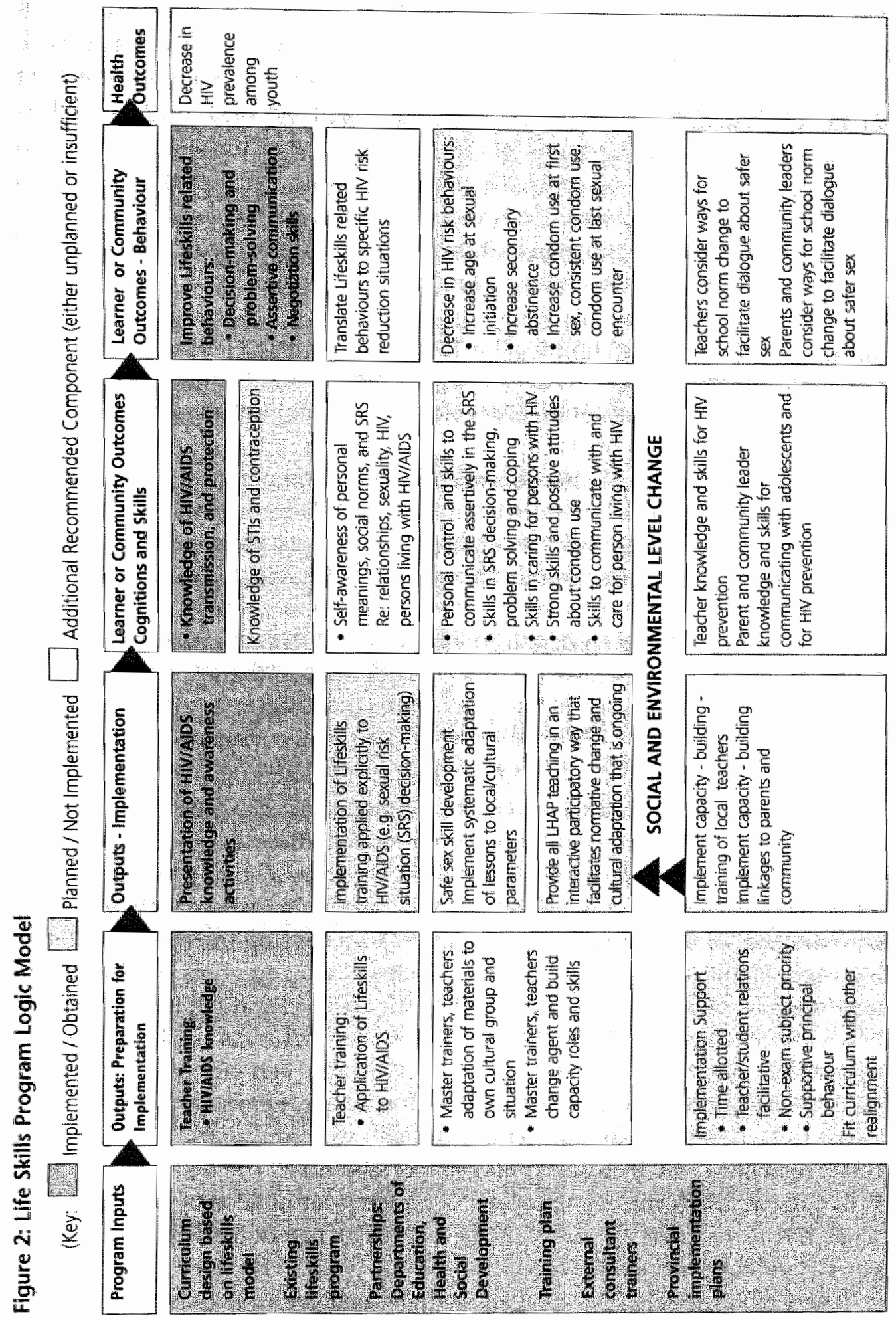


the right across the columns, all program components and outcomes have been coded as either implemented/obtained, planned but not implemented, or a component that was not included in the original programme plan but that might be needed to better address the factors depicted in the risk model in Figure 1. The first two categories are from the review of the three evaluation studies of the Programme while the third one depicts elements that do not seem to be present, but would be necessary to fully address factors in the risk model. We analysed the program as it was described in the reports and depicted characteristics of the programme reading from the left column of the figure as the following:

- Inputs such as partnerships for the design and implementation of the LHAP

- Outputs including: (1) processes to prepare for implementation such as teacher training and (2) those processes involved in implementation such as instruction provided by teachers

- Outcomes including: (1) learner and community cognitive and skill changes such as decision making and condom use knowledge and skills, (2) learner and community behavioural changes such as application of decision making to sexual risk situations, and (3) health such as decreases in HIV risk exposure.

This picture of the program then projected the foundation for the recommendations in the next section.

\section{Recommendations for Program Change}

Based on both the risk model (Figure 1) and the logic model of the putative program (Figure 2), we offer several recommendations for reconsidering the LHAP and keeping the forward momentum of activities in tact. In this section we use an IM planning device, the matrix, which is a simple table to depict what performance we are suggesting and by whom paired with suggested determinants of the performance (Tables 1-3). To develop the implementation matrices (Tables 1, 2 and 3) for principals and teachers we used the determinants of behaviour as described by the Social Cognitive Theory (SCT) of behaviour change (Bandura, 1986). Each of the constructs used, behavioural capability, outcome expectations and attitude, self-efficacy and skills, perceptions of norms, intentions and reinforcement, represent the aspect that needs to be developed or experienced through exposure to the programme in order to achieve the identified performance objective. The detail within each cell of the matrix is the change objective which is formulated by noting exactly what has to be done in terms of the particular determinant to achieve the corresponding performance objective.

These tables should help program planners achieve an understanding of the 
nature of the tasks ahead and match methods and strategies to proposed change. However, these tables should only be a starting place for formative work with teachers, principals and others about what is desirable and feasible.

\section{Enactive Leaming for Skill Development and Practice}

It seemed clear from the evaluation studies that the primary difficulty with the LHAP was in its implementation. As Schaalma and colleagues suggest; sex education as health promotion should be intensively skill based and most teachers are not equipped to provide appropriate skill development without first developing their own skills (Schaalma, Abraham, Gillmore, \& Kok, 2004). Programme developers realized that HIV/AIDS risk reduction required both skills specific to sexual behaviour such as condom use, and those skills applicable to any stress or conflict laden situation (lifeskills). However, as in many programs, the skill development strategies seemed to be missing from most of the implementation.

Figure 2 suggests that a new implementation should include an emphasis on learner skill development. Of course for this to be possible, preparation for implementation must enable teachers to develop their own skills in the application of lifeskills processes to sexual risk situations. Table 1 presents a matrix of suggested teacher performance considerations to add or highlight the continued implementation. Determining whether learner materials and teacher manuals fully support these objectives is beyond the scope of this paper. However, we think that needed additions would be modest. On the other hand, the scope and nature of the teacher training would have to be substantially modified to achieve the objectives depicted on the table. 


\begin{tabular}{|c|c|c|c|c|c|}
\hline : & 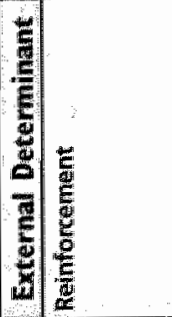 & 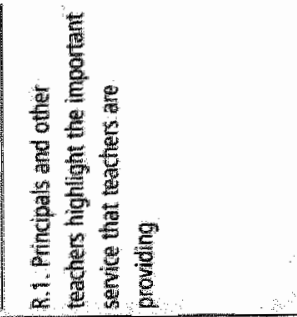 & 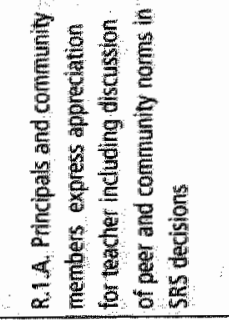 & 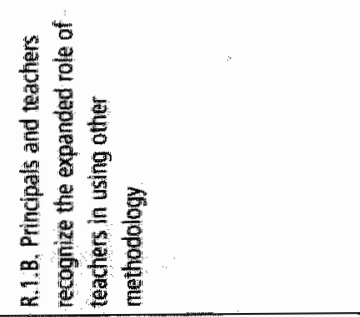 & 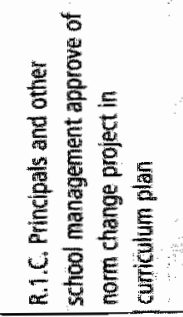 \\
\hline 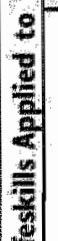 & 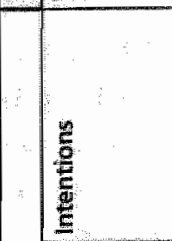 & 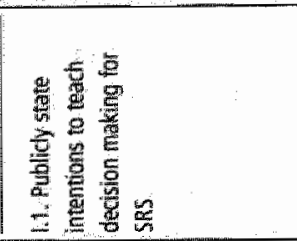 & 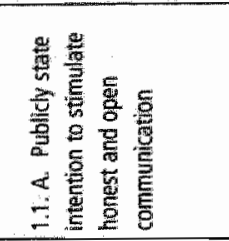 & 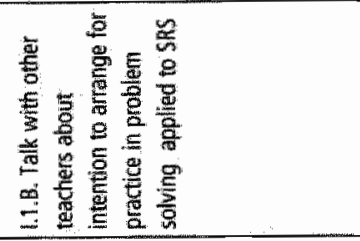 & 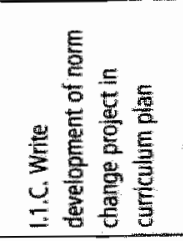 \\
\hline 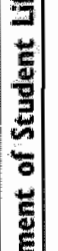 & 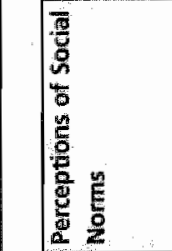 & 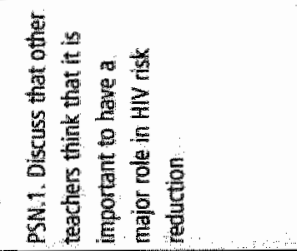 & 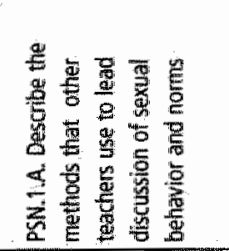 & 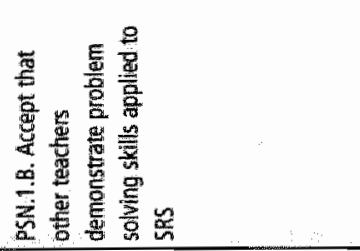 & 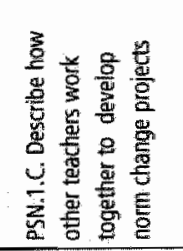 \\
\hline 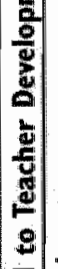 & 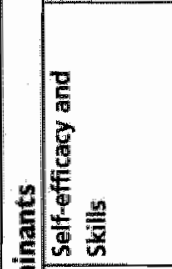 & 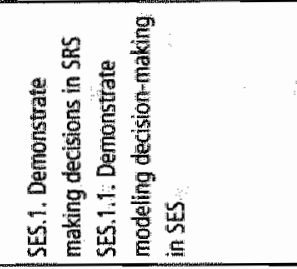 & 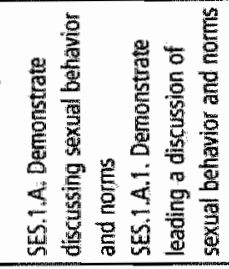 & 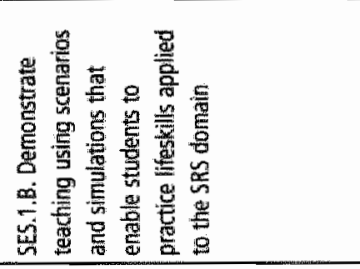 & 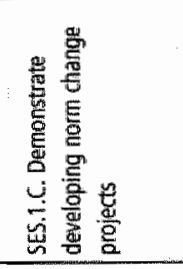 \\
\hline 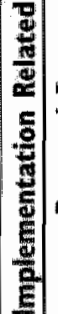 & 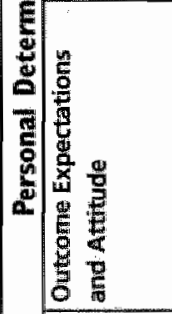 & 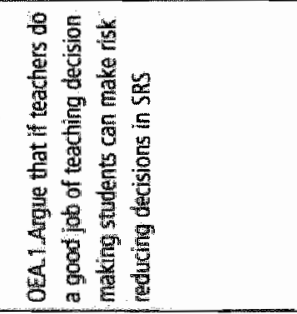 & 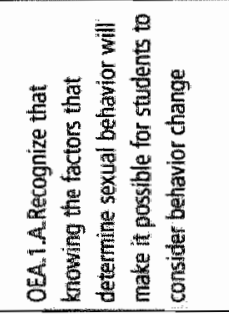 & 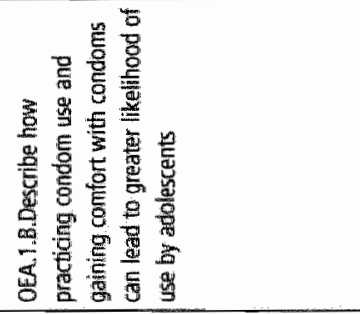 & 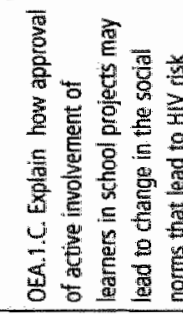 \\
\hline 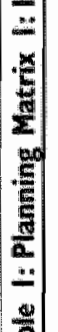 & 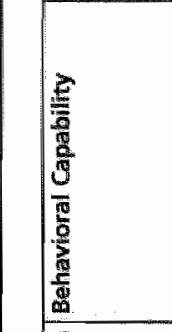 & 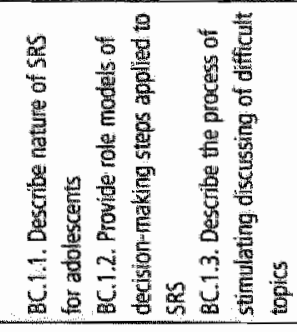 & 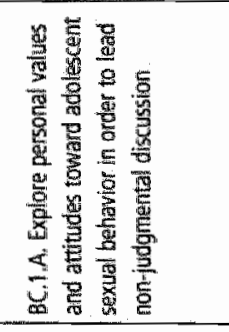 & 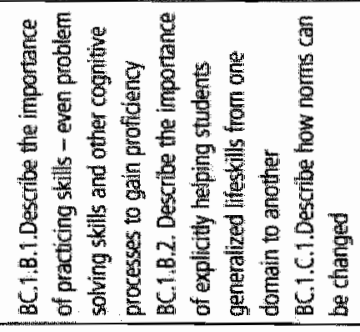 & 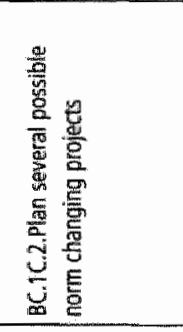 \\
\hline$\frac{9}{5}$ & 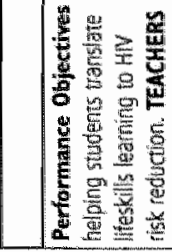 & 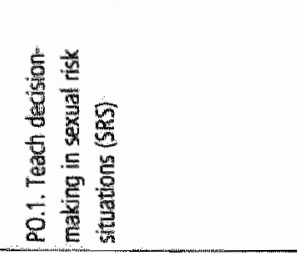 & 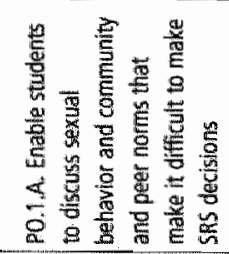 & 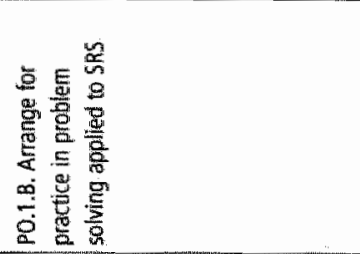 & 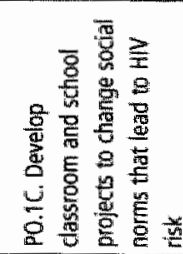 \\
\hline
\end{tabular}




\begin{tabular}{|c|c|c|c|}
\hline \multicolumn{2}{|l|}{ 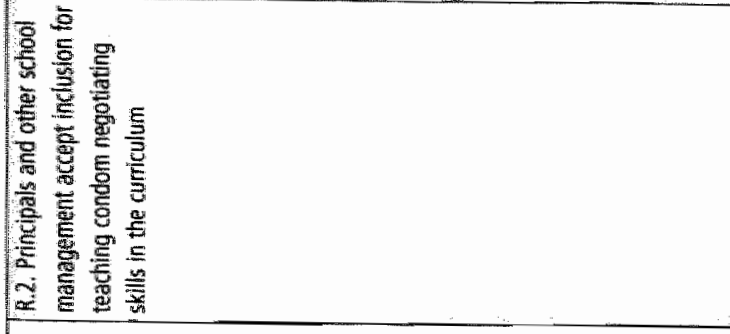 } & 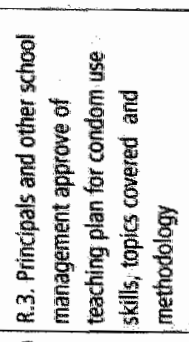 & \\
\hline 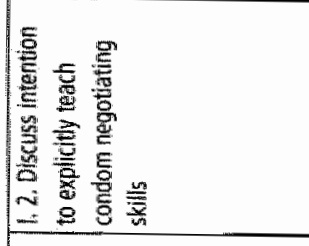 & & 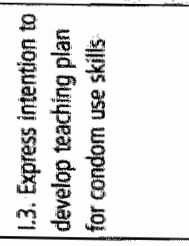 & 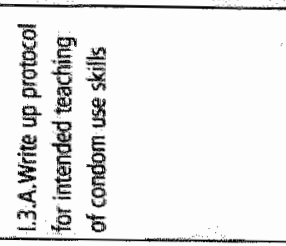 \\
\hline 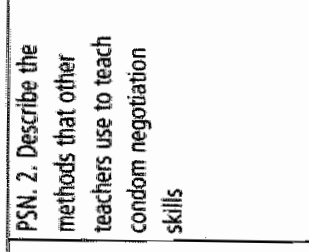 & 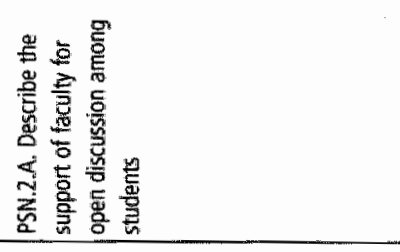 & 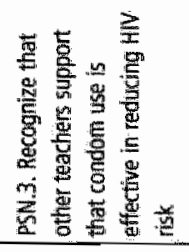 & 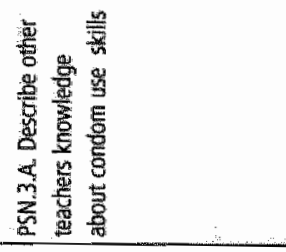 \\
\hline 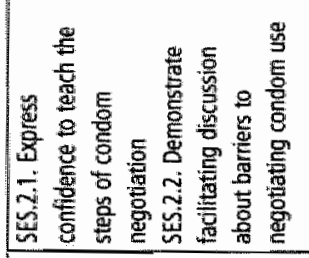 & 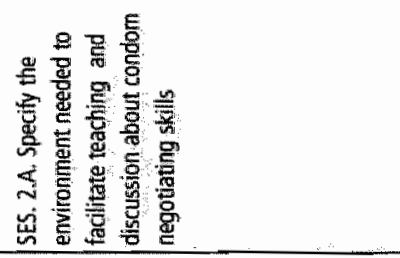 & 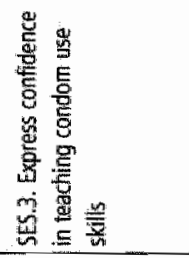 & 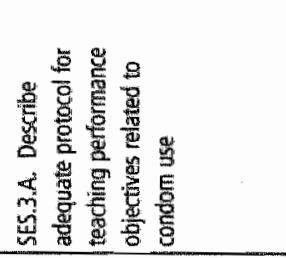 \\
\hline 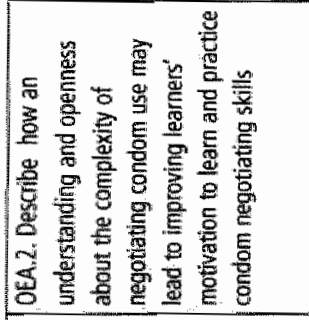 & 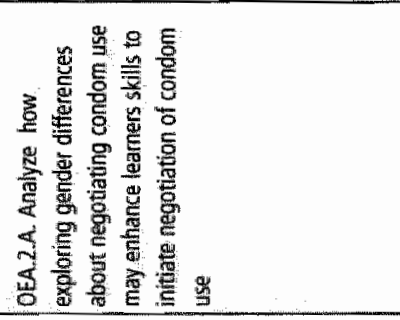 & 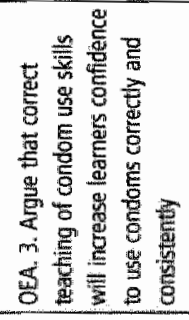 & 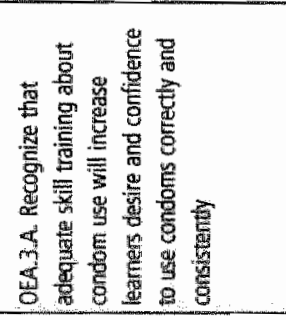 \\
\hline 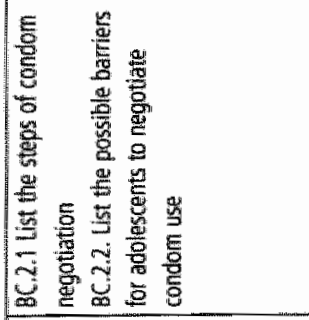 & 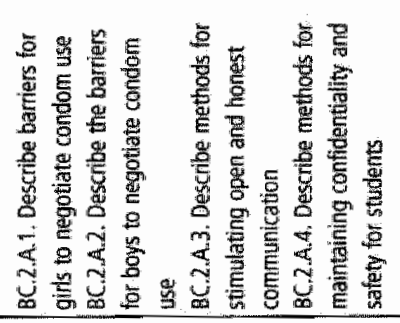 & 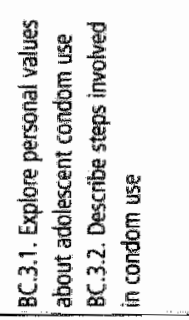 & 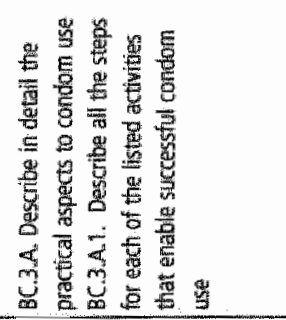 \\
\hline 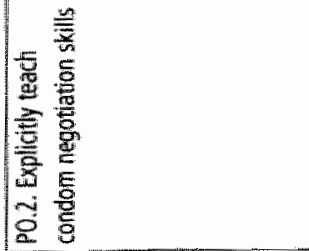 & 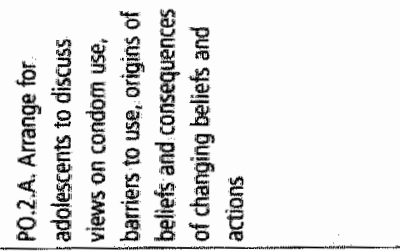 & 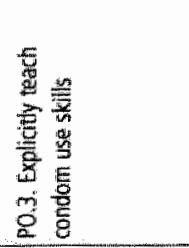 & 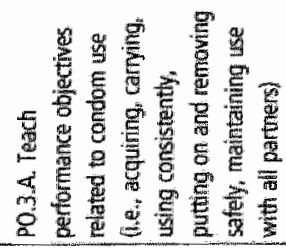 \\
\hline
\end{tabular}




\begin{tabular}{|c|c|c|c|c|}
\hline 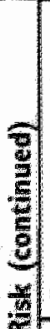 & 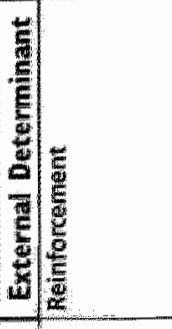 & & 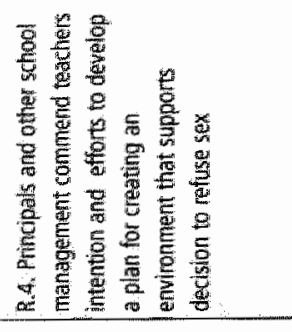 & \\
\hline $\begin{array}{l}2 \\
2 \\
3 \\
\frac{2}{2} \\
\frac{9}{2}\end{array}$ & $\underline{\underline{E}}$ & 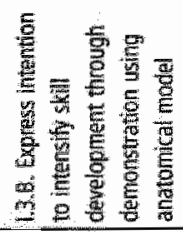 & 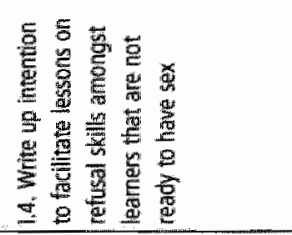 & \\
\hline 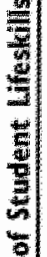 & 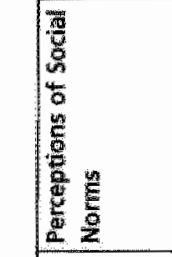 & 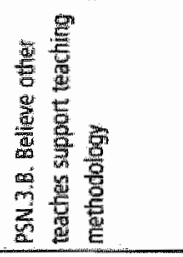 & 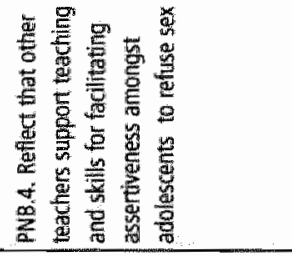 & \\
\hline 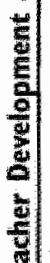 & 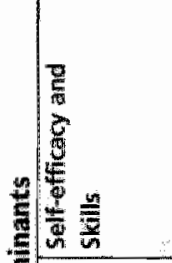 & 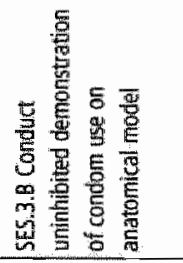 & 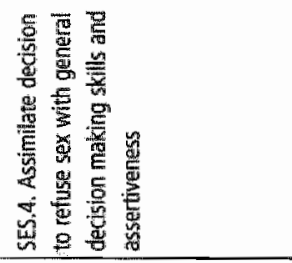 & 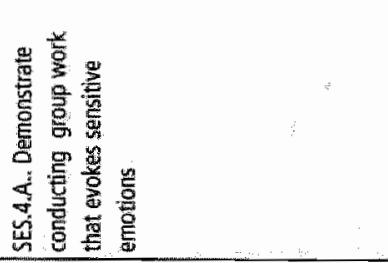 \\
\hline 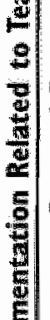 & 焉| & 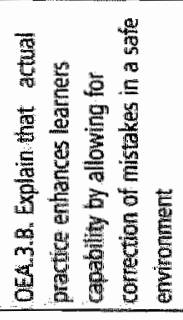 & 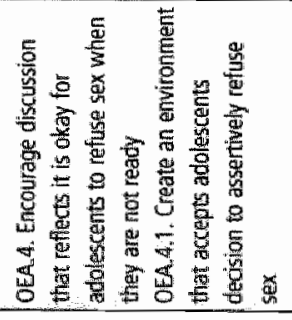 & 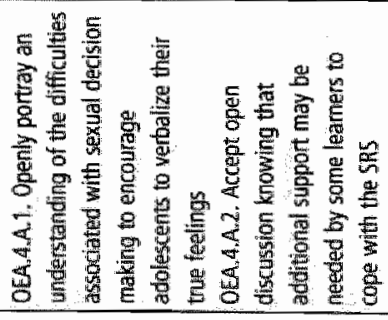 \\
\hline 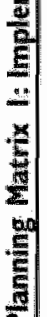 & 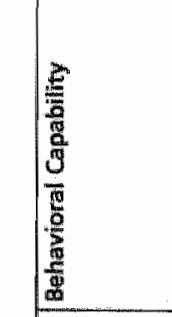 & 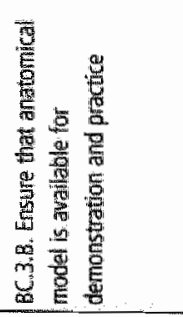 & 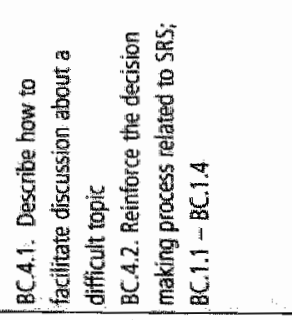 & 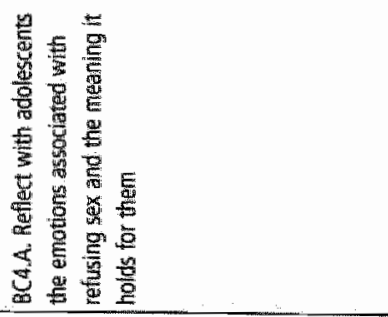 \\
\hline $\begin{array}{l}\bar{a} \\
- \\
\frac{4}{5}\end{array}$ & 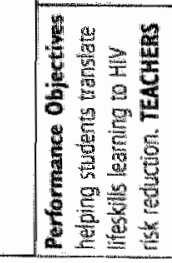 & 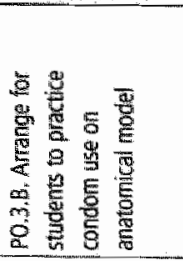 & 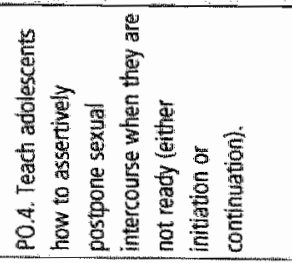 & 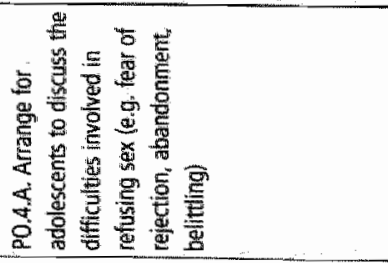 \\
\hline
\end{tabular}




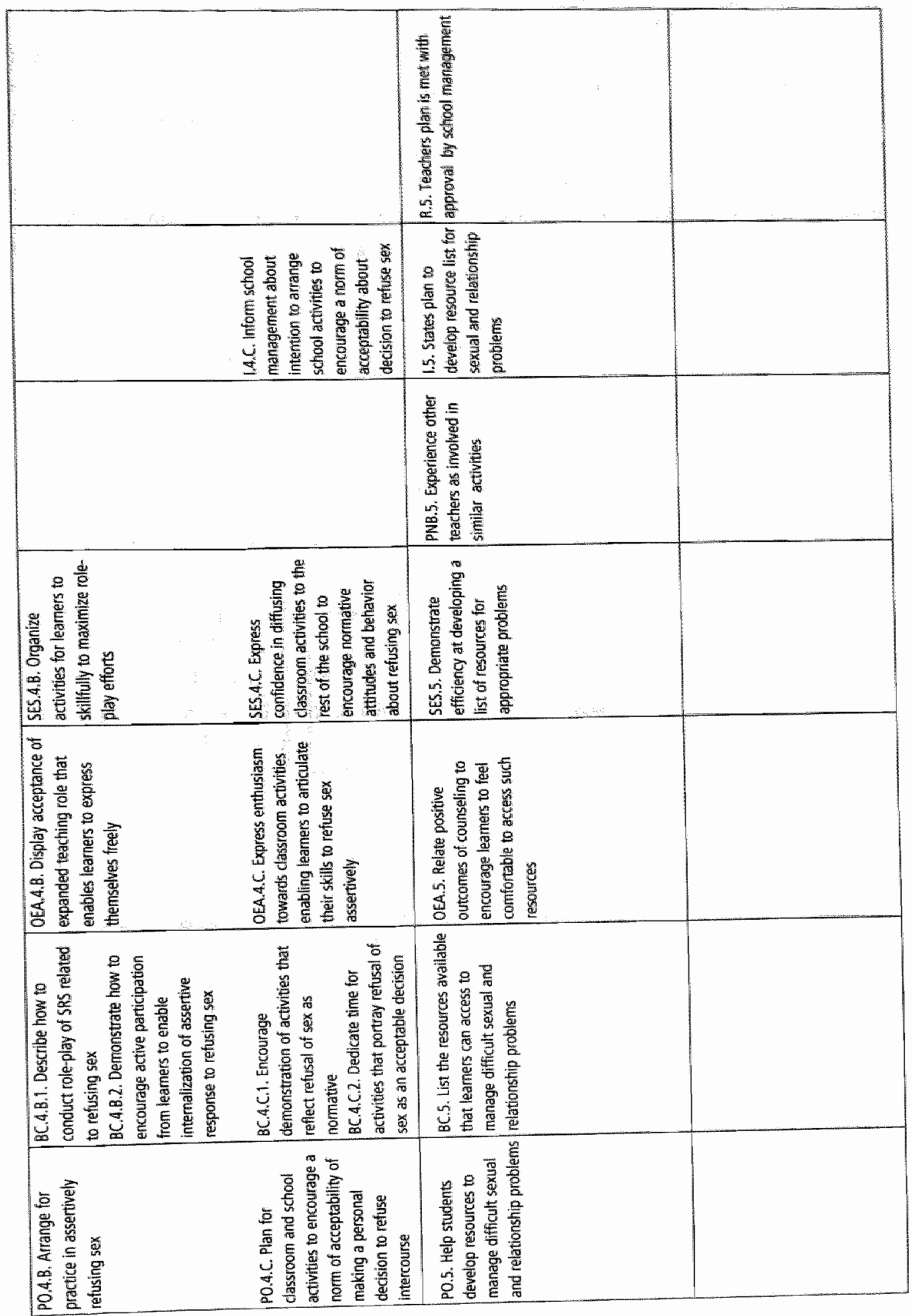




\section{Enable Implementation}

Table 2 presents a second aid to enabling fuller implementation of the program and addresses the principals" role in contextualizing the LHAP within the school curriculum and broader school environment. The principal has a firm hand in formalizing and setting up such a context. Changes to the context will effect adequate teacher implementation through the devellopment of policy. that places the LHAP on the timetable and provision of time that allows for capacity development of fellow teachers by trained teachers. This will provide the necessary support that teachers need to fully implement the programme in addition to the skills training they have received.

\section{Emphasis on Social Environment: School, Parents and Community}

The final major recommendation has to do with the grounding of the program in an effort to make the school and the wider communities more hospitable to adolescent safer sex behaviour. This will enable learners can express themselves, make intentions and plans and change behaviour either toward delay in sexual debut, secondary abstinence, decrease in partners and use of condoms. The original program seemed to intend that teachers would perform capacity development roles in their schools. However, there might not have been sufficient consideration of what teachers were really being asked to do and the complexity of the undertaking. Figure 2 depicts a recommendation for a slight expansion of this role so that teachers are not only expected to train other teachers but also to develop both teacher and community support for and evaluation of the effort. Table 3 suggests the requirements of this expansion. For example teachers need to have the skills to set up training meetings for other teachers and information sharing meetings for parents and the wider community. They also need to develop themselves as role models for HIV risk reduction. 







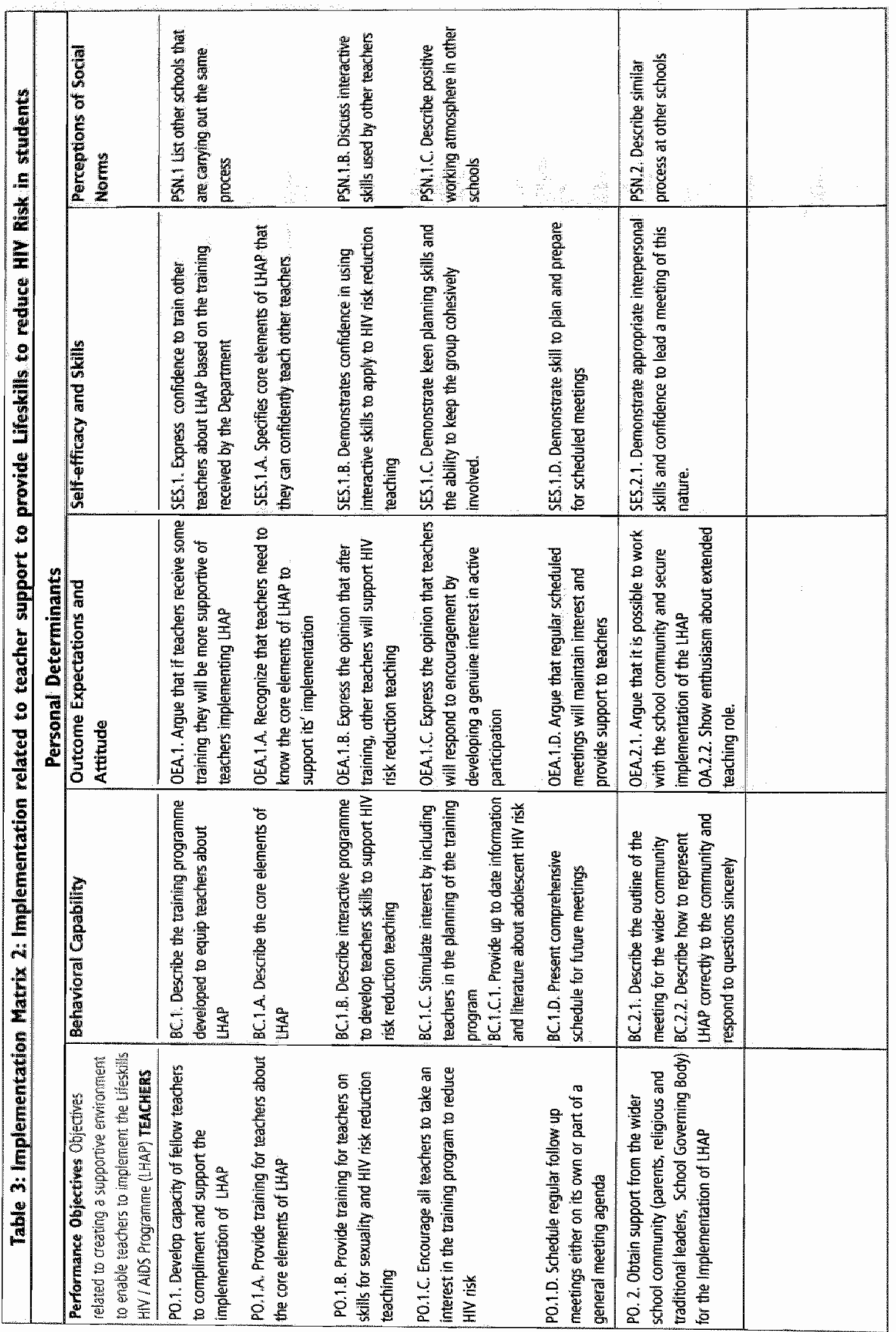




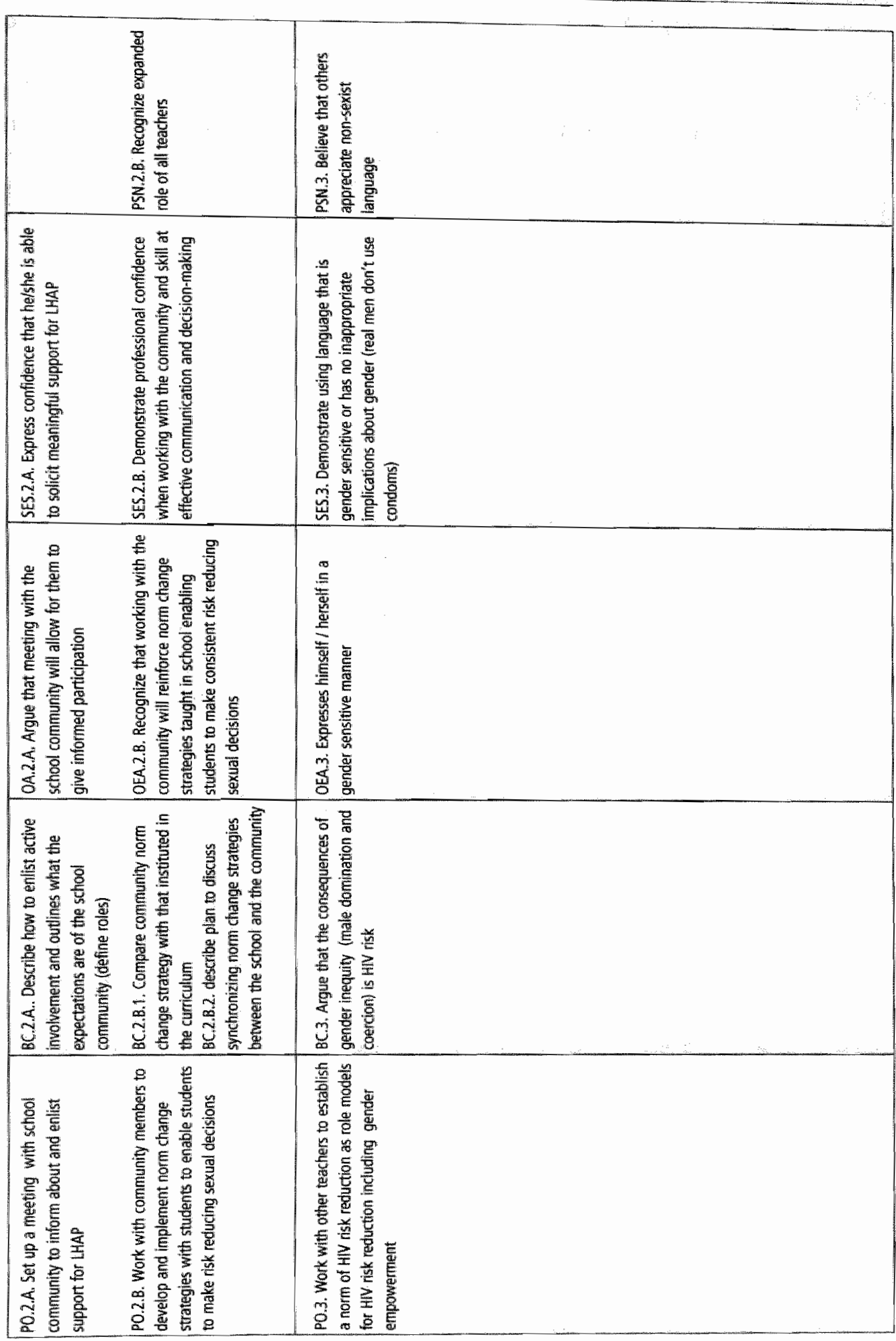


We recognize that these recommendations do not go as far toward participatory development as Campbell and MacPhail (2002) have suggested. However, it may be an achievable beginning. It is embracing existing supports and infra-structure with slight modifications to meet the identified gaps in implementation. This aspect of implementation however calls for specific behaviours or behaviour change on the part of principals and teachers. In the day to day operations of the school Fullen (2006) recognised that no amount of professional change in individuals will have an impact on student achievement if certain organisational features are not in place. Several strategies are advocated to get schools organised and the core element behind well functioning schools is believed to be the task of the school heads. They are the "human face behind any reform" and have to sensitively engage their staff to buy into the need for change. Any form of school reform raises questions from the teachers and altering teacher behaviour requires exposure to various strategies and skills such as presentations, demonstrations, modelling, and peer coaching (Norman, 2006; Fullan, 2006).

\section{Recommendations for the next wave of program evaluation}

Programme evaluation needs to be directed to the recommendations made for refocusing the LHAP which were mainly measures that will enhance teacher skill development to reduce student HIV risk and improve programme implementation through increased support by the principals, fellow teachers and the community.

\section{Measuring Program Process as a Part of Implementation}

An evaluation plan monitoring the processes involved in implementation, early in the programme delivery, will provide information about the extent to which programme implementation takes place and what the possible facilitating and inhibiting factors to implementation are. This can be done through qualitative research methods, focus groups and interviews with the trained teachers, principals and fellow teachers to assess their experience of the implementation and allowing for adjustments to be made accordingly. Such process evaluation can be built into the teachers' work plan and continuously used to refine the issues related to programme implementation.

\section{Measuring Mediating Variables}

Measuring the mediating variables at different times in the implementation process allows for comparisons to be made regarding, for example, changes in the learners' skill development or knowledge level. The design and methodology needs to be rigorous so that appropriate deductions may be made. In both the studies by Visser and colleagues (2004) and Magnani and colleagues (2005) it was difficult to attribute the changes found to the programme possibly 
due to poor study design. The mediating variables or determinants of behaviour may be evaluated quantitatively, through a self administered questionnaire, to determine the effect of the programme on specific outcome variables. The questionnaire needs to include questions that relate to the refocused skins component of the programme such as the application of lifeskills (decisionmaking) in sexual risk situations and self-efficacy related to condom use (acquiring a condom, carrying a condom and consistently using a condom). The evaluation question will be guided by the performance matrix developed and needs to measure the specific skill or aspect of the construct that is targeted. in terms of the behaviour to be achieved.

\section{Summary and Conclusions}

The risk model depicts several social ${ }_{r}$ environmental, cognitive and behavioural factors that contribute to the three very specific behaviours (early initiation of sex, unprotected sexual intercourse and multiple sexual partners) that lead to HIV transmission. The logic model depicts the extent to which implementation to address student HIV risk behaviours have been met following a review of three evaluations undertaken on the South African school-based Lifeskills HIV/AIDS Programme. The areas that showed the least implementation guided the focus for revision. These areas pertained to the actual delivery and content of the programme. The delivery was ineffective at two levels; (1) teachers felt inadequately prepared to translate the lifeskills behaviours to HIV risk reduction situations and (2) school management (principals) felt pressured to concede to the competing needs of the curriculum resulting in teachers not fully implementing the programme. These barriers to implementation are not uncommon and have been found to hinder teacher implementation for the reasons reported on in this evaluation, lack of time, resources and content delivery requiring more innovative teaching methodology (Kealey, Peterson, Gaul, \& Dinh, 2000). The implementation matrices developed for the teachers and the principals serves as a starting point for addressing the gaps in programme delivery. Delivery of a skill based HIV risk reduction programme may be new to many schools and requires on-going monitoring and evaluation.

The suggested revisions in the program will enable the program to meet the standards for sex education and health promotion by developing the skills that teachers need to facilitate risk reducing HIV behaviours in adolescents like decision-making in sexual risk situations and condom negotiating skills. The recommendation for principal development will enable the work of the teachers by addressing the functional aspects of the programme delivery that is by accommodating the lessons on the time-table and soliciting the support of other teachers and the community. 


\section{References}

Abdool Karim, S. 5., Abdool Karim, Q. Preston-Whyte, E. \& Sankar, N. (1992). Reasons for lack of condom use arnong high school leamers. SAM/1.82, 107.110.

Albarracin, D. johnson, B. T. Fishbein .M. \& Muellerleile, P. A. (2001). Theories of Reasoned Action and Planned Behavior as Models of Condom Use: A Meta-Analysis. Psychologicol Bulletin, 127(1), 142,161.

Bandura. A. (1986). Socol foundotions of thought and action a Social Cognitive Theory. Englewood Cliffs. N: Prentice-Hall.

Bartholomew, L. K. Shegog, R., Parcel, G. S., Gold, R. S. Fernandez, M, Czyzewski, D I., Sockrider, M. M. \& Berlin, N. (2000). Watch, Discower, Think, and Act: a model for patient education program development. Potient Edicotion and Counseling, 39, $253-268$.

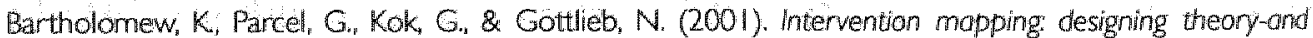
evidence-bosed heolth promotion programs. Mountoin View, CA: Maylield.

Bartholomew, L. K. Parcel. G. S. Kok, G. \& Gottlieb, N. (in Press 2006). Planning Health Promotion Progirams: An Intervention Mapping Approach (2nd ed.). Jossey-Bass, San Francisco.

Brug, $f_{\text {n }}$ Oenema $A_{\text {, }}$ \& Ferreira 1 . (2005). Theory, evidence and Intervention Mapping to improve behavior nutrition and physical activity interventions. The Intemotional journol of Behoviord Nutrition and Physical Activity, $2: 2$.

Campbell, C. \& MacPhail, C. (2002). Peer education, gender and the development of critical consciousness: participatory HIV prevention by South African youth. Social Science and Medicine 55 . $331-345$.

Campbell, C., Foulis, C. A. Maimane, S. \& Sibiya, Z (2005). The impact of social emvironments on the effectiveness of youth prevention: A South African case study. AlDS Care. 17(4), 47|-478.

Departiment of Education, South Africa. (997). Curriculum 2005, Lifelong learning for the 2/st century. Absolutely Media Marketing.

Department of Education, Soutly Africa. (2005). Education Statistics in South Africo ot o Glonce in 2003. Department of Education.

Department of Health. (2004). National HN And Syphilis Antenatal Sero-Prevalence Survey in South Africa. Department of Health.

Eaton, L. Flisher, A. I; \& Aaro, L. E. (2003). Unsafe sexual behaviour in South African adolescents. Sociol Science and Medicine, 56, 149-165.

Hisher, A. I. Roberts, M. M., \& Blignaut, R. J. (1992). Youth attending Cape Peninsulla day hospitalls. SAMJ. Vol 82.

Flisher, A. I. Reddy, P. Muller. M., \& Lomband C. (2003). Sexual behaviour of Cape Town high-school learners. 5AM/, 93(7).

Fullan, M. (2006). The nole of the head in school improwement. [Online] available: http:/ accessed, 9 th January, 2006.

James, 5. Reddy, S. P. Taylor, M. \& Jinabhai, C.C. (2004). Young people, HWVIAIDSiSTIs and sexuality in South Africa: the gap between awareness and behaviour. Acto Poediatr, $92,1-7$.

Jarnes, S. Reddy, S. P. Ruiter, R. A. C., Taylor; M., Jinabhai, C. C., Van Empelen, P., \& Van den Borne, B. (2005). The effects of a systematically developed photo-nowella on knowledge, attitudes communication and behavioural intentions with respect to sexually transmitted infections among secondary school learners in South Africa. Health Promotion intemotionol, 20(2).

James, S. Redidy, S. P., Ruiter, R. A. C., \& Van den Bome, B. In Review. The Impact of a HIV and AlDS Lifeskills Programme on Secondary School Students in KwaZulu-Natal, South Africa.

lewkes, R. K., Levin, J. B., \& Penn-Kekana, L. (2003). Gender inequalities, intimate partner violence and HW preventive practices: findings of a South African cross-sectional study. Social Science \& Medicine, 56 , 125.134.

Green: L. W. \& Kreuter, M. W. (2005). Heolth Program Plonwing: An Educotional Ecological Approach. 4th ed. McGraw-Hill, New York.

Kealey, K. Peterson, A.V., Gaul, M. A. \& Dinh, K.T. (2000). Teacher Training as a Behavior Change Process: Principles and Results from a Longitudinal Study Health Educotion \& Behovior, 27(1), 64-81.

Kirby D. (2002). Effective Appraaches to Reducing Adolescent Unprotected Sex, Pregnancy and Childbearing. The joumd of Sex Resecrch, 39(1), 51-57. 
Macintyre, K. Rutenberg, N., Brown, l. \& Karim, A. (2004). Understanding Perceptions of HV Risk Among Adolescents in KwaZulu-Natal. AIDS and Behowour, 8(3), $237-250$.

MacPhail, C, \& Campbell, C. (2001) "I think condoms are good but, aai, I hate those things": condom use among adolescents and adolescents in a Southern African township. Socid Science \& Medicine, 52 , $1613-1627$

Magnani, R, Macintyre, $K$, Karim, A. M. Brown, L, \& Hutchinson, P. (2005). The impact of life skillis education on adolescent sexual risk behaviours in KwaZulu-Natal, South Africa. Joumal of Adolescent Heatth, 36, 289-304.

Mandela Foundation/HSRC. (2002). South Africon Notionol HN Prevolence, behaviound risks and mass media: Household Survey 2002. Cape Town: Human Sciences Research Council Publishers.

Meyer-Weitz, A, Reddy P., Weijts, P., Van den Bome, B., Kok, G. \& Pietersen, J. (1999). Risky sexual behaviours of potients with sexuolly transmitted diseases in South Africo: Implications for interventions. Cited in Sense and Sensibilities. Medical Research Council.

Nomman, S. I. (2006). The Human Face of School Reform. [Online] Available: http:/ ummmationalforum.com, accessed, 9th January, 2006.

Pettifor, A. E., Measham, D. M., Rees, H.V., \& Padian, N. S. (2004). Sexual Power and HIV Risk, South Africa. Emerging infectious Diseases. Vol. 10, No. II, [Online] available: http//wmwcdc.gov/ncidod/EID/ voll Onoll 1/04-0252htm, accessed 13th December 2005

Pettifor, A. E., Rees, H. V., Kleinschmidt, I, Steffenson, A. E, MacPhail, C., Hongwa- Madikizela, L, Vermaak, K., \&. Padian, N. S. (2005). Young people's sexual health in South Africa: HIV prevalence and sexual behaviors from a nationally representative household survey. ADS, 19, 1525-1534.

Pettifor, A. E. Kleinschmidt, I., Levin, J., Rees, H.V. MacPhail, C. Madikezela- Hongwa, L., Vermaak, K., Napier. G. Stevens, W. \& Padian, N. S. (2005). A Community-Based Study to Examine the Effect of a Youth HIV Prevention Intervention on Young People Aged 15-24 in South Africa. Results of the Beseline Survey. [Online] Available: http:/www.comminit.com/africa/evaluations/evaluation2005/evaluation161. html, accessed, 9th December 2005.

Reddy, P. Meyer-Weitz, A. Van den Bome, B., Kok, G. (2000). Determinants of Condom-use behavior among STD clinic attenders in South Africa, int $\rfloor$ STI and ADS, $1 /(8)$.

Reddy, P., James, S. \& McCauley, A. (2003). Progromming for HIV Prevention in South African Schools: A Report on Pragram Implementation. Cape Town: Medical Research Council.

Reddy, S. P., Panday, S., Swart, D., Jinabhai, C. C., Amosun, S. L., James, S., Monyeki, K. D., Stevens, G., Morojele, N., Kambaran, N. S., Orrardien, R. G., Van den Bome, H.W. (2003). Umthenthe Uhlobo Usamilo - The South African Youth Risk Behowiour Survey 2002. Cape Town: South African Medical Research Council.

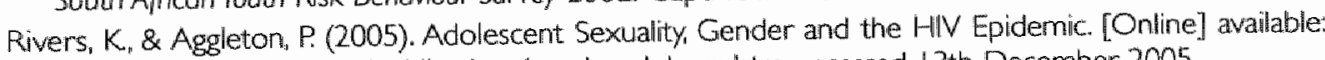
http://mww.undp.org/hiv/publications/genderadolesce.htm, accessed $\| 3$ th December 2005.

Schaalma, H. P. Abraham, C., Gillmore M. Ra \& Kok, G. (2004). Sex Education as Health Promotion: What Does it Take? Archives of Sexual Behowior, 33(3), 259-26\%.

Sineeran, P. Abraham, C., \& Obell, S. (1999). Psychosocial Correlates of Heterosexual Condom Use: A Meta-Analysis. Psychologicol Bulletin, 125(1), 90-132.

Simbayi, L. C., Chauveau, J., \& Shisana, O. (2004). Behavioural responses of South African youth to the HIV/AIDS epidemic: a nationwide survey. AIDS Core, 16(5), 605-618.

Simbay, L. Kalichman, S. C., Jooste, S. Cherry, C. Mfecane, S. \& Cain, D (2005). Risk Fartors for HIV-AIDS Among Youth in Cape Town, South Africa. ADS and Behowior, 9(1), 53-61,

Taylor, M., Dlarnini, S. B., Kagoro, H. Jinabhai, C. C., \& de Vries, H. (2003) Understanding High School Students' Risk Behaviors to Help Reduce the HIVIAIDS Epidemic in KwaZulu-Natal, South Africa. journal of 5 chool Heath, 73(3), 97-100.

Tortolero, S. R. Markham, C. M. Parcel, G. S. Peters, R. J. Escobar-Chaves, S. L., Basen- Engquist, K. \& Lewis, H. L. (2005). Using Intervention Mapping to Adapt an Effective HIV, Sexually Transinitted Disease; and Pregnancy Prevention Program for High-Risk Minority Youth. Heolth Promotion Proctice, 6(3), 286-298.

Varga, C. A. (1997). Sexual decisionmaking and regotiation in the midst of ADS youth in KwaZulu Natal, South Africa. Heath Tronsition Review; Supplement 3 to Vol. 7, 45-67.

Visser, M. J. Schoeman. J. B., \& Perold, J. J. (2004). Evaluation of HV I AlDS Prevention in South African Schools. Journal of Health Psychalogy $9(2), 263-280$. 
The Ewaluation of HW and ADS Interventions in Secondary Schools in South Africa: recommendations 
Q

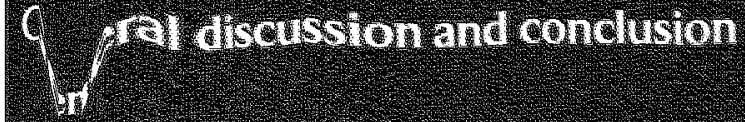




\section{General discussion and conclusion}

This thesis detalls the reported sexual behaviour, knowledge and perceptions regarding sexual behaviour of a specific target group at a given point in time, in the context of their exposure to educational HIV and AIDS messages via several sources (media, family and friends) and following the evaluation of two types of educational interventions about sexually transmitted infections including HIV and AIDS. Both of these interventions (i.e., single exposure to print media and an enhanced teacher-driven lifeskills programme focussing on HIV and AIDS) were developed in response to a growing need to address the HIV and AIDS issue amongst young people and the population at large in South Africa.

A range of literature at different times calling for the development of sexuality programmes that are more skills based, more comprehensive and outlining the core tenets of sexual behaviour programmes that have been known to be effective probably informed the development of a number of programmes within South Africa. However, a lack of information about the development and evaluation of such educational material made it difficult to comment on the effect of the education on intended recipients or on the quality of the educational material. It is probably for this reason that little is known about the development of the KZN Lifeskills HIV/AIDS programme. It has all the core topics that are thought to be effective in addressing sexual behaviour change but lacks the explicit theoretical underpinnings related to behaviour change in its contents, lesson planning and strategies for implementation for a curriculum of this nature as well as a rigorous evaluation of its effectiveness.

In view of the lack of evaluation carried out on educational material generally, and that the KZN Lifeskills HIV/AIDS programme was being formally introduced into the curriculum, it became imperative that an evaluation be carried out on it despite the lack of information on its development and theoretical underpinnings. In addition to providing crucial information on the learners' responses following exposure to general HIV and AIDS awareness programmes and the two interventions namely the print media intervention Laduma and the KZN Lifeskills HIV/AIDS programme, this thesis also aims to analyse the implementation of the Lifeskills HIV/AIDS programme. By doing an analysis of the findings of the latter evaluation together with that of other evaluation studies about the Lifeskills HIV/AIDS programme, suggestions for improving the programme are made that serve as a starting point for programme developers to refocus their effort (see Chapter 6).

The learners across all the studies reported on in this thesis were almost all Zulu speaking, were in grades $8-11$ and ranged in ages from 15-21 years. 


\section{Part 1: Cross-sectional Studies}

Part 1 comprises of two chapters, chapter 2 and chapter 3 . In Chapter 2 the responses of the learners in a cross-sectional study carried out amongst grade 11 learners were presented. The findings showed that learners already had a substantial amount of knowledge about the facts related to HIV and AIDS and they reported that such knowledge is gained from their day to day encounters with the media, friends, family, campaigns and some education in schools targeting sexual behaviour. The findings also showed that learners scored less highly for variables regarding more specific information for example, if they would know that they had an STI or if they would know when and where to go for treatment. Statements related to their attitude to condom use again showed that they scored high on the expected benefits of condom use (condoms prevent STIs, pregnancy and show you care about your partner's health) but less positively on the more personal statements like "condoms take the fun out of sex" and "condoms are embarrassing to use and can harm the body". Learners" felt that in general STIs were a big problem but reported feeling less vulnerable in the short term than the long term and less affected than their friends.

The findings related to sexual behaviour showed that significantly more male than female learners responded positively to ever having had sex and of those that reported having had sex about $15 \%$ reported always having used a condom. Further, the findings showed that there was a gender difference with regard to what male and female learners communicated about to their friends. Males talked more about having sex and condom use and females talked more about HIV and AIDS.

The results of this study further highlight some important factors that need to be considered in future intervention development such as their perception of vulnerability to contracting HIV and the gender differences related to communication and sexual behaviour. Adolescents are generally seen as a healthy group but it needs to be recognised that the risks they take such as indulging in unprotected sex have consequences later on in life. Therefore an investment in well thought through programmes will have large payoffs later (Burt, Zweig, \& Roman, 2002). As this study was carried out at a time when the emphasis was largely on information dissemination and awareness raising about the HIV infection, the findings of high levels of knowledge maybe explained. However the main conclusion drawn in this study calls for reorienting educational efforts to address behaviour change in a meaningful and coherent manner that is reflective of an understanding of the elements that allow for systematic planned development and implementation of interventions.

Chapter 3 presents the responses of a group of grade 8-11 learners where the 
specific association of alcohol and substance use with sexual behaviour was investigated. An unexpected finding amongst those learners that reported being sexually active was that those that reported using alcohol in the past month were also more likely to report using condoms. This finding is contrary to some studies in which it was found that alcohol use was associated with more risky sexual behaviour Uemmott \& Jemmott, 1993; Ford \& Norris, 1994; Cooper, Peirce, Huselid, 1994) and non-use of condoms amongst a group of adolescent detainees and inner city junior high school learners (Kingree, Braithwaite, \& Woodring, 2000). However the finding was supported by a study on a subgroup of adolescents who were likely to use condoms when drinking alcohol (Hingson et al., 1990 cited in Ford \& Norris, 1994) and to a lesser extent by studies reviewed in Donavan and McEwan, (1995) that reported no association between alcohol use and risky sex in event-specific sexual encounters involving alcohol use.

The contradictory results are hard to explain and in the study by Kingree et al., (2000) a social desirability response was refuted as it was thought unlikely that it would be more desirable to report the use of one substance (marijuana) and not the other (alcohol) with regard to unprotected sex. In the most part the contradictory results reported regarding alcohol use and unsafe sexual practices have been attributed to methodological issues such as not taking the context of the relationship into account like whether it is a monogamous relationship, whether drinking occurred at or before having sex, whether drinking occurred with the sexual partner or friends, the amount of alcohol consumed or the underlying personality of the respondents (Cooper et al., 1994; Donavan \& McEwan, 1995; Ford \& Norris, 1994). These findings as well as the findings reported on in this thesis (see chapter 3 ) show the need for further research that explains the association between condom use and alcohol use amongst learners, taking into account factors like personality and the timing between alcohol use and the sexual episode.

Also, learners that reported having had HIV and AIDS lessons in the class were more likely to report using condoms when having sex. It is possible that apart from increasing knowledge and creating awareness that the lessons addressed determinants pertinent to condom using behaviour such as perceived personal vulnerability and attitude to condom use.

A striking finding was that learners that had drunk alcohol and also used drugs were much more likely to be sexually active (63\%) compared to those learners that used alcohol only ( $43 \%$ ) or only used drugs $(47 \%)$ or did not use alcohol or drugs (27\%). Other studies that found similar associations have explained this behaviour in several ways. In particular amongst adolescents (Wills, Gibbons, Gerrard, Murry, \& Brody, 2003) found a significant correlation 
of substance use and sexual behaviour at a young age when levels of these behaviours were relatively low. They also found a substantial correlation between peers substance use and sexual behaviour and concluded that a number of psychosocial factors like attitude and perception of peers sexual behaviour contribute to the correlation of sexual behaviour and substance use in early adolescence. In a study amongst Black male adolescents Jemmott and Jemmott (1993) argued that, in addition to the explanation that alcohol and drug use clouds good judgement and logical thinking and provides an excuse for engaging in risky sexual behaviour a second explanation may be plausible. The problem behaviour theory that adolescents that engage in one type of problem behaviour may be prone to other problem behaviours was presented as a second explanation. Following this line of thinking they surmise that adolescents who use alcohol and drugs are more likely to engage in more frequent sexual activity as compared to more risky, different sexual behaviour. Therefore they further contend that the risk of unprotected sex may be controlled if the amount of sex is controlled. These explanations are important when considering the development of preventive interventions as it determines what needs to be addressed. Current education focuses blankly on condom use and negates the fact that for some adolescents, alcohol and drug use in addition, may be the determinant to target thereby reducing sexual activity and subsequently risky or unprotected sex.

These findings that allude to behaviours being interrelated and the findings in chapter 2 where one is alerted to the discrepancy between unprotected sexual behaviour and improved knowledge and acceptance of condoms beckons the need for an expansive approach to sex education that reflects an understanding of the strategies that target behaviour change (Harrison, Smit, \& Meyer, 2000; Svenson, Carmel, \& Varnhagen, 1997; Salt, Boyle, \& Ives, 1997) as well as cautions one to the ineffectiveness of addressing these behaviours or determinants independently of each other. HIV and AIDS programmes in schools therefore need to more stringently consider and incorporate the determinants and factors associated with protective sexual behaviour as indicated by several studies, for example age, gender, attitude to condom use, self-efficacy related to condom use, personal vulnerability to HIV infection and alcohol and drug use (Reddy, Meyer, Weitz, Van den Borne, \& Kok, 2000; Meyer-Weitz, Reddy, Weijts, Van den Borne, Kok, \& Pietersen, 1999; Macintyre, Rutenberg, Brown, \& Karim, 2004; James, Ruiter, Taylor, Jinabhai, Van Empelen, \& Van den Borne, 2005).

The studies presented in chapters 2 and 3 were carried out in the context of on-going educational attempts through a variety of media campaigns, regular advertising about condom use when having sex and television programmes 
which have HIV and AIDS as a theme. However, the lack of information about the development, implementation and evaluation of this type of media education as well as the cross-sectional nature of the study design make it difficult to attribute the findings to the specific media interventions. It is possible, however, that this type of general exposure to information serves to heighten ones awareness, knowledge and attitude to condom use but in the most part does little to translate these factors into protective action, serving to confirm the theory that knowledge and a positive attitude towards condom use are prerequisites but not sufficient to realize actual behaviour change (Prewitt, 1989; Petosa \& Wessinger, 1990).

\section{Part Two: Intervention Studies}

Part two comprises of two chapters. In chapters 4 and 5 the evaluation of two types of interventions are presented. Chapter 4 details the impact of a single reading of a photo-novella (Laduma) on grade 11 learners with regard to their knowledge, attitudes, communication and behavioural intentions with respect to sexually transmitted infections. In chapter 5 the evaluation was carried out on an enhanced teacher-driven programme, which was implemented amongst grade 9 learners over 12 lessons, and assessed the effect on their knowledge of HIV infection; attitudes to condom use and people living with HIV and AIDS, perceived social support, confidence to assert oneself, perceptions about sexual behaviour $r_{i}$ communication about HIV and AIDS and safer sex, reported sexual behaviour, condom use and intended sexual behaviour.

In reviewing the literature related to these studies ones attention is drawn to the lack of evaluation done on educational material whether it is print media or teacher-driven interventions within the school context in South Africa. Where interventions have been evaluated they lacked the methodological rigour required for sound evaluation for example the use of an appropriate control group, the collection of pre-intervention measures and random sampling (Gallant \& Maticka-Tyndale, 2004; Kaaya, Flisher, Mbwambo, Schaalma, Aaro, \& Klepp, 2002a; Kaaya, Mukoma, Flisher, \& Klepp, 2002b; Schaalma, Kok, Abraham, Hospers, Klepp, \& Parcel, 2002). In both the evaluation studies reported on in this thesis such factors have been taken into account. Both the studies demonstrate the use of an experimental design with a pre-test multiple post-test experimental-control group design. The findings of these two different interventions showed that despite learners" high knowledge the interventions were able to increase their knowledge further. This indicates that there will always be a need for updated information (MacPhail \& Campbell, 2001) and its value can be enhanced by programmes that present information in combination with strategies that help to translate knowledge into behavioural action. 
The evaluation of Laduma as described in detail in chapter 4 showed that further to the effect found on knowledge the evaluation also found an impact on learners in the intervention group with regard to attitude towards condom use and towards persons with a sexually transmitted infection (STI) or HIV /AIDS. At both the post tests the learners in the intervention group showed more positive attitudes to condom use than the learners in the control group and male learners in the intervention group showed a more positive attitude towards people with STIs or HIV/AIDS than female learners or male learners in the control group.

Laduma did not have an effect on reported sexual behaviour, condom use or communication with a boy or girlfriend and with other friends or parents about sexually transmitted infections and HIV and AIDS or about prevention of infection. These findings indicate that while a lack of change was found in reported behaviours like communication, sexual behaviour and condom use Laduma may be appropriate to influence some of the important elements that are considered prerequisites to behaviour change but not sufficient to change behaviour. The strength of Laduma lies in the fact that it was developed in a systematic and participatory way and considered all the communication issues relevant to message delivery for example the choice of models and language used was that which the learners could identify with and the content was developed through a participatory process and included issues that arose out of focus group discussions with young people and the research team. Print media like Laduma therefore, need to be used in a targeted manner and for maximum effect preferably in conjunction with other strategies that are known to effect actual behaviour change for example modelling and enactment of the desired behaviour in a safe environment through guided practice (Bandura, 1997). Further such programmes will be enhanced when there is a clear focus on the desired behaviour or outcome (Kirby, 1997).

The evaluation of the enhanced teacher driven programme detailed in chapter 5, apart from knowledge, did not show any significant effect on any of the variables tested for, such as attitude towards condom use, attitude towards people living with AIDS, perceived social support from significant others like family, friends and school teachers, confidence to assert oneseif, perceptions of sexual behaviour, communication about HIV and AIDS and safer sex, reported sexual behaviour, condom use and intention about sexual behaviour. This may, in part, be due to the fact that the information about the degree of programme implementation by teachers in the intervention group showed that teachers implemented the programme to varying extents in the different schools. Some of the teachers implemented the programme every week for many weeks and covered all 11 topics (full implementation) while others implemented the 
programme every week for a few weeks or less often and covered only 7 or less of the 11 topics (partial implementation).

Findings from the exploratory analysis carried out amongst the two intervention groups (full and partial) and the control group showed reasonably more significant results than the original results. However, the significant results were confined to learners in the full implementation group and importantly there were no significant differences between the control and partial implementation groups. Similar to the effects of Laduma; the full implementation was able to impact reported sexual behaviour and condom use immediately after the intervention (T2) and on learners" knowledge, perceptions of sexual behaviour, perceived social support at the second followup measure four months after the intervention (T3). The full implementation group, however, despite having impacted on some relevant cognitive determinants was unable to sustain a change in condom using behaviour at T3. Due to the lack of randomisation between the full and partial intervention groups the effects found cannot be attributed entirely to the intervention, however it may mean that the enhanced results found when the programme was fully implemented resulted from a programme that was sufficient in content and well presented while the lack of results on other variables and sustained condom use behaviour may mean that despite motivation on the part of the teacher the programme may have lacked the relevant content and strategy to effect changes.

Furthermore, the programme was not systematically developed in a way that reflected for example, that the determinants of sexual behaviour addressed were based on empirical findings and theory. The process evaluation showed that even though the programme was intensive, the topics covered were diffuse, and there was no distinct strategy for addressing the behaviours (abstinence and condom use) in a specific way except by way of being mentioned. Teachers also reported feeling more comfortable with teaching lessons that were fact based and required didactic teaching, as compared to skills based and requiring, for example, role play (Reddy, James, \& McCauley, 2003). Behaviour change is about skill development therefore school-based programmes will benefit from teachers that are effectively trained on the relevant content, methods and strategies for facilitating lessons about particular behaviours. For example, the behavioural outcomes will need to be specifically set out and targeted (broken down into smaller units of activity), taking into account the determinants of the behaviour, based on theories that are known to influence the behaviour (Jemmott, Jemmott, \& Fong, 1998), as well as the methods and strategies that may be used to achieve the behaviour (Bartholomew, Parcel, Kok, \& Gottlieb, 2001; 2006). 
The limited findings of these studies, like other evaluation studies of schoolbased programmes, indicate that intervention development and implementation needs to be critically re-appraised (Swenson, Carmel, \& Varnhagen, 1997; Merson, Dayton, \& O'Reilly, 2000; Khun, Steinberg; \& Mathews, 1994). Schaalma et al., (2002) reviewed a range of intervention effectiveness studies and presented some of the factors that were identified in distinguishing effective interventions such as those having a sound theoretical base, sufficient contact time to influence behaviour change, clear statements of norms supporting the health behaviour and or disapproving the consequences of adverse behaviour as well as quality training for those delivering the programme. However, it is pointed out that these reviews may have limitations in the developing world context and a new levell of expertise may be required that looks at adaptation of such interventions that result in it being context specific in terms of the countries culture, social and economic situations. Further to address the paucity in evaluations carried out, all of these interventions need to be subjected to rigorous evaluation (Oakley, Fullerton, \& Holland, 1995).

\section{Part 3: Refocusing the Lifeskills HIV/AIDS Programme}

Chapter 6 presents the analysis of three evaluation studies of the Lifeskills HIV/AIDS Programme (James, Reddy, Ruiter, \& Van den Borne, under review; Visser, Schoeman, \& Perold, 2004; Magnani, Macintyre, Karim, Brown, \& Hutchinson, 2005). Due to the limited findings of the effect evaluations the aim of the chapter was to use the analyses of the process and effect evaluations to improve the programme. To begin with, a detailed model of sexual risk behaviours was developed using the available research on HIV/AIDS risk behaviours of South African youth. The model suggests that sexual risk behaviours are a complex problem that needs to be addressed taking the proximal and distal contexts that impact on such behaviours into account. The mapping of the analysis of the evaluations onto a logic model depicted the varying extents to which the intended programme inputs, programme outputs, potential determinants of behaviour and outcomes of the programme were implemented. The gaps in implementation that were identified were related mainly to aspects of teacher and principal implementation which formulated the foundation upon which the recommendations for improving the programme were developed. Using Intervention Mapping (IM) as a planning device (Bartholomew et al., 2001; 2006)., examples of rnatrices were developed that focused on teacher development related to the training for student lifeskills applied to HIV risk and principal development related to strengthening the environmental context (policy and teacher support) that will enable teachers to fully implement an improved programme. 
Visser et al., (2004) in their evaluation of the South African lifeskils programme in two specific districts in another province of the country, found that the implementation process was thwarted by organisational problems in the schools such as the lack of resources, lack of support of the principals and other teachers and conflicting goals in the educational system. The outcoms evaluation, despite having showed some positive change in knowledge aboul HIV and AIDS and protective behaviour, could not (possibly due tc methodological weakness) attribute this change to the programme. What they did identify in the programme from a systems theory point of view were fou major flaws. These were identified as: the content of the programme which relled heavily on the assumption that communication and education will resull in behaviour change; the choice of change agents, in this case the teachers, who were not equipped for all the tasks expected of them; the lack of participation cue to the programme being handed down by grovernment to the implementers: and, the lack of consultation with the implementers and recipients in the development of the programme and the capacity to change. The capacity to change referred to the creation of a climate within the education system conducive to implementing such a programme.

These findings are similar to that reported on by Varga and Shongwe (1999) about the Family Life and Guidance programmes addressing sexuality and teenage pregnancy in the early eighties and serves to confirm the lack of progress made in developing sexuality intervention programmes. This lack of progress is due possibly to both a lack of expertise in the area of sexual behaviour change and intervention development as well as major infrastructure issues within the Department of Education (e.g. poor integration of the curriculum into time-table and lack of resources). It highlights the urgency with which the barriers to effective intervention development need to be dealt with.

The suggested revisions for the Lifeskills HIV/AIDS Programme therefore, will enable the program inplementers to meet the standards for sex education and health promotion by developing the skills that teachers need to faclitate risk reducing HIV behaviours in adolescents like decision-making in sexual risk situations and condom negotiating skills. The recommendation for principal development will enable the work of the teachers by addressing the functional aspects of the programme delivery that is by accommodating the lessons on the time-table and soliciting the support of other teachers and the community.

\section{Implications of the Evaluations}

The evaluation of programmes serve to alert programme developers and evaluators to a range of issues such as whether the programme is meeting the preset objectives or not and if not what and where the shortfall is. It therefore serves 
as a guiding tool to improve or make programme adjustments depending on the type of evaluation carried out. In evaluating the wo studies in this thesis an opportunity for programme developers and the evaluators has arisen that calls for a critical re-look at the programme development implementation and evaluation.

From the evaluation point of view it needs to be conceded that even though the interventions were not grounded in theory, a questionnaite incorporating all the theoretical constructs like self-efficacy might have helped to better interpret the effects of the programme on outcome measures such as condom use. The questionnaire for the lifeskills programme in particular was in fack guided by the programme which was a given intervention that was not developed from a particular theoretical perspective. It did, however reflect some concepts that are borne out of theory like attitudes to condom use and people with HIV and ADS and perception of normative sexual behaviour. However, the lack of effects found related to sexual behaviour reflects the limitations of such unsystematically developed interventions that do not inculcate all the theoretical concepts and strategies required for behaviour change.

The latter concern is confirmed by the process evaluation of the lifeskills programme that showed that even though the teachers received the same training they differed markedly in their implementation of the programme. This indicates that programme implementation within a school requires more than a set of topics put together, training of teachers and the intention of addressing the problematic behaviour. It requires systematic development from the formative stages through to the implementation and evaluation stages.

South Africa may have had every reason to resort to quick fix solutions to its HIV and AIDS problem; however these evaluations and other studies confirm that it is not in the countries' best interest to continue to do so. A recent study by Simbayi and colleagues (2005) concluded that South African youth despite adequate general AIDS knowledge and risk sensitisation, still demonstrate high rates of sexual practices that place them at risk for HIV infection (Simbayl, Kalichman, Jooste, Cherry, Mfecane, \& Cain, 2005). Even more disconcerting was a study by Peltzer and Promtussananon (2005) among junior secondary school learners that found that knowledge of HIV and AIDS was poor in some areas and more satisfactory in other areas and generally not satisfactory enough to sustain adequate HIV and AIDS response in a context of high and widespread HIV and AIDS prevalence.

In the light of the findings of this thesis and the more current studies, it is evident that South Africa is in need of both an urgent and a truly systematic approach to HIV and AIDS curriculum development, implementation and evaluation. 


\section{Challenges for HIV and AIDS Education in South Africa}

South Africa is undeniably the country with the highest HIV prevalence in the world (UNAIDS, 2000). It is also one of the countries that have taken strides to address this issue. There are several policies in place that make HIV and AIDS education mandatory. An attempt to address this issue in whatever way plausible has been demonstrated. However, following some of the evaluations reported on, a critical look at the situation calls for a more coherent stance to be taken that effectively monitors the processes that go into developing and implementing effective programmes.

\section{The HIV and AIDS Curriculum Development}

In evaluating the KZN Lifeskills programme focusing on HIV and AIDS one of the first factors that come to light is that the programme was neither grounded in theory nor underpinned by evidence of the behaviour of young people. It was further not based on a coherent curriculum that standardised crucial elements pertaining to behaviour change and it would appear that the flexibility of the programme worked against achieving critical outcomes. While these are some of the challenges related to the pedagogic issues that need to be addressed in re-developing this programme, the overarching challenge that remains is that the development of the programme needs to be underpinned by sound theoretical and empirical evidence.

Chapter 6 outlines the process involved in identifying the gaps in the existing programme and the process of applying Intervention Mapping, a framework designed to provide systematic guidance to health promotion programme development, implementation and evaluation based on theoretical and empirical evidence (Bartholomew et al., 2001; 2006). In South Africa the major cause of HIV transmission is through unprotected heterosexual intercourse. In young people several determinants have been identified that predispose to unprotected sexual activity such as communication with ones partner, attitudes towards condom use and general self-efficacy in condom use (Reddy et al., 2000). Table 1 of Chapter 6 is an example of what teachers need to know to implement an intervention that addresses theses determinants and that aims to reduce HIV risk behaviour. Furthermore, the use of these determinants makes the programme more specific to the needs of the target group and helps to make the curriculum content more relevant and applicable. Such programmes need to be supported by the theories of behaviour change like the Health Belief Model, the Social Cognitive Model and theories of Planned Behaviour Change and Reasoned Action (Glanz \& Rimer, 1995) with the aim of reducing a specific behaviour or group of behaviours that impact on the HIV and AIDS prevalence. The core content and methodology employed to 
address these critical behavioural outcomes require that the curriculum be standardised across schools in terms of its delivery:

The strengths of the lifeskills programme, in keeping with a community health perspective of HIV and AIDS, is that the programme did have in its favour a training programme for teachers with the emphasis of providing such education within the milieu of community support. The school community, i.e. the school management, the school governing body, traditional leaders and healers, parents and educators were reached through workshops that served to inform, motivate and gain their support. This reinforces that various complex processes underlie the HIV and AIDS prevalence that extends beyond it being a personal medical condition. It in fact pervades all levels (individual, interpersonal and community) of an individuals' being (Visser et al., 2004).

\section{The Teacher Training}

It is a foregone conclusion that the effective delivery of the curriculum requires a well- designed training programme for educators that is engaging and allows for guided practice of activities that promote skill development like condom negotiation. The training programme needs to be semi-structured and interactive to give educators a chance to practice the skill of facilitating such education, as it may be markedly different from their usual manner of teaching and lesson delivery especially if they normally teach more academic subjects (Schenker \& Nyirenda, 2002). The critical challenge here is for curriculum planners to transcend the realms of traditional lesson planning and seek acceptance among teachers for innovative ways of presenting material which may at first appear daunting and as curriculum overload or extra to an already full work load.

Teachers need to gain confidence to enable them to use interactive, learnercentred methods which are beneficial for several reasons such as enabling young people to become involved in and responsible for their own learning, be active, learn faster and cover subjects more quickly and consider issues, choices and consequences. Teachers will need to be trained and gain experience that will enable them to dispense with pre-set texts and allow for learner input (Casey \& Thorn, 1999).

\section{The HIV and ADS Curriculum Implementation}

The evaluation of the teacher implementation revealed some astounding information in terms of differences in implementation. Some of this was reflective of larger institutional difficulties and others more personal to the teacher capability and preferences. The huge institutional problem in South African schools is evidenced in other studies as well (Visser et al., 2004; Harrison et al., 2000; Magnani et al., 2005, Macintyre et al., 2000) and one that needs to be addressed once again in a systematic way. 
Considering that there will be individual differences related to the educators skill to facilitate a topic that may be perceived as sensitive as well as manage large numbers of learners in the classroom, it is imperative that the curriculum provides clear objectives of the exercises, detailed lesson plans that emphasise the core material to be covered as well as suggestions for delivery in terms of methodology. This will ensure that at least the minimum criteria are met in a standardised and measurable way. This is important for programmes to be deemed effective as those that are not, appear to have compromised on providing more than one behavioural option (e.g., abstinence only programmes), skills that discourage early teenage sexual activity or that lacked clear guidelines for decision making (Casey \& Thorn, 1999).

The challenge of delivery of the programme at school level needs to be supported by an operational plan within the Department of Education that goes beyond inference to such education but assists the various districts to develop a working plan for each of the schools. Such a plan may be developed by finding an entry point to AIDS related education in the school curriculum by looking at the current curriculum more critically. The South African education system has been changed to inculcate a more critical outcomes based approach to education which presents policy-makers and curriculum planners with the opportunity to integrate lessons and seek out areas of skill that are common to various learning outcomes. Furthermore, the designated learning area called life orientation allows for health related education to be taught. A study carried out in Cape Town amongst teachers to asses the factors associated with HIV and AIDS implementation at schools showed that teachers who were involved in life orientation, trained in HIV and AIDS education or had a school policy about HIV and AIDS were more likely to teach HIV and AIDS (Boon, 2004).

An example of such an innovation which is not entirely new to the South African education system ${ }_{\imath}$ and which lifeskills education may use as an entry point and overarching tool to guide programme implementation is the concept of Health Promoting Schools or whole school development. This will serve as a map on which to charter lifeskills education and provide indicators (at school level) for the adequate measure of a policy plan, educational lesson plan, teacher training programme and the development of an environment conducive to lifeskills education that is supported by the community.

\section{Limitations of the studies}

The studies reported on in this thesis were conducted between 1999 and 2001. It is well documented that South Africa was moving into an epidemiological crisis during the nineties regarding HIV and AlDS. As large numbers of people were getting rapidly infected and there was no cure for the HIV infection there 
was an urgency to respond from a public health perspective. The early responses were thus immediate and based on epidemiological studies rather than a detalled understanding of the context which includes the complex socio-cultural, gender, economic aspects and as well as perceptions and beliefs at the individual level.

The studies in this dissertation were defined by the above response to HIV prevention of which the limitations will be discussed below. Each of the studies presented in this dissertation were commissioned either by the South African government or non-governmental organisations for the specific purpose of gaining an understanding of the prevalence of risk behaviours affecting young people as well as the usefulness of interventions that were being used at the time (Reddy, Panday, Swart, Jinabhai, James, \& Amosun et al., 2003; James et al., 2005; James et al., under review). A discussion of the limitations of the empirical studies is presented below.

Chapter 2 presents the analysis of quantitative data gathered through a cross sectional study that formed the baseline assessment for the evaluation of the print media intervention entitled Laduma. Methodologically it is a cross sectional study carried out in one district of KZN and the results can therefore not be generalised to the rest of the province or country. The questionnaire included the knowledge and attitude constructs and was guided by the focus of education delivered at the time, which was primarily information dissemination and awareness raising. A limitation of the study was that it did not use a theoretical framework and therefore omitted to explore all the determinants of the range of behaviours associated with sexual intercourse. Thus a determinant such as self efficacy with regard to acquiring and using condoms was not explored.

The data described in Chapter 3 is a sub set derived from a national epidemiology study, which reports on the prevalence rates of a range of risk behaviours. It is the first and only such national study amongst school-going youth in southern Africa and was commissioned by the South African government. The analysis of this study explores the associations of sexual behaviour with alcohol and substance use and recognises that there can be no causative attribution made between the factors investigated. The review of the South African literature on alcohol and substance use in schools provides epidemiological studies conducted primarily in the Western Cape using a cross sectional study design (Flisher, Roberts, \& Blignaut, 1992; Flisher, Reddy, Muller, \& Lombard, 2003). Further research in this area is indicated that lends itself to more rigorous evaluation.

The study design in Chapter 4 attempted to address all the aspects that are attributed to rigorous evaluation of interventions namely that it was a 
randomised control triall with pre and post test measures. The intervention was a given intervention that was systematically developed following consultation with health professionals, the research team and focus group session with young people from KZN and the Western Cape. It is unclear though what the explicit theoretical underpinnings used in develloping this intervention was. The study questionnaire perpetuated this limitation by addressing only those variables that were implicit in the intervention like attitude, gender norms and knowledge. It failled to explore all the determinants that are likely to lead to behaviour change like self efficacy to acquire and negotiate condom use.

Chapter 5 also presents a rigorously designed study that had a repeated measures design with randomisation of schools and learners into control and intervention groups. Like Laduma it had some of the elements of a sound intervention targeting sexual behaviour. $\mathrm{It}_{t}$ however, showed gaps regarding all the steps needed to adopt a new behaviour such as condom use. The gaps related to a lack of detailed explanation, demonstration and opportunity to role-play the new behaviour. The intervention would have benefited from a better application of methods and strategies targeting the adoption of a new behaviour. Once again the study questionnaire negated to address all the constructs from a theoretical perspective resulting in gaps in the data collected and a missed opportunity to fully evaluate the intervention and draw conclusive evidence about its usefulness in terms of impacting on actual behaviour change.

Chapter 6 attempted to address some of the implementation issues associated with the poor delivery of interventions that aimed to reduce sexual risk behaviour. Due to a lack of formative work in this area the determinants used to address teacher and principal development are based on theory and only to a limited extent on evidence. These implementation matrices while demonstrating how such implementation tools are developed will benefit substantially from further research that contextualises the implementation behaviours of teachers and principals.

\section{Conclusion}

Sexual behaviour of South African youth is impacted on by a range of personal and environmental factors. The prevalence of HIV/AIDS has made it imperative that we begin to understand the complexities surrounding adolescent sexuality. This has opened up a range of issues that need to be worked with for example, teacher and principal behaviour as well as parent and community behaviours. All of this requires in depth expertise in managing adolescent sexual behaviour in the context of all the factors that impact on it. It further calls for additional expertise that provides support and sustainability to the body of work that leads to health promoting sexual behaviour of youth. 


\section{References}

Bandura, A. (1997) Selfefficocy The Exercise of Control. Freeman New York.

Bartholomew, K. Parcel, G. Kok, G, \& Gottieb, N. (200 1). Intervention mopping designing theorywand evidence-bosed heolth promotion progroms. Mountain View CA: Mayfietd.

Bartholomew, L. K. Parcel, G. S. Kok, G. \& Gottlieb, N. (In Press, 2006). Plonning Heoth Promotion Progroms: An Intervention Mapping Approoch (2nd ed.) Jossey-Bass, San Francisco.

Boon "H. (2004). Foctors associated with the implementotion of schoolbased HWADS educotion in secondary schools in Cope Town. Masters Dissertation

Burt, R. M. Zweig, J. M. \& Roman, I. (2002). Modeling the Payoffs of Interventions to Reduce Adolescent Vulnerability. Joumal of Adolescent Heolth, 315, 40-57.

Cooper, M. L., Peirce, R. S., \& Huselid, R. F. (1994). Substance Use and Sexual Risk Taking Among Black Adolescents and White Adolescents. Health Psychology. 13(3), 253-262.

Casey. N., \& Thom. A. (1999). Lessons for life HIV/AIOS and lifeskills education in schools. Edited by Fransen, L. \& Willcott, C. Luxembourg: Office of Official Publications of the European Communities. United Kingdom.

Donavan, $\mathrm{C}_{-}$\& MCEwan, R. (4995). A review of the literature examining the relationship between alcohol use and HIV-related sexual risk-taking in young people. Addiction, 90, 319-328.

Fissher, A. J., Roberts, M.M., \& Blignaut, R. J. (1992). Youth attending Cape Peninsula day hospitals. SAMJ, Vol 82.

Flisher, A. J., Ziervogel, C. F., Chalton, D. O., Leger, P.H., \& Robertson, B. A. (1993). Risk-taking behaviour of Cape Peninsula high-school teamers. Part IV. Alcohol use. 5AMH, Vol. 83. Julie.

Flisher, A. J. Reddy, P. Muller, M. \& Lomband, C. (2003). Sexual behaviour of Cape Town high-school learners. SAM, $93(7)$.

Ford, K. \& Norris, A. (1994). Urban Minority Youth: Alcohol and Marijuana Use and Exposure to Unprotected Intercourse journal of Acquired Immune Deficiency Syndrame 1389-395.

Gallant, M. \& Maticka-Tyndale, E. (2004). School-based HN prevention programmes for African youth. Social Science \& Medicine, 58, $1337-1351$

Glanz, K, \& Rimer, B. K (1995). Theory at, a Glance. A Guide for Health Promotion Practice. National Institute of Health.

Harrison, A. Smit, J. A. \& Myer. L. (2000). Prevention of HIV/AIDS in South Africal a review of behaviour change interventions, evidence and options for the future. South African journol of Science, 96, 285-290.

lames, S., Reddy, S. P. Ruiter. R. A. C., Taylor, M., Jinabhai, C. C., Van Empelen, B. \& Van den Borne, B. (2005). The effects of a systematically developed photo-novella on knowledge, attitudes, communication and behavioural intentions with respect to sexually transmitted infections among secondary school learners in South Africa. Health Promotion Intemotiond, 20(2).

James, S. Reddy, S.P., Rutter, RA. C. \& Van den Bome, B. In Review. The limpact of a HIV and ADS Lifeskills Programme on Secondary School Students in KwaZulu-Natal. South: Arrica.

Jermott, J. B. \& Jemmott, L. S. (1993). Alcohol and Drug Use During Sexual Activity Predicting the HIVRisk-Related Behaviors of Inner-Gity Black Male Adolescents. Joumal of Adolescent Reseorch, 8(1). 41-7.

Jemmott, I. $B_{4}$ Jemmott L. S. \& Fong, G. T. (1998). Abstinence and Safer Sex HIV Risk-Reduction intervention for African American Adolescents A Randomised Controlled Trial. JMA, Wo 279. No 19, $1529-1536$

Kaaya, S. F. Flisher, A. J. Mbwambo, J. K., Schaalma, H., Aaro, L. E, \& Klepp, K.1. (2002a). A review of studies of sexual behaviour of school leamers in sub-Saharan Africa. Scond J Public heolth, 30, $148-160$.

Kaaya S. F. Mukoma W. Flisher, A. 1. \& Klepp, K-1. (2002b). School-based Sexual Health Interventions in Sub-Saharan Africa: A Review. Sociol Dynamics, 28(1), 64-88.

Kingree I. B. Braithwaite, R, \& Woodring, T. (2000). Unprotected Sex as a Function of Alcohol and Marijuana Use Among Adolescent Detainees. Jourrol of Adolescent Heolth, 27, 179-85.

Kirby D. (1997). No Eosy Answers: Research Findings on Programs to Reduce Teen Pregnancy Washington, DC. The National Campaign to Prevent Teen Pregnancy, 28-30.

Kuhn, L., Steinberg, M, \& Mathews, C. (1994). Participation of the school community in AIDS education: an evaluation of a high school programme in South Africa. Aids Care, 6(2). 
MacPhal, $C$. Campbell, C. (2001). I think condoms are good but, aai, I hate those things: condom use among adolescents and adolescents in a Southem African township. Sociol Science \& Mecione, 52. $1613-1627$

Macintyre, K, Rutenberg, W. Brown, L, \& Karm, A (2004). Understanding Perceptionsof HV Risk Among: Adolescents in KwaZulu-Natal. AlDS and Behoviour, 8(3), 237-250.

Magnari, R, Macintyre, K, Karim, A.M., Brown, L, B Hutchinson, P. (2005). The impact of lifeskills education on adolescent sexual risk behaviours in KwaZulu-Watal, South Africa, joumal of Adolescent Health, 36. 289-304.

Merson; M. H. Dayton; I. M, \& OReifly, K. (2000). Effectiveness of HW prevention interventions in developing countries, AIDS, 14 (Suppl. 2), 568 -S84.

Meyer Weitz, A., Reddy, P, Weits, P., Van den Borne, B., Kok, G. \& Pietersen, J. (1999). Risky sexual behoviours of potients with sexwolly tranisritted diseoses in South Africa: Implicotions for interventions. Cited in Sense and Sensibilities. Medical Research Council.

Oakley, A. Fullerton, $D_{4}$ \& Holland, . (1995). Behavioural interventions for HIVIAIDS prevention. AIOS, 9. $479-486$.

Peltzer, K. \& Promtussananon, S. (2005). HW/AIDS Knowledge and Sexual Behaviour Among junior Secondary School Learners in South Africa. Journol of Sociol Sciences, $1(1)$, 1-8.

Petosa, R. \& Wessinger; ). (1990). AlDS education needs of adolescents: A theory-based approach. ADS Educotion and Prevention, 2,126-136.

Prewitt VR (1989), Health beliefs and ADSS educotional materials. Fomily Community Heolth, 12, 65- 76.

Reddy, P. James, S. \& McCauley, A. (2003). Programming for HIV Prevention in South African Schools:A Repont on Program Implementation. Cape Town: Medical Research Council.

Reddy, P., Meyer - Weitz, A. Van den Borne, B., \& Kok, G. (2000). Determinants of condom-use behaviour among STI clinic attenders in South Africa. Internotional journal of 5TI \& AIDS $11,521-530$.

Reddy, S. P., Panday, S. Swart, D. jinabhai, C. C., Amosun, S. L., James, S., Monyeki, K. D., Stevens, G., Monojele, N., Kambaran, N. S. Omandien, R. G. \& Van den Borne, H.W. (2003). Umthenthe Uhloba Usamila - The South African Youth Risk Behoviaur Survey 2002. Cape Town: South African Medical Research Council.

Salt, $H_{\text {. }}$ Boyle, M. \& Ives, I. (1997). HIV prevention: current health promoting behaviour models for understanding psycho-social determinants of condom use. ADS Care, 2(1).

Schaalma, H. P. Kok, G., Abraham, C., Hospers, H. J. Klepp, K. 1., \& Pancel, G. (2002). HIV Education for Young People Intervention Effectiveness, Programme Development, and Future Research. Prospects, wol. $\times \times X M$, no. 2, june.

Schenker, 1. 1. \& Nyirenda J. M. (2002). Prewenting HIVIADS in Schoois. Intemational Academy of Education. Belgium.

Simbayi, L, Kalichman, S. C. Jooste, S., Cherry C., Mfecane, S., \& Cain, D. 2005). Risk Factors for HW-AIDS Among Youtth in Cape Town, South Arrica. ADS and Behowior, 9(1), 53-61.

Svenson, L. W., Carmel, S., \& Vamhagen, C. K. (1997). A review of the knowledge, attitudes and behaviours of university learners conceming HVIAIDS. Health Promotion Internationol, 12(1),61-68.

UNAIDS, 2000. Report on the global HIV and AIDS epidemic June (2000). Geneva, Switzerland: foint United Nations Prograrime on HV and AlDS.

Varga, $\mathrm{C}_{\mathrm{i}}$ \& Shongwe, B. (1999). School Bosed Reproductive Health Educotion. Durban: Health Systems Trust.

Visser, M. J., Schoeman. J. B., \& Perold, J. 1. (2004), Evaluation of HIV/AIDS Prevention in South African Schools. Joumal of Health Psychology, 9(2), $263-280$.

Wills, T. A. Gibbons, F. X., Gerrard, M., Murry, V. M., \& Brody, G. H. (2003). Family Communication and Religiosity related to Substance Use and Sexual Behaviour in Early Adolescence: A Test for Pathways Through Self-Control and Prototype Perteptions. Psychology of Addictwe Behowours, 17(4), 312-323. 


\section{Summary}

This thesis addresses a critical issue affecting young people in South Africa namely an educational response to HV and ADDS. Such a response is intertwined in a variety of factors for example the history of sexuality education in South African schools, the sexual developmental needs of school-based youth, the response of the South African government to the problems of HIV and AIDS and the individual departments involved, in particular, the Departments of Health and Education. The main purpose of this thesis was to present an overview of adolescent sexual behavior in a specific context, regarding their knowledge, attitudes and sexual behavior alone and in association with other risk behaviours, evaluate their responses to two schoolbased interventions and propose recommendations for improving school-based interventions following a rigorous analysis of evaluations carried out on the South African Lifeskills HIV/AIDS Programme.

Chapter 1 provides an overview of the extent to which young people are affected by HIV and AIDS as well as a description of the context within which sexuality education takes place. It also provides insight into a review of literature related to school-based programmes that showed that there is a paucity of evaluations being carried out on HIV/ADDS interventions in schools. A call for a more systematic and theory-based development, implementation and evaluation of school-based HIV/AIDS education programmes is made. The chapter ends with an overview of the three parts of the thesis namely part 1 the cross-sectional studies (Chapters 2 and 3), part 2 the intervention studies (Chapters 4 and 5) and part 3 the refocusing of the Lifeskills HIV/AIDS Programme (Chapter 6).

Chapter 2 describes a cross-sectional study that was carried out amongst secondary school learners. It provides detailed insight into learners' knowledge, their beliefs and attitudes about HIV and AIDS as well as their self-reported sexual behavior. The results showed that learners were well informed about STIs including HIV and AIDS but that didn't seem to be in concordance with their sexual behaviours. It calls for a re-orientation of sexuality education to include those elements that impact on sexual behaviour in South Africa namely the gender inequities and the lack of communication skills.

The second cross-sectional study carried out amongst secondary school learners (chapter 3 ) confirmed the findings of other studies that a substantial number of learners are sexually active, some practice unprotected sex, are influenced by substance use and show gender differences in their sexual behaviours. This chapter recommends therefore that any education that addresses the sexual behavior of young people needs to take the determinants 
identified through theory and empirical evidence into account. Some of these determinants are age, gender, alcohol use and HIV and AIDS education in schools.

In delivering effective sexuality education it is imperative that in addition to developing systematically planned programmes, an effort is made to systematically evaluate the planned interventions.

Chapter 4 describes the development and evaluation of a single intervention that aimed to impact on learners' knowledge, attitudes, communication with parents; friends and boyfriend or girlfriend about sexually transmitted infections (STIs) and behavioural intentions with regard to STIs among secondary school learners in South Africa. The intervention was a photonovella called Laduma and the evaluation showed that after a single reading, learners showed an increase in knowledge on the spread of STIs, change in attitude to condom use and towards people with STIs and/or HIV/AIDS, as well as increased intention to practice safe sex. While this form of print media was an effective strategy to reach large numbers of young people and prepare them for adequate preventive behaviours, it did not influence their communication with parents, friends and boyfriend or girlfriend about STIs, reported sexual behavior and condom use. This chapter therefore identified the need to combine print media with other planned theory-based interventions that build confidence and skills to initiate the preventive behavior.

Chapter 5 describes the evaluation of a teacher led sexuality curriculum. The 16 hour long curriculum was delivered by trained educators and comprised of several fact based topics about HIV and AIDS namely the spread of, prevention of and protection against HIV and AIDS. The findings showed that there was a significant increase in knowledge at two follow-up measurements. There was no increase in reported protective behaviours or change in the psychosocial determinants of these behaviours. A process evaluation among the educators showed that the implementation differed in the various schools. The intervention schools could therefore be categorized into those schools that implemented the programme fully ( 7 schools) and those that implemented the programme only partially ( 4 schools). An exploratory analysis of these schools showed that learners who received the full intervention reported less sex and more condom use at T2 (immediately after the completion of the intervention 6 months after baseline (T1), were more positive in their perceptions about safe sexual behavior and scored higher on perceived social support at T3 (4 months after completion of intervention) than learners in the partial and control groups. This chapter, due to the limited effects found on the psychosocial determinants and sustained condom use in the longer term (T3) of the progamme on learners, calls for further research in South Africa into the development, implementation 
and analysis of the content and implementation strategies used in the classroom.

Chapter 6 describes the three evaluations carried out on the South African Lifeskills HIV/AIDS Programme as well as a model of sexual risk behaviour that was developed following an analysis of existing data. The results of the analysis of the evaluations of the Lifeskills programme were mapped onto a logic model of programme input and output that delineated the degree of lack in terms of programme implementation. The specific areas that were identified to improve the programme related to teacher and principal skills development. Teacher skills need to be improved to facilitate learner skill development related to HIV/AIDS for example negotiation of condom use. Principal skill development needed to improve with regard to facilitating support mechanisms that will enable trained teachers to implement the Lifeskills HIV/AIDS programme at school level. As a start to improve the Lifeskills HIV/AIDS programme, examples of implementation matrices for teacher and principal training were developed using Intervention Mapping (IM).

Chapter 7 presents a reflection on all the chapters and looks at the implications of the evaluations as well as the challenges associated with HIV/AIDS education in South Africa. More specifically it looks at the Lifeskills HIV/AIDS curricullum development, teacher training and implementation. Finally the limitations of the studies in this thesis are discussed and the chapter concludes by acknowledging the complexity of adolescent sexuality and the need to address it by developing an understanding of the all the factors that impact on or facilitate it. 


\section{Samenvatting}

Dit proefschrift heeft een belangrijk vraagstuk met betrekking tot jongeren in Zuid-Afrika als onderwerp, namelijk een antwoord vanuit het onderwijs op HIV en AIDS. Zo'n antwoord hangt samen met een verscheidenheid aan factoren, zoals bijwoorbeeld de geschiedenis van seksuele voorlichting op Zuid-Afrikaanse scholen, de behoeften van schoolgaande jongeren op seksueel gebied en de reactie van de Zuid-Afrikaanse overheild en de afzonderlijke, hierbij betrokken ministeries, met name de ministeries van Gezondheid en Onderwijs, op het vraagstuk van HIV en AIDS. Het belangrijkste doel van dit proefschrift is het presenteren van een overzicht van het seksuele gedrag van adolescenten in een specifieke context, wat betreft kennis, houding en seksueel gedrag op zich en in combinatie met ander riskant gedrag, het evalueren van hun reacties op twee interventies die op scholen zijn uitgevoerd en het doen van voorstellen voor het verbeteren van interventies op scholen op basis van een uitvoerige analyse van evaluaties van het South African Lifeskills HIV/AIDS programma.

Hoofdstuk 1 geeft een overzicht van de mate waarin jongeren getroffen worden door HIV en AIDS en beschrijft de context waarbinnen seksuele voorlichting plaatsvindt. Uit literatuuronderzoek naar voorlichtingsprogramma's op scholen bleek dat er maar heel weinig evaluaties worden uitgevoerd ván HIV/AIDS interventies op scholen. Er wordt gepleit voor het meer systematisch en op theorie gebaseerd ontwikkelen, implementeren en evalueren van voorlichtingsprogramma's over HIV/AIDS op scholen. Het hoofdstuk eindigt met een overzicht van de drie delen van het proefschrift, namelijk deel 1 de cross-sectionele onderzoeken (hoofdstuk 2 en 3), deel 2 de interventie onderzoeken (hoofdstuk 4 en 5) en deel 3 de aanpassing van het South African Lifeskills HIV/AIDS programma (hoofdstuk 6).

Hoofdstuk 2 beschrijft een cross-sectioneel onderzoek dat werd uitgevoerd onder middelbare scholieren. Het geeft een gedetailleerd inzicht in de kennis van de leerlingen, hun opvattingen over en hun houding tegenover HIV en AIDS en inzicht in hun door henzelf gerapporteerd seksueel gedrag. De resultaten lieten zien dat de middelbare scholieren goed geïnformeerd waren over seksueel overdraagbare aandoeningen en HIV en AIDS maar dit bleek niet in overeenstemming met hun seksueel gedrag. Dit vraagt om een heroriëntatie op seksuele voorlichting, waarbij meer aandacht besteed moet worden aan de aspecten die in Zuid Afrika belangrijk zijn met betrekking tot seksueel gedrag, met name de ongelijkheid tussen jongens en meisjes en het gebrek aan communicatievaardigheden.

Het tweede cross-sectionele onderzoek dat werd uitgevoerd onder middelbare scholieren (hoofdstuk 3), bevestigde de uitkomsten van andere 
onderzoeken dat een aanzienlijk deel van de leerlingen seksueel actief is; sommigen hebben onbeschermde seks, gebruiken regelmatig alcohol of drugs en er zijn verschillen in seksueel gedrag tussen jongens en meisjes. In dit hoofdstuk wordt daarom aanbevolen dat elke vorm van voorlichting die zich richt op het seksueel gedrag van jongeren; rekening moet houden met de determinanten die zijn bepaald op basis van theorie en uitkomsten van empirisch onderzoek. Enkele van deze determinanten zijn: leeftijd, sekse, alcoholgebruik en voorlichting over HIV en AIDS op scholen.

Bij het geven van effectieve seksuele voorlichting is het noodzakelijk dat in aansluiting op planmatig ontwikkelde programma's, geprobeerd wordt de geplande interventies systematisch te evalueren.

Hoofdstuk 4 beschtijft de ontwikkeling en evaluatie van één interventie onder middelbare scholieren in Zuid-Afrika die als doel had invloed uit te oefenen op de kennis van leerlingen, de houding tegenover seksueel overdraagbare aandoeningen (STIs), de communicatie met ouders, vrienden en vaste vriend of vriendin over STIs en gedragsintenties met betrekking tot STIs. De interventie was een photo-novella (met foto's ondersteund stripverhaal) onder de naam Laduma en uit de evaluatie bleek dat na één keer lezen leerlingen meer kennis hadden van de verspreiding van STIs, verandering in houding ten opzichte van condoomgebruik en ten opzichte van mensen met STIs en/of HIV/AIDS lieten zien en een verhoogde intentie hadden om veilige seks te bedrijven. Hoewel deze vorm van schriftelijke voorlichting een effectieve strategie bleek te zijn om grote aantallen jonge mensen te bereiken en hen voor te bereiden op adequaat preventief gedrag, had deze interventie geen invloed op hun communicatie over STIs met ouders, vrienden of vaste vriend of vriendin, gerapporteerd seksueel gedrag en condoomgebruik. In dit hoofdstuk wordt daarom de noodzaak benadrukt om schriftelijke voorlichting te combineren met andere op theorie gebaseerde, planmatige interventies die zelfvertrouwen en vaardigheden voor preventief gedrag aanleren.

Hoofdstuk 5 beschrifft de evaluatie van een door een docent begeleid curriculum over seksualiteit. Het curriculum van totaall 16 uur werd verzorgd door getrainde docenten en bestond uit verschillende op feiten gebaseerde onderwerpen over HIV en AIDS, met name over de verspreiding en preventie van en de bescherming tegen HIV en AIDS. De uitkomsten lieten zien dat er een significante toename was van kennis bij de twee follow-up nametingen. Er was geen toename van gerapporteerd vellig gedrag of verandering in de psychosociale determinanten van dit gedrag. Een procesevaluatie onder de docenten liet zien dat in de verschillende scholen de implementatie niet op dezelfde manier was uitgevoerd. De interventiescholen kunnen daarom verdeeld worden in scholen die het programma volledig implementeerden ( 7 
scholen) en scholen die het programma slechts gedeeltelik implementeedien (4 scholen). Een exploratieve analyse van deze scholen het zien dat leerlingen die deehamen aan alle onderdelen van de interventie, rapporteerden dat zi minder seks hadden en meer condooms gebruikten bi) T2 (onmiddellik na de afronding van de interventie 6 maanden na de baseline (T1), positiever waren in hun percepties over veilig seksueel gedrag en hoger scoorden op waargenomen sociale steun bij T3 (4 maanden na afronding van de interventie) dan leerlingen die het programma slechts gedeeltelijk konden volgen en leerlingen in de controlegroepen. In dit hoofdstuk wordt vanwege de beperkte effecten die gevonden werden bij de psychosociale deteminanten en het blijven gebruiken van condooms op de langere termijn (T3), gepleit voor verder onderzoek naar de ontwikkeling, inhoud, implementatie en implementatiestrategieën van programma's die op scholen gebruikt worden.

Hoofdstuk 6 beschrijft de drie evaluaties van het Zuid Afrikaanse Lifeskills HV/AIDS Programma en een model van riskant seksueel gedrag dat werd ontwikkeld op basis van een analyse van bestaande onderzoeksgegevens. De uitkomsten van de analyse van de evaluaties van het Lifeskills programma werden samengebracht in een logic model van programma input en output dat met name tekorten liet zien met betrekking tot de implementatie van het programma. De onderdelen die met name in aanmerking kwamen voor verbetering van het programma, betroffen het ontwikkelen van de vaardigheden van docenten en directeuren. De vaardigheden van docenten moeten verbeterd worden om de ontwikkeling van de vaardigheden van leerlingen met betrekking tot HIV/AIDS te bevorderen, bijwoorbeeld onderhandelen over het gebruiken van condooms. De vaardigheden van directeuren moeten verbeterd worden ter bevordering van het ondersteunen van getrainde docenten om hen in staat stellen het Lifeskills HIV/AIDS programma op schoolniveau te implementeren. Als aanzet tot het verbeteren van het Lifeskills HIV/AIDS programma werden voorbeelden van implementatiematrixen voor het trainen van docenten en directeuren ontwikkeld waarbij gebruik werd gemaakt van Intervention Mapping (IM).

In hoofdstuk 7 wordt teruggekeken op alle hoofdstukken en er wordt gekeken naar de implicaties van de evaluaties en naar de problemen met betrekking tot de voorlichting over HIV en AIDS in Zuid Afrika. In het bijzonder wordt er gekeken naar de ontwikkeling van het Lifeskills HIV/AIDS curriculum, de training van docenten en de implementatie van het programma. Tenslotte worden de beperkingen van de onderzoeken in dit proefschrift besproken en het hoofdstuk wordt afgesloten met het onderschrijven van de complexiteit van het vraagstuk van de seksuele ontwikkeling van adolescenten en de noodzaak tot het proberen te begrijpen van alle factoren die van invloed zijn 
op de seksuele ontwikkeling of deze bevorderen wanneer men het seksuele gedrag wil beïnvloeden. 


\section{Curriculum Vitae}

Shamagonam James was born in Pletermaritzburg in KwaZum-Natal, South Aftica. She matriculated in 1978 and thereafter pursued and obtaned a degree in Nursing and Diplomas in Communty Nurstng Sclence and pychtatric Nursing. She worked in the Private and Public Health sectors as a Professional Nurse in the areas of medical, surgical, community and school health nursing. During this time she studied Psychology through the University of South Africa (UNISA) and obtained an Honours degree in Psychology. In June 1998 she started working at the Medical Research Council (MRC) in the Mealth Ptomotion Research and Development Unit. While coordinating a research project she continued to study for a Masters degree in Medical Science at the Nelson Mandela School of Medicine, University of KwaZult-Natal. Her merest in young people, schools and health research was strengthened by her continued work at the MRC which motivated her to pursue a PhD, the outcome of which is presented in this dissertation. 